\title{
Programação em Lógica Anotada: Teoria e Aplicações
}

\section{Daniela Vasconcelos Carbogim}

\author{
DISSERTAÇÃO APRESENTADA \\ $\mathrm{AO}$ \\ INSTITUTO DE MATEMÁTICA E ESTATÍSTICA \\ DA \\ UNIVERSIDADE DE SÃO PAULO \\ PARA \\ OBTENÇÃO DO GRAU DE MESTRE \\ EM \\ MATEMÁTICA APLICADA \\ Área de Concentração: Ciência da Computação \\ Orientador: Prof. Dr. Flávio Soares Corrêa da Silva
}

Durante a elaboração deste trabalho a autora recebeu apoio financeiro do CNPq

- São Paulo, outubro de 1996 - 


\section{Programação em Lógica Anotada: Teoria e Aplicações}

Este exemplar corresponde à redação final da dissertação devidamente corrigida e defendida por Daniela Vasconcelos Carbogim e aprovada pela comissão julgadora.

São Paulo, 22 de novembro de 1996.

Banca examinadora:

- Prof. Dr. Flávio Soares Corrêa da Silva (orientador) - IME-USP

- Prof. Dr. Marcelo Finger - IME-USP

- Profa. Dra. Sandra Aparecida Sandri - INPE 
Para meu grande companheiro, Zé, para meus pais

e para meu irmão. 
Ao Flávio, pela dedicação, motivação e imbaiível bom-humor na orientação deste trabalho.

Ao Bob, um dos principais "culpados", por tudo.

Aos participantes da banca de qualificação, Profa. Dra. Iole de Freitas Druck e Prof. Dr. Leucio de Azevedo Guerra, pelas correçōes e sugestões na ocasião do exame e pelo constante interesse no desenvolvimento deste trabalho.

A Michael Kifer, Krishnaprasad Thirunarayan, James Lu, Victor Marek, Melvin Fitting e Howard Blair, pelas sugestões e envio de material.

Ao Orlando e ao Keidi, pelas inúmeras dicas e ajudas em $\mathrm{ITTXX}_{\mathrm{E}}$ e afins.

Muito obrigada. 


\section{Résumo}

As lógicas anotadas são uma classe de lógicas não-clássicas introduzida em [Sub87a] e que vem sendo cuidadosamente estudada e desenvolvida, tanto sob o aspecto de seus fundamentos quanto do ponto de vista da programação em lógica. Estas lógicas têm se mostrado de grande utilidade na área de Inteligência Artificial, uma vez que constituem um formalismo para o raciocínio na presença de inconsistências. O principal aspecto deste trabalho é constatar a importância das lógicas anotadas como uma ferramenta para desenvolvimento de sistemas para representação de conhecimento.

Apresentamos aqui um apanhado geral dos fundamentos das lógicas anotadas e um estudo da teoria da programação em lógica anotada e de algumas de suas extensões. Investigamos e discutimos várias de suas aplicações, estabelecendo relações entre estas lógicas e outros formalismos para representação de conhecimento e apresentando as especificações de um metainterpretador para raciocínio dedutivo em lógica anotada.

\footnotetext{
Abstract

Annotated logics are a class of non-classical logies, introduced in [Sub87a]. Both its foundational aspects and the associated logic programming theory have been carefully studied. These logics are of great importance to Artificial Intelligence, since they can formalize reasoning in the presence of inconsistencies. Our main goal is to present annotated logics as a tool for developing knowledge based systems.

In this work, we briefly present the basic concepts of the foundations of annotated logics, and also study the theory of annotated logic programming and some of its extensions. We investigate and discuss several of its applications, establishing relations between these logics and several other formalisms for knowledge representation. We also present the specifications of a meta-interpreter for automated reasoning in annotated logic.
} 


\section{Sumário}

1 Introdução 13

1.1 Origem das Lógicas Anotadas . . . . . . . . . . . . . . . . . . . . . . . 13

1.1.1 Conjuntos de Regras Quantitativas . . . . . . . . . . . . . . 14

1.1.2 Problemas com os Conjuntos de Regras Quantitativas . . . . . . 14

1.1.3 Programas em Lógica Quantitativos . . . . . . . . . . . . . . . . . . 15

1.2 Desenvolvimento das Lógicas Anotadas . . . . . . . . . . . . . . . . . . . 16

1.2.1 Fundamentos da Lógica Anotada . . . . . . . . . . . . . . . . 18

1.3 Importância do Estudo das Lógicas Anotadas . . . . . . . . . . . . . . 19

1.4 Organização deste Trabalho . . . . . . . . . . . . . . . . . . 21

2 O Cálculo de Predicados $Q_{\tau} \quad 23$

2.1 Linguagem . . . . . . . . . . . . . . . . . . . . . . . . . . . . . . . . . . . . .

2.2 Estruturas e Modelos . . . . . . . . . . . . . . . . . . . . . . . . . . . . . . . . . . .

2.3 Deduções . . . . . . . . . . . . . . . . . . . . . . . . . . . 27

2.4 Paraconsistência e Paracompletude . . . . . . . . . . . . . . . . 30

2.4.1 Princípios do 3ọ Excluído e da Não Contradição . . . . . . . . . . 31

3 Lógicas Anotadas e IA: Outra Abordagem 33

3.1 Fatos e Argumentos . . . . . . . . . . . . . . . . . . . . . . . . . . . . . . . . . 33

3.2 Uma Linguagem Objeto Clássica . . . . . . . . . . . . . . . . . . . . 36

3.2 .1 Uma Questão de Notação . . . . . . . . . . . . . . . . . . . . 38

3.2.2 Uma Versão Consistente da Linguagem Anotada . . . . . . . . . 40

3.3 Uma Metalinguagem Anotada . . . . . . . . . . . . . . . . . . . . . 47

3.3.1 E Se a Metalinguagem Fosse Clássica? . . . . . . . . . . . . . 51

3.4 Meta-metalinguagens, Meta-meta-metalinguagens, ... . . . . . . . . 55

4 Programação em Lógica Anotada $\quad 59$

4.1 Programação em Lógica Clássica . . . . . . . . . . . . . . . . . . . . . . . . . . . . . . . . . . . . 59

4.1 .1 Sintaxe . . . . . . . . . . . . . . . . . . . . . . . . . . . . . . . . . 59

4.1 .2 Substituições e Unificadores . . . . . . . . . . . . . . . . . . . 60

4.1 .3 Semântica Declarativa . . . . . . . . . . . . . . . . . 61

4.1 .4 Semântica Operacional . . . . . . . . . . . . . . . 62 
4.2 Programaçāo en Lógica Anotada: Sintaxe . . . . . . . . . . . . . . 63

4.2 .1 Programas em Lógica Anotada . . . . . . . . . . . . . . . . . . 64

4.2 .2 Substituiçōes e Unificadores . . . . . . . . . . . . . . . . . . 65

4.3 Programação em Lógica Anotada: Semântica . . . . . . . . . . . . . . 65

4.3 .1 Semântica Declarativa . . . . . . . . . . . . . . . 69

4.3 .2 Semântica Operacional . . . . . . . . . . . . . . . . 71

4.4 Um Meta-Interpretador Anotado . . . . . . . . . . . . . . . . . . . 77

5 Extensões da Programação em Lógica Anotada $\quad 81$

5.1 Programação em Lógica Anotada Generalizada . . . . . . . . . . . . . . 81

5.2 Uma Lógica Para Raciocínio com Inconsistência . . . . . . . . . . . . . . 84

5.2 .1 Inconsistência . . . . . . . . . . . . . . . . . . . . 86

5.2 .2 Implicação . . . . . . . . . . . . . . . . . . . . . . . 87

5.2.3 Raciocínio Não-Monotônico e Crenças Inconsistentes . . . . . . 88

5.3 Outras Extensões . . . . . . . . . . . . . . . . . . . . . . . . . . . . . . . . 89

6 Aplicações $\quad 91$

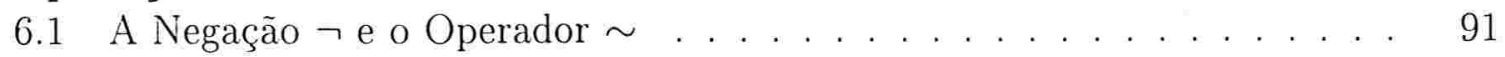

6.1.1 Propriedades Clássicas e Intuicionistas . . . . . . . . . . . . 92

6.1 .2 Monotonicidade e Antitonicidade . . . . . . . . . . . . . . 95

6.1 .3 Bi-reticulados . . . . . . . . . . . . . . 96

6.2 Instâncias da Lógica Anotada . . . . . . . . . . . . . . . . . . . . 100

6.2.1 Programação Paraconsistente . . . . . . . . . . . . . . . . . 100

6.2 .2 Programação em Lógica Usual . . . . . . . . . . . . . . . . . . . . . . . 105

6.2.3 Raciocínio sobre Evidência . . . . . . . . . . . . . . . . . 106

6.2.4 Raciocínio sobre Incertezas . . . . . . . . . . . . . . . . . 108

6.2 .5 Raciocínio por "Defaults" . . . . . . . . . . . . . . . . . 109

6.3 Considerações a Respeito das Aplicações . . . . . . . . . . . . . . . . . 112

7 Conclusão $\quad 113$

7.1 Trabalhos Futuros . . . . . . . . . . . . . . . . . . . . . . . 114 


\section{Capítulo 1}

\section{Introdução}

As lógicas anotadas são uma classe de lógicas não-clássicas que vem sendo cuidadosamente estudada e desenvolvida, tanto sob o aspecto de seus fundamentos como sob o ponto de vista da programação em lógica. São um assunto bastante recente e constituem o tema central do presente trabalho ${ }^{1}$.

Estas lógicas foram introduzidas no âmbito da programação em lógica. Seus fundamentos só foram estudados posteriormente, quando já existiam vários resultados na área da programação em lógica. Por ser um tema recente e, comø veremos mais adiante, de grande interesse para certas áreas de Ciência da Computação, estes resultados continuam sendo ampliados e desenvolvidos. As aplicações das lógicas anotadas são significativas e crescentes, principalmente no que se refere à Inteligência Artificial (IA).

\subsection{Origem das Lógicas Anotadas}

Os primeiros sistemas lógicos anotados foram introduzidos em [Sub87a] em função de uma teoria de programação em lógica baseada em conjuntos de regras quantitativas e da semântica declarativa associada, apresentada em [vE86].

Ao invés de uma dedução qualitativa, os conjuntos de regras quantitativas associam valores-verdade em um intervalo $[0,1]$, representando graus de incerteza. Porém, a linguagem introduzida em [vE86] apresentava alguns problemas. Estes foram revistos e corrigidos em [Sub87a] através da introdução de uma nova linguagem para programas em lógica quantitativos, dando origem assim às lógicas anotadas.

Para entendermos melhor a importância e as idéias por trás destas lógicas, faremos aqui um estudo um pouco mais detalhado de sua origem.

\footnotetext{
${ }^{1}$ Aparentemente, existe uma relação entre as lógicas anotadas e os sitemas rotulados de Dov Gabbay (Labelled Deductive Systems - LDS) [GdQ92]. Esta relação, porém, não é trivial e ainda não foi completamente estudada. Nos restringiremos às lógicas introduzidas por Subrahmanian, não sendo do escopo desta dissertação abordar os formalismos de LDS.
} 


\subsubsection{Conjuntos de Regras Quantitativas}

Em [vE86], foi proposta uma linguagem de programação em lógica na qual a cada implicação é associado um fator de atenuação $f, 0<f \leq 1$. Intuitivamente, se $v$ é o valor-verdade da premissa, então $f$ contribui com $f \times v$ ao valor-verdade da conclusão. Desta forma, as cláusulas - ou regras - da linguagem são expressões da forma:

$$
A \leftarrow f-B_{1} \wedge \ldots \wedge B_{n}
$$

oncle $A, B_{1}, \ldots, B_{n}$ são átomos e $n \geq 0$. Termos, átomos e fórmulas são definidos da maneira usual. Um conjunto de regras quantitativas é um conjunto finito de regras.

A base de Herbrand $B_{R}$ de um conjunto de regras quantitativas $R$ constitui o conjunto de todos os átomos fechados da linguagem associada a $R$. Uma interpretação de Herbrand para $R$ associa a cada elemento de $B_{R}$ um valor-verdade no intervalo $[0,1]$. Os valores no intervalo são ordenados de acordo com a relação usual $\leq$.

Seja $I(A)$ o valor-verdade associado ao átomo fechado $A$ pela interpretação $I$. Então, $I$ satisfaz uma instância fechada de uma regra

$$
A \leftarrow f-B_{1} \wedge \ldots \wedge B_{n}
$$

se

$$
I(A) \geq f \times \min \left\{I\left(B_{i}\right) \mid 1 \leq i \leq n\right\} .
$$

Podemos assumir que $\min \emptyset=1$.

Como esperado, $I$ satisfaz uma regra em $R$ se satisfaz toda instância fechada desta regra; $I$ satisfaz um conjunto de regras $R$ se satisfaz toda regra em $R$.

A ordem dos valores-verdade é estendida a interpretações da maneira usual.

\subsubsection{Problemas com os Conjuntos de Regras Quantitativas}

Em [Sub87a], o autor detectou alguns problemas na linguagem apresentada em [vE86], relativos à ordem dos valores e ao tratamento da negação no corpo das cláusulas.

A linguagem dos conjuntos de regras quantitativas não permitem a introdução de átomos negados no corpo das regras. De fato, como foi verificado em [Sub87a], a existência de literais negativos no corpo de uma regra faz com que o operador de consequência imediata $T_{R}^{2}$ definido em [vE86] se torne não-monotônico. A não-monotonicidade

${ }^{2}$ Dado um conjunto de regras quantitativas $R$, o operador de consequência imediata $T_{R}$ associado a $R$ é definido da seguinte forma:

$$
\begin{aligned}
T_{R}(I)(A)= & \sqcup\left\{f \times \min \left\{I\left(B_{i}\right) \mid 1 \leq i \leq n\right\} \mid A \leftarrow f-B_{1} \wedge \ldots \wedge B_{n}\right. \text { é uma instância } \\
& \text { fechada de uma cláusula em } R\} .
\end{aligned}
$$

Uma interpretação $I$ é modelo de $R$ se e somente se $T_{R}(I) \leq I$; ou seja, se e somente se $I$ for um pré-ponto-fixo de $T_{R}$. 
deste operador não garante a existência de um pré-ponto-fixo de $T_{R}$. e portanto não garante a existência de um modelo para $R$.

Outro problema apresentado pela linguagem dos conjuntos de regras quantitativos diz respeito à relação entre a ordenação dos valores-verdade e sua interpretação intuitiva. Considere, por exemplo, duas interpretações $I_{1}$ e $I_{2}$ e um átomo fechado $A$ tal que $I_{1}(A)=0$ e $I_{2}(A)=0.5$. Intuitivamente, $I_{1}$ nos diz que $A$ é falso, enquanto $I_{2}$ não fornece nenhuma informação a respeito da veracidade ou falsidade de $A$. Assim, $I_{2}$ nos fornece menos informações sobre $A$ do que $I_{1}$. Mas, de acordo com a ordem associada aos valores-verdade, temos que $I_{1} \leq I_{2}$.

\subsubsection{Programas em Lógica Quantitativos}

A solução encontrada para se resolver estes problemas foi definir uma nova linguagem, baseada nas idéias da apresentação original, porém sem os problemas citados acima.

Esta nova linguagem, introduzida em [Sub87a], constitui uma variação da linguagem dos conjuntos de regras quantitativas, mantendo a idéia de associar aos átomos valoresverdade pertencentes ao intervalo $[0,1]$. Além da noção usual de átomos e literais, temos agora o conceito de átomos e literais anotados. Assim, se $A$ é um átomo (literal) e $\mu \in[0,1]$, então $A: \mu$ é dito um átomo (literal) anotado. Intuitivamente, $\mu$ pode ser interpretado como sendo o grau de crença ou conhecimento em relação a $A$ (associado a um agente raciocinador).

Uma cláusula quantitativa (ou cláusula-q) é uma fórmula da forma:

$$
A: \mu \leftarrow A_{1}: \mu_{1} \wedge \ldots \wedge A_{n}: \mu_{n}
$$

onde $A: \mu$ é um átomo anotado e $A_{1}: \mu_{1}, \ldots, A_{n}: \mu_{n}$ são literais anotados. Um programa em lógica quantitativa (PLQ) é um conjunto finito de cláusulas-q.

As fórmulas da linguagem são definidas usualmente, tomando como elementos básicos átomos anotados ao invés de átomos.

Para estabelecer uma relação bem-definida entre os valores-verdade e sua interpretação intuitiva, consideramos agora o conjunto de valores-verdade como sendo $[0,1] \cup$ $\{T\}$, cuja ordem « é definida de acordo com o diagrama da figura 1.1. Intuitivamente, o valor-verdade $T$ representa inconsistência ${ }^{3}$ Note que os elementos de $[0,1]$ também são usados na descrição sintática da linguagem.

Uma interpretação de Herbrand $I$ associa um valor-verdade em $[0,1] \cup\{\top\}$ a cada elemento da base de Herbrand associada.

Seja $I(A)$ o valor-verdade associado a uma átomo fechado $A$ por uma interpretação I. Definimos satisfatibilidade de uma fórmula fechada $F$ da linguagem em relação a uma interpretação $I(I \models F)$ da seguinte forma:

\footnotetext{
${ }^{3} \mathrm{O}$ termo inconsistência é considerado no sentido bi-valorado; ou seja, quando literais $A: \mu \mathrm{e} \neg A: \mu$, $\mu \neq 0.5$, são simultaneamente válidos. As noções de satisfatibilidade são definidas mais adiante nesta seção.
} 


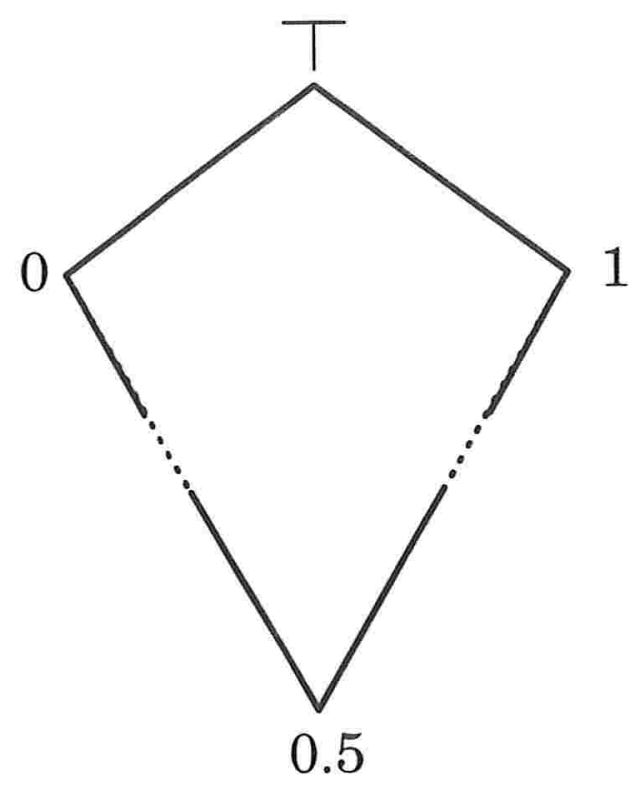

Figura 1.1: Ordem dos Valores-Verdade para um PLQ

1. Se $F$ é da forma $A: \mu$, então $I \models A: \mu$ se e somente se $I(A) \gg \mu$.

2. Se $F$ é da forma $\neg A: \mu$, então $I \models \neg A: \mu$ se e somente se $I \models A: 1-\mu$. (Em particular, $1-\top=\top$.)

3. Se $F$ é da forma $G \wedge H$, onde $G$ e $H$ são fórmulas anotadas fechadas, então $I \models G \wedge H$ se e somente se $I \models G$ e $I \models H$.

4. Se $F$ é da forma $G \rightarrow H$, onde $G$ e $H$ são fórmulas anotadas fechadas, então $I \models G \rightarrow H$ se e somente se $I \not \models G$ ou $I \models H$.

Note que, no caso da negação de um átomo, a mesma é incorporada pela anotação através de uma função definida no conjunto de valores-verdade. Esta característica da negação é um dos aspectos mais importantes das lógicas introduzidas em [Sub87a].

Uma interpretação $I$ satisfaz uma fórmula qualquer se satisfaz todas as instâncias fechadas desta fórmula. Consequentemente, $I$ satizfaz um PLQ $\mathcal{P}$ se satisfaz todas as cláusulas-q de $\mathcal{P}$.

\subsection{Desenvolvimento das Lógicas Anotadas}

As lógicas anotadas surgiram como uma teoria na área da programação em lógica. Após sua introdução [Sub87a], a idéia de se representar o conhecimento através de átomos anotados continuou sendo desenvolvida. 


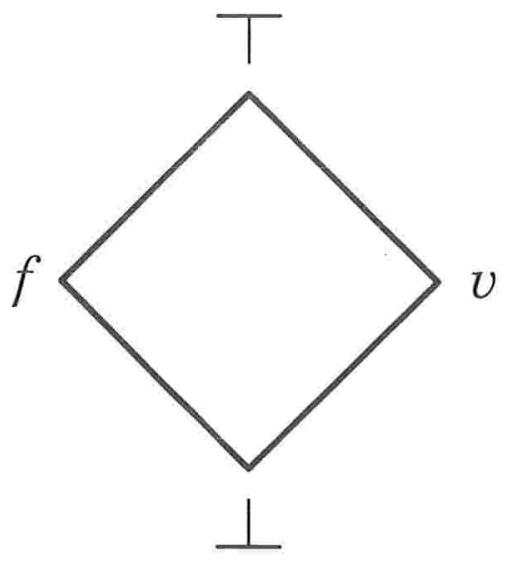

Figura 1.2: O Reticulado FOUR

Em [BS89], foi definida uma linguagem de programação em lógica semelhante àquela apresentada em [Sub87a]. A diferença básica está no conjunto de valores-verdade considerado que, juntamente com a relação de ordem associada, define o reticulado completo FOUR, representado pelo diagrama da figura 1.2.

O reticulado FOUR foi introduzido por Belnap (cf. [Bit96, Fit91]) para servir como base de um sistema que fosse capaz de tratar adequadamente situações onde surgem respostas ou informações conflitantes e continuar gerando respostas compatíveis com as outras informações já existentes.

A questão que surge é "o que fazer com respostas conflitantes?". Ao contrário da lógica clássica, que trivializa o raciocínio, devemos ignorar e insistir em um consenso, assumindo que respostas conflitantes não acrescentam nenhuma informação ao sistema? Ou devemos aceitar as duas respostas, registrando no sistema a existência de um conflito?

O conjunto de valores-verdade proposto por Belnap constitui assim um formalismo para esta abordagem. Os valores-verdade de FOUR podem ser considerados como subconjuntos dos valores-verdade clássicos. Temos os valores $\{$ falso $\}$ e $\{$ verdadeiro $\}$, que denotamos por $f$ e $v$, respectivamente; $\emptyset$, que denotamos por $\perp$, e que intuitivamente pode ser considerado como o valor indefinido; e $\{$ falso, verdadeiro $\}$, que denotamos por $T$ e representa o valor inconsistente ${ }^{4}$.

Desta forma, a linguagem apresentada em [BS89] se mostrou adequada para formalizar sistemas em que inconsistências possam surgir, sem que isto trivialize o raciocínio. Esta é uma das principais aplicações das lógicas anotadas e sua importância motivou ainda mais o desenvolvimento desta área.

Sobre o conjunto de valores-verdade desta linguagem é necessário definir um operador para efetuar a absorção da negação pela anotação. Em [Sub87a], de acordo com

\footnotetext{
${ }^{4}$ No mesmo sentido bi-valorado considerado na seção anterior.
} 
a definição de satisfatibilidade, temos que $\sim \mu=1-\mu$, onde $\mu \in[0,1] \cup\{T\}$. Em [BS89]. o operador $\sim$ é definido da seguinte forma: $\sim f=v, \sim v=f, \sim \perp=\perp$ e $\sim T=T$. Como veremos a seguir, este operador pode ser qualquer mapeamento entre valores-verdade, desde que o conjunto destes valores constitua um reticulado completo.

De fato, a idéia original foi ampliada em [BS88], onde foi introduzida uma linguagem de programação em lógica anotada tal que o conjunto de valores-verdade e a ordem associada a seus elementos definem um reticulado completo. Nenhuma outra restrição é feita a este conjunto, nem ao operador de absorção de negação associado. A linguagem continua sendo um formalismo para sistemas inconsistentes, uma vez que em um reticulado completo há sempre um elemento mínimo $\perp$ e um elemento máximo $T$ que representam, respectivamente, os valores desconhecido e inconsistente.

No escopo da programação em lógica, estas lógicas continuam sendo ampliadas e desenvolvidas. No capítulo 5, a título de exemplo, apresentaremos algumas de suas extensões. Porém, a idéia por trás das lógicas anotadas continua presente e reside em representar o conhecimento através dos átomos anotados, onde as anotações constituem tanto objetos sintáticos quanto semânticos. Intuitivamente, um átomo anotado $A: \mu$ pode ser interpretado como o valor-verdade de A é pelo menos $\mu$. A anotação de um átomo também pode ser considerada como um grau de crença de um agente raciocinador sobre o átomo $A$. Neste caso, $A: \mu$ pode ser interpretado como acredita-se que o valorverdade de $A$ é pelo menos $\mu$. Apesar das interpretações associarem aos átomos da linguagem valores-verdade de um reticulado, a extensão para fórmulas é bi-valorada no sentido clássico, o que caracteriza o raciocínio humano como sendo essencialmente clássico, independentemente da interpretação de cada um. Desta forma, dizemos que a anotação está em um nível epistêmico da linguagem. Geralmente, este termo se refere a conhecimento, mas também tem sido usado na literatura relativamente a crença.

\subsubsection{Fundamentos da Lógica Anotada}

Só depois de vários resultados na área da programação em lógica anotada é que surgiram os primeiros estudos sobre seus fundamentos [dCSV91, dCAS91].

Os objetos deste estudo foram as lógicas que servem como base para uma linguagem de programação em lógica já desenvolvida: a programação em lógica anotada. As lógicas anotadas foram obtidas a partir de uma lógica positiva com implicação à qual se acrescentou um operador de negação denominado negação fraca. Como veremos no capítulo 2, as lógicas anotadas foram caracterizadas como lógicas paraconsistentes e paracompletas.

Em termos gerais, um sistema lógico é paraconsistente se e somente se a linguagem $L$ associada for inconsistente e não-trivial em relação a um operador de negação $\neg$; i.e. se existir uma interpretação $I$ para $L$ tal que $I$ seja simultaneamente inconsistente e não-trivial. Uma interpretação $I$ é dita inconsistente se e somente se satisfaz $A$ e $\neg A$ para alguma fórmula $A$ de $L$. Por outro lado, $I$ é dita não-trivial se e somente se existe 
alguma fórmula $A$ de $L$ tal que $A$ não é satisfeita por $I$. Desta forma, o princípio da não contradição não é válido nas lógicas anotadas.

Um sistema lógico é paracompleto se e somente se a linguagem $L$ associada for paracompleta; i.e. se existir uma interpretação $I$ para $L$ tal que $I$ seja paracompleta. Uma interpretação $I$ é dita paracompleta se e somente se existe uma fórmula $A$ de $L$ tal que $I$ não satisfaz nem $A$ nem $\neg$ A. Da mesma forma, o princípio do 30 excluído não é válido nas lógicas anotadas.

Um outro resultado interessante é que a lógica anotada é também uma extensão da lógica clássica. Isto porque é possível definir um operador de negação forte - ou clássico - nesta lógica. Mais ainda. a lógica anotada acrescida da negação forte pode ser considerada como a base para a uma das extensões da teoria introduzida em [BS88] e que será brevemente discutida no capítulo 5 .

Um estudo geral dos fundamentos das lógicas anotadas, incluindo tópicos como teoria anotada de modelos e teoria anotada de conjuntos, pode ser encontrado em [Abe92, Abe93].

\subsection{Importância do Estudo das Lógicas Anotadas}

As lógicas anotadas têm se mostrado de grande importância nas áreas de Ciência da Computação e Inteligência Artificial, uma vez que constituem um formalismo para o raciocínio na presença de inconsistência.

Na tentativa de generalizar a teoria da programação em lógica anotada para formalizar vários tipos de raciocínio [Sub90, Sub87b], um grande número de extensões [KS92, KL92] da teoria original ${ }^{5}$ vêm sendo propostas e desenvolvidas. Este poder de generalização é uma das razões dc crescente interesse nesta área e um dos principais motivos que nos levaram a estudar mais profundamente este tópico.

O principal aspecto do presente trabalho é constatar a importância das lógicas anotadas como uma ferramenta para desenvolvimento de sistemas para raciocínio dedutivo. Para tanto, apresentamos todo um estudo de seus fundamentos e da teoria original de programação em lógica anotada, cujo desenvolvimento foi motivado principalmente pela possibilidade de se tratar adequadamente sistemas inconsistentes. Essa importância é reforçada quando verificamos que diversos formalismos podem ser expressos via lógicas anotadas, aproveitando assim os resultados já existentes.

Assim, investigamos aqui que sistemas inconsistentes não são a única aplicação destas lógicas. Por exemplo, a interpretação intuitiva de um átomo $A: \mu$ onde $\mu$ é considerado um grau de crença de um agente raciocinador sobre $A$ nos leva a investigar um outro aspecto das lógicas anotadas: existe uma diferença entre raciocinar com fatos da realidade e raciocinar com argumentos a respeito de fatos da realidade que pode ser

\footnotetext{
${ }^{5}$ Consideramos como a teoria original aquela apresentada em [BS88], por ser a primeira a não especificar o conjunto de valores-verdade e o operador associado à negação.
} 


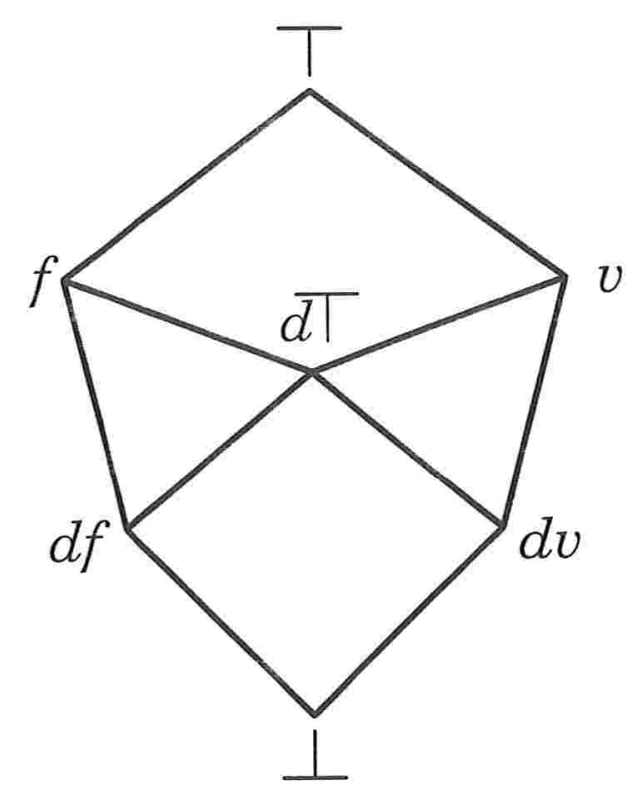

Figura 1.3: O Reticulado SEVEN

caracterizada por estas lógicas. Nas lógicas clássicas, esta caracterização não é possível, uma vez que o raciocínio nos diferentes níveis acima se confundem. Já nas lógicas anotadas, é possível fazer uma distinção entre aquilo que é realmente verdadeiro no mundo real e aquilo em que um agente acredita. Uma vez que estas lógicas formalizam o raciocínio de um agente - e não de fatos da realidade em si -, nos parece razoável usá-las para formalizar o raciocínio no nível dos argumentos.

Além desta caracterização, apresentamos outros tipos de aplicações que têm sido desenvolvidos, estabelecendo relações entre as lógicas anotadas e formalismos já existentes. Isto é feito através da especificação do reticulado de valores-verdade e do operador de negação associado, considerados arbitrários na teoria da programação em lógica anotada.

Por exemplo, se considerarmos o reticulado SEVEN, cuja ordem é definida pela figura 1.3 , e definirmos adequadamente o operador $\sim$, podemos formalizar o raciocínio com "default" através das lógicas anotadas. Neste caso, os valores $d f$ e $d v$ são interpretados como falso por "default" e verdadeiro por "default", respectivamente. O valor $d T$ indica uma conclusão "default" inconsistente, porém com um grau menor de inconsistência em relação a $T$.

Por conta do crescente surgimento de extensões e aplicações da programação em lógica anotada, resolvemos dedicar um capítulo a algumas destas extensões.

O fato de que esta teoria está em constante desenvolvimento é um aspecto muito positivo. Mostra que o estabelecimento de relações com outros formalismos e a especificação destes como instâncias das lógicas anotadas é uma linha de pesquisa bastante 
rica e produtiva, que nos fornece resultados cada vez mais generalizados.

\subsection{Organização deste Trabalho}

Os aspectos a serem abordados no presente trabalho foram brevemente discutidos nas seções anteriores. A organização apresentada aqui visa destacar os principais pontos e objetivos, fornecendo uma visão geral e estruturada do mesmo.

A sequência de apresentação não obedece à ordem cronológica de desenvolvimento do tema em questão. Optamos aqui por uma ordem que nos parece mais natural para entender os aspectos e características das lógicas anotadas.

No capítulo 2, apresentamos o cálculo de predicados de primeira ordem anotado e fazemos um estudo dos fundamentos das lógicas anotadas, provando inclusive que estas são um caso particular das lógicas paraconsistentes.

No capítulo 3, passamos a investigar um dos aspectos das lógicas anotadas que permite caracterizá-las como um formalismo para o raciocínio no nível de argumentos.

No capítulo 4, apresentamos a teoria da programação em lógica anotada. Baseados nos resultados desta teoria, desenvolvemos um sistema para raciocínio dedutivo para a lógica anotada na forma de um meta-interpretador PROLOG. Neste capítulo, definimos ainda as especificações deste sistema.

O capítulo 5 é dedicado a algumas extensões da teoria da programação em lógica anotada original. Discutimos duas abordagens distintas e alguns motivos que levaram ao seu desenvolvimento.

Mais aplicações das lógicas anotadas são investigadas e discutidas no capítulo 6 . Neste caso, as aplicações são obtidas pela especificação do reticulado de valores-verdade ou do operador associado a negação.

Finalmente, na Conclusão, retomamos a importância destas lógicas, principalmente para a IA. Além de uma análise dos resultados obtidos, citamos algumas outras aplicações que vêm sendo desenvolvidas mais recentemente e discutimos brevemente alguns temas de investigação para trabalhos futuros. 


\section{Capítulo 2}

\section{O Cálculo de Predicados $Q \tau$}

Como foi visto na Introdução, as lógicas anotadas surgiram na literatura em 1987 [Sub87a], dentro do escopo da programação em lógica. Um estudo de seus fundamentos só foi realizado anos mais tarde [dCSV91, dCAS91], quando foram apresentadas as lógicas proposicionais e de primeira ordem anotadas, denotadas respectivamente por $P \tau$ e $Q \tau$.

Neste capítulo apresentamos o cálculo de predicados de primeira ordem anotado $Q \tau$. Nos baseamos principalmente em [Abe92] e [Abe93], onde o autor apresenta um apanhado geral dos fundamentos das lógicas anotadas.

\subsection{Linguagem}

No cálculo de predicados $Q \tau, \tau=<|\tau|, \leq>$ é um reticulado finito, denominado reticulado de valores-verdade, onde $|\tau|$ representa o conjunto dos elementos de $\tau$. Em particular, o elemento mínimo de $\tau$ é denotado por $\perp$, e o elemento máximo por $T$. Os operadores de supremo e ínfimo são denotados por $\sqcup$ e $\sqcap$, respectivamente.

Os resultados foram originalmente desenvolvidos para um reticulado completo qualquer. No entanto, como estamos dando ênfase ao aspecto das aplicações, podemos assumir que o reticulado $\tau$ em questão é finito. Em particular, todo reticulado finito é completo. Alguns exemplos de reticulados que valem para este formalismo são representados pelas figuras $1.1,1.2$ e 1.3 .

Em $\tau$, é fixado um operador arbitrário qualquer $\sim:|\tau| \rightarrow|\tau|$, que constituirá o "significado" do símbolo de negação (fraca) $\neg$ do sistema $Q \tau$.

A linguagem $L \tau$ de $Q \tau$ é uma linguagem de primeira ordem com igualdade, constituída dos seguintes símbolos primitivos:

1. Um conjunto enumerável de símbolos de variáveis, denominados variáveis individuais;

2. Os conectivos lógicos $\neg, \wedge, \vee, \rightarrow$; 
3. Quantificadores $\forall, \exists$;

4. O símbolo de igualdade $=$ :

5. Símbolos auxiliares: parênteses, vírgula;

6. Os elementos de $\tau$, chamados de constantes anotacionais;

7. Para cada número natural $n<\omega$, uma coleção de símbolos funcionais $n$-ários. Símbolos funcionais 0-ários são também chamados de constantes individuais;

8. Para cada número natural $n<\omega$, uma coleção de símbolos predicativos $n$-ários.

Os símbolos descritos em 1-j são ditos símbolos lógicos e estão presentes em toda linguagem de primeira ordem com igualdade. Os demais símbolos constituem os símbolos não-lógicos de $L \tau$ e caracterizam a linguagem em questão.

Definição 2.1 (Termos) Os termos da linguagem $L \tau$ de $Q \tau$ são definidos indutivamente da maneira usual:

1. Se $v_{k}$ é uma variável individual, então $v_{k}$ é um termo;

2. Se c é uma constante individual, então c é um termo;

3. Se $f$ é um símbolo funcional $n$-ário e $t_{1}, \ldots, t_{n}$ são termos, então $f\left(t_{1}, \ldots, t_{n}\right)$ é um termo.

Definição 2.2 (Fórmulas) As fórmulas de L $\tau$ são definidas indutivamente da seguinte forma:

1. Se p é um símbolo predicativo $n$-ário, $\mu$ é uma constante anotacional e $t_{1}, \ldots, t_{n}$ são termos de $L \tau$, então $p\left(t_{1}, \ldots, t_{n}\right): \mu$ é dito um átomo anotado ou uma fórmula atômica. As expressões da forma $p\left(t_{1}, \ldots, t_{n}\right)$, porém, são denominadas átomos da linguagem;

2. Se $t_{1}, t_{2}$ são termos, então $t_{1}=t_{2}$ é uma fórmula atômica;

3. Se A é uma fórmula, então $(\neg A)$ é uma fórmula;

4. Se $A$ e $B$ são fórmulas, então $(A \wedge B),(A \vee B)$ e $(A \rightarrow B)$ são fórmulas;

5. Se $A$ é uma fórmula e v' é uma variável individual, então $(\forall v) A$ e $(\exists v) A$ são fórmulas. 
Intuitivamente, um átomo anotado $p\left(t_{1}, \ldots, t_{n}\right): \mu$ pode ser interpretado como "o valor-verdade de $p\left(t_{1}, \ldots, t_{n}\right)$ é pelo menos $\mu$ ". Conforme discussão apresentada na Introdução, também podemos considerar a seguinte leitura intuitiva: "acredita-se que o valor-verdade de $p\left(t_{1}, \ldots, t_{n}\right)$ é pelo menos $\mu$ ".

Dizemos que $A$ é uma fórmula fechada se $A$ não contém ocorrências livres de uma variável. Um termo livre da ocorrência de variáveis é dito fechado.

NOTAÇÃO: Denotamos por $(\exists) A$ e $(\forall) A$ o fecho existencial e universal de uma fórmula $A$, respectivamente.

Definição 2.3 Se $p\left(t_{1}, \ldots, t_{n}\right): \mu$ um átomo anotado e $k$ é um número natural, então um hiper-literal é uma fórmula de L $\tau$ definida indutivamente da seguinte forma:

$$
\begin{aligned}
& \text { 1. } \neg^{0} p\left(t_{1}, \ldots, t_{n}\right): \mu \equiv p\left(t_{1}, \ldots, t_{n}\right): \mu ; \\
& \text { 2. } \neg^{k} p\left(t_{1}, \ldots, t_{n}\right): \mu=\neg\left(\neg^{k-1} p\left(t_{1}, \ldots, t_{n}\right): \mu\right), k \geq 1 .
\end{aligned}
$$

Uma fórmula que não é um hiper-literal é denominada complexa.

Definição 2.4 Seja $\mu \in|\tau|$. Então:

$$
\begin{aligned}
& \text { 1. } \sim^{0} \mu \equiv \mu ; \\
& \text { 2. } \sim^{k} \mu=\sim\left(\sim^{k-1} \mu\right), k \geq 1 .
\end{aligned}
$$

Vale a pena ressaltar que não conseguimos redefinir os conectivos da linguagem de $Q \tau$ a partir de apenas dois conectivos, como no caso clássico (por exemplo, $\neg$ e $\wedge$ ). Neste caso, a negação (fraca) não se comporta necessariamente da mesma forma para fórmulas complexas e hiper-literais, sendo necessário assim definir todos os conectivos.

Em particular, usaremos conectivos adicionais como abreviações para certas expressões envolvendo os símbolos primitivos da linguagem:

- $(A \leftrightarrow B) \stackrel{\text { def }}{=}(A \rightarrow B) \wedge(B \rightarrow A)$

- $(\neg A) \stackrel{\text { def }}{=}(A \rightarrow((A \rightarrow A) \wedge \neg(A \rightarrow A)))$

O primeiro conectivo representa o símbolo bi-condicional usual. O segundo, chamado de negação forte, provou-se ser uma negação clássica. Provou-se ainda que os outros conectivos de $L \tau(\wedge, \vee$ e $\rightarrow)$ também podem ser caracterizados como clássicos [Abe92]. Desta forma, as lógicas anotadas podem ser vistas como uma extensão das lógicas clássicas. 


\subsection{Estruturas e Modelos}

Nesta seção, descrevemos uma semântica para a linguagem $L \tau$.

Definição 2.5 (Estrutura) Uma estrutura $\mathcal{A}$ para L $\tau$ consiste dos seguintes objetos:

1. Um conjunto não-vazio $|\mathcal{A}|$, denominado domínio ou universo de $\mathcal{A}$. Os elementos de $|\mathcal{A}|$ são chamados indivíduos de $\mathcal{A}$.

2. Uma função $f^{\mathcal{A}}:|\mathcal{A}|^{n} \rightarrow|\mathcal{A}|$ para cada símbolo funcional n-ário $f$ de $L \tau$. Em particular, para cada constante individual c de $L \tau, c^{\mathcal{A}}$ é um indivíduo de $\mathcal{A}$.

3. Uma função $p^{\mathcal{A}}:|\mathcal{A}|^{n} \rightarrow|\tau|$ para cada símbolo predicativo n-ário $p$ de $L \tau$.

Sejam $\mathcal{V}$ e $\mathcal{T}$ os conjuntos de variáveis e de termos de $L \tau$, respectivamente. Se $\mathcal{A}$ é uma estrutura para $L \tau$ e $s: \mathcal{V} \rightarrow|\mathcal{A}|$ é uma avaliação de variáveis para $\mathcal{A}$, então $s: \mathcal{T} \rightarrow|\mathcal{A}|$ é a avaliação de termos obtida da forma usual como extensão da avaliação original.

Definição 2.6 Seja $\mathcal{A}$ uma estrutura para $L \tau$, s uma avaliação para $\mathcal{A}$, e $A$ uma fórmula de $L \tau$. Então, $\mathcal{A} \models A[s]$ é definido da seguinte forma:

1. Se $A$ é uma fórmula atômica da forma $p\left(t_{1}, \ldots, t_{n}\right): \mu$, então $\mathcal{A} \vDash A[s]$ se $e$ somente se $p^{\mathcal{A}}\left(s\left(t_{1}\right), \ldots, s\left(t_{n}\right)\right) \geq \mu$.

2. Se $A$ é um hiper-literal $\neg^{k} p\left(t_{1}, \ldots, t_{n}\right): \mu, k \geq 1$, então $\mathcal{A} \models A[s]$ se e somente se $\mathcal{A} \models \neg^{k-1} p\left(t_{1}, \ldots, t_{n}\right): \sim \mu$.

3. Se $A$ é uma fórmula atômica da forma $t_{1}=t_{2}$, entầo $\mathcal{A} \models A[s]$ se e somente se $s\left(t_{1}\right)=s\left(t_{2}\right)$.

4. Se $A$ é da forma $(\neg F)$, onde $F$ é uma fórmula complexa, então $\mathcal{A} \models A[s]$ se $e$ somente se não é o caso que $\mathcal{A} \models F[s]$.

5. Se $A$ é da forma $(B \wedge C),(B \vee C)$ ou $(B \rightarrow C)$, onde $B, C$ são fórmulas, então:

(a) $\mathcal{A} \models(B \wedge C)[s]$ se e somente se $\mathcal{A} \models B[s]$ e $\mathcal{A} \models C[s]$.

(b) $\mathcal{A} \models(B \vee C)[s]$ se e somente se $\mathcal{A} \models B[s]$ ou $\mathcal{A} \models C[s]$.

(c) $\mathcal{A} \models(B \rightarrow C)[s]$ se e somente se $\mathcal{A} \models C[s]$ ou não é o caso que $\mathcal{A} \models B[s]$.

6. Se A é da forma $(\exists v) B$ ou $(\forall v) B$, onde $v$ é uma variável individual e $B$ é uma fórmula, então:

(a) $\mathcal{A} \models(\exists v) B[s]$ se e somente se $\mathcal{A} \models B[s(v \mid m)]$ para algum $m \in|\mathcal{A}|$, onde $s(v \mid m)$ é a avaliaçào definida da seguinte forma nas variáveis de $L \tau$ : 


$$
s(v \mid m)\left(v_{k}\right)= \begin{cases}s\left(v_{k}\right) & \text { se } v_{k} \text { é diferente de v } \\ m & \text { se } v_{k} \text { év. }\end{cases}
$$

(b) $\mathcal{A} \models(\forall v) B[s]$ se e somente se $\mathcal{A} \models B[s(v \mid m)]$ para todo $m \in|\mathcal{A}|$, onde $s(v \mid m)$ é a avaliação definida acima.

Assim, se $\mathcal{A} \models A[s]$, dizemos que $\mathcal{A}$ satisfaz $A$ para a avaliaçẫo s, ou que $A$ é verdadeira em $\mathcal{A}$ para a avaliação s. Freqüentemente, denotaremos por $\mathcal{A} \forall \forall A[s]$ quando não é o caso que $\mathcal{A} \models A[s]$. Se $\mathcal{A} \models A[s]$ para toda avaliação $s: \mathcal{V} \rightarrow|\mathcal{A}|$, dizemos que $\mathcal{A}$ é modelo de $A$, ou ainda que $A$ é verdadeira ou válida em $\mathcal{A}$, e denotamos por $\mathcal{A} \models A$. Uma fórmula $A$ é dita logicamente válida ou tautologia $(\models A)$ se $\mathcal{A} \models A$ para toda estrutura $\mathcal{A}$ para $L \tau$. Se $\Gamma$ é um conjunto de fórmulas de $L \tau$, dizemos que $A$ é uma consequência semântica de $\Gamma(\Gamma \models A)$ se, para toda estrutura $\mathcal{A}$ tal que $\mathcal{A} \models B$ para toda fórmula $B \in \Gamma$, temos que $\mathcal{A} \models A$. Se $\Gamma=\emptyset$, então $\Gamma \models A$ se e somente se $\models A$.

Lema 2.1 ([Abe92]) Sejam $p$ um símbolo predicativo $n$-ário, $t_{i}, 1 \leq i \leq n$ termos $e$ $\lambda, \mu, \mu_{i}, 1 \leq i \leq m$ constantes anotacionais da linguagem $L \tau$. Então:

$$
\begin{aligned}
& \text { 1. } \models p\left(t_{1}, \ldots, t_{n}\right): \perp \\
& \text { 2. } \models p\left(t_{1}, \ldots, t_{n}\right): \mu \rightarrow p\left(t_{1}, \ldots, t_{n}\right): \lambda, \mu \geq \lambda \\
& \text { 3. } \models\left(\neg^{k} p\left(t_{1}, \ldots, t_{n}\right): \mu\right) \leftrightarrow\left(\neg^{k-1} p\left(t_{1}, \ldots, t_{n}\right): \sim \mu\right), k \geq 1 \\
& \text { 4. } \models\left(p\left(t_{1}, \ldots, t_{n}\right): \mu_{1} \wedge \ldots \wedge p\left(t_{1}, \ldots, t_{n}\right): \mu_{m}\right) \rightarrow p\left(t_{i}, \ldots, t_{n}\right): \mu, \mu=\bigsqcup_{i=1}^{m} \mu_{i}
\end{aligned}
$$

Lema 2.2 ([Abe92]) Seja $p$ um símbolo predicativo $n$-ário, $t_{i}, 1 \leq i \leq n$ termos, $\mu$ uma constante anotacional de $L \tau$ e $k \geq 0$. Então:

$$
\models\left(\neg^{k} p\left(t_{1}, \ldots, t_{n}: \mu\right) \leftrightarrow\left(p\left(t_{1}, \ldots, t_{n}\right): \sim^{k} \mu\right) .\right.
$$

\subsection{Deduções}

Nesta seção, tratamos da axiomatização do cálculo de predicados $Q \tau$. Daqui por diante, podemos assumir que as fórmulas mencionadas são fórmulas de $L \tau$.

Conceitos sintáticos como variável individual livre (ligada) em uma fórmula, ocorrência livre (ligada) de variável individual em uma fórmula, substituição de uma variável individual livre por um termo e termo sustitutivel por uma variável individual em uma fórmula são extensões naturais dos mesmos conceitos definidos no Cálculo de Predicados Clássico.

Assim, $A_{v}[t]$ denota a fórmula obtida pela troca das ocorrências livres da variável individual $v$ pelo termo $t$ na fórmula $A$. quando $t$ é substitutível por $v \mathrm{em} A$. Por um 
abuso de notação, escrevemos apenas $A[t]$ quando estiver claro pelo contexto qual a variável que está sendo substituída.

Também como no caso clássico. se as rariv́eis individuais que ocorrem livres em uma fórmula $A$ estão entre $v_{1}, \ldots, v_{m}$, escrevemos $A\left(v_{1}, \ldots, v_{m}\right)$.

Nas figura 2.1 e 2.2 apresentamos, respectivamente, um sistema de axiomas e regras de inferência para o cálculo $Q \tau$ proposto em [Abe93]. Os sistemas apresentados nos outros trabalhos de referência são equivalentes ao que aqui apresentamos.

Lema 2.3 ([Abe92]) Todo axioma é uma tautologia.

Definição 2.7 (Dedução) Seja $\Gamma$ um conjunto de fórmulas. Uma dedução ou prova a partir de $\Gamma$ é uma sequência finita $\left(B_{1}, \ldots, B_{n}\right)$ de fórmulas tal que, para cada $k \leq n$ vale:

1. ou $B_{k}$ é um axioma;

2. ou $B_{k} \in \Gamma$;

3. ou $B_{k}$ é consequência imediata de fórmulas precedentes da sequência por uma das regras de inferência do cálculo $Q \tau$.

As fórmulas de $\Gamma$ são geralmente chamadas de hipóteses ou premissas da dedução. Se $A$ é a última fórmula de uma dedução a partir de $\Gamma$, dizemos que $\Gamma$ prova $A$, ou ainda que $A$ é uma consequência sintática de $\Gamma$, e denotamos por $\Gamma \vdash A$. Se $\Gamma \vdash A$ e $\Gamma=\emptyset$, dizemos que $A$ é um teorema ou tese de $Q \tau$ e denotamos por $\vdash A$.

Lema 2.4 ([Abe92]) Seja $p$ um símbolo predicativo $n$-ário, $t_{i}, 1 \leq i \leq n$ termos, $\mu$ uma constante anotacional de $L \tau$ e $k \geq 0$. Então:

$$
\vdash\left(\neg^{k} p\left(t_{1}, \ldots, t_{n}: \mu\right) \leftrightarrow\left(p\left(t_{1}, \ldots, t_{n}\right): \sim^{k} \mu\right) .\right.
$$

Teorema 2.1 (Dedução) ([Abe92]) Seja $\Gamma$ um conjunto de fórmulas e sejam $A$ e $B$ fórmulas quaisquer. Então, $\Gamma, A \vdash B$ se e somente se $\Gamma \vdash(A \rightarrow B)$.

Como esperado, o conjunto de axiomas e regras de inferência (figuras 2.1 e 2.2) para o cálculo de predicados $Q \tau$ é correto e completo em relação à semântica apresentada aqui. Os resultados abaixo podem ser encontrados, por exemplo, em [dCAS91, Abe92, Abe93].

Teorema 2.2 (Correção) Seja $\Gamma$ um conjunto de fórmulas e $A$ uma fórmula de $Q \tau$. Se $\Gamma \vdash A$, então $\Gamma \models A$.

Teorema 2.3 (Completude) Seja $\Gamma$ um conjunto de fórmulas e A uma fórmula de $Q \tau$. Se $\Gamma \models A$, então $\Gamma \vdash A$. 
Sejam $A, B, C$ fórmulas quaisquer, $F, G$ fórmulas complexas, $p$ um símbolo predicativo $n$-ário, $t_{i}, 1 \leq i \leq n$ termos, $\lambda, \mu, \mu_{i}, 1 \leq i \leq m$ constantes anotacionais e $u, v$ variáveis individuais de $L \tau$.

1. $A \rightarrow(B \rightarrow A)$

2. $(A \rightarrow(B \rightarrow C)) \rightarrow((A \rightarrow B) \rightarrow(A \rightarrow C))$

3. $((A \rightarrow B) \rightarrow A) \rightarrow A$

4. $(A \wedge B) \rightarrow A$

5. $(A \wedge B) \rightarrow B$

6. $A \rightarrow(B \rightarrow(A \wedge B))$

7. $A \rightarrow(A \vee B)$

8. $B \rightarrow(A \vee B)$

9. $(A \rightarrow C) \rightarrow((B \rightarrow C) \rightarrow((A \vee B) \rightarrow C))$

10. $(F \rightarrow G) \rightarrow((F \rightarrow \neg G) \rightarrow \neg F)$

11. $F \rightarrow(\neg F \rightarrow A)$

12. $F \vee \neg F$

13. $A[t] \rightarrow(\exists v) A(v)$

14. $(\forall v) A(v) \rightarrow A[t]$

15. $p\left(t_{1}, \ldots, t_{n}\right): \perp$

16. $p\left(t_{1}, \ldots, t_{n}\right): \mu \rightarrow p\left(t_{1}, \ldots, t_{n}\right): \lambda, \mu \geq \lambda$

17. $\left(\neg^{k} p\left(t_{1}, \ldots, t_{n}\right): \mu\right) \leftrightarrow\left(\neg^{k-1} p\left(t_{1}, \ldots, t_{n}\right): \sim \mu\right), k \geq 1$

18. $\left(p\left(t_{1}, \ldots, t_{n}\right): \mu_{1} \wedge \ldots \wedge p\left(t_{1}, \ldots, t_{n}\right): \mu_{m}\right) \rightarrow p\left(t_{1}, \ldots, t_{n}\right): \mu, \mu=\sqcup_{i=1}^{m} \mu_{i}$

19. $v=v$

20. $(v=u) \rightarrow\left(A(v) \leftrightarrow A_{v}{ }^{\prime}[u]\right)$,

onde $A_{v}{ }^{\prime}[u]$ é a fórmula obtida pela troca de algumas ocorrências livres de $v$ por $u$ em $A$, tal que $u$ é substitutível por $v$ em $A$.

Figura 2.1: Sistema de axiomas para o Cálculo de Predicados $Q \tau$ 
Regras de Inferência:

1. $\frac{A \quad A \rightarrow B}{B}$ (Modus Ponens)

2. $\frac{A(v) \rightarrow B}{(\exists v) A(v) \rightarrow B}$, onde $v$ não ocorre livre em $B$.

3. $\frac{B \rightarrow A(v)}{B \rightarrow(\forall v) A(v)}$, onde $v$ não ocorre livre em $B$.

Figura 2.2: Regras de inferência para o Cálculo de Predicados $Q \tau$

\subsection{Paraconsistência e Paracompletude}

$\mathrm{Na}$ introdução, definimos informalmente as noções de paraconsistência e paracompletude em relação a um sistema lógico. Nesta seção, apresentamos uma definição mais precisa destes conceitos e provamos que o cálculo $Q \tau$ pode servir como fundamento para sistemas paraconsistentes e/ou paracompletos.

Definição 2.8 (Não-trivialidade) Dizemos que uma estrutura $\mathcal{A}$ para $L \tau$ é nãotrivial se existe um átomo anotado fechado $p\left(t_{1}, \ldots, t_{n}\right): \mu$ tal que $\mathcal{A} \not \models p\left(t_{1}, \ldots, t_{n}\right): \mu$.

Note que uma estrutura $\mathcal{A}$ para $L \tau$ é trivial se e somente se $p^{\mathcal{A}}\left(t_{1}, \ldots, t_{n}\right)=\mathrm{T}$, para todo átomo fechado $p\left(t_{1}, \ldots, t_{n}\right)$.

Definição 2.9 (Inconsistência) Dizemos que uma estrutura $\mathcal{A}$ para $L \tau$ é inconsistente se existe um átomo anotado fechado $p\left(t_{1}, \ldots, t_{n}\right): \mu$ tal que $\mathcal{A} \models p\left(t_{1}, \ldots, t_{n}\right): \mu$ e $\mathcal{A} \models \neg p\left(t_{1}, \ldots, t_{n}\right): \mu$

Definição 2.10 (Paraconsistência) Dizemos que uma estrutura $\mathcal{A}$ para $L \tau$ é paraconsistente se $\mathcal{A}$ é simultaneamente inconsistente e não-trivial. O sistema $Q \tau$ é dito paraconsistente se existe uma estrutura $\mathcal{A}$ para $L \tau$ tal que $\mathcal{A}$ é paraconsistente.

Definição 2.11 (Paracompletude) Dizemos que uma estrutura $\mathcal{A}$ para $L \tau$ é paracompleta se existe um átomo anotado fechado $p\left(t_{1}, \ldots, t_{n}\right): \mu$ tal que $\mathcal{A} \not \models p\left(t_{1}, \ldots, t_{n}\right): \mu$ $e \mathcal{A} \not \forall \neg p\left(t_{1}, \ldots, t_{n}\right): \mu$. O sistema $Q \tau$ é dito paracompleto se existe uma estrutura $\mathcal{A}$ para $L \tau$ tal que $\mathcal{A}$ é paracompleta.

A linguagem $L \tau$ é paraconsistente se existe uma estrutura paraconsistente $\mathcal{A}$ para $L \tau$.

Teorema 2.4 O sistema $Q \tau$ é paraconsistente se e somente se \#| $|\geq| \geq 2$, onde \# $|\tau|$ indica a cardinalidade de $|\tau|$. 
Demonstração. Suponha que $Q \tau$ é paraconsistente: ou seja, existe uma estrutura paraconsistente $\mathcal{A}$ para $L_{\tau}$. Suponha, por absurdo, que $\#|\tau|=1$. Logo, $|\tau|=\{\mu\}$ e portanto $p^{\mathcal{A}}\left(t_{1}, \ldots, t_{n}\right)=\mu$ para todo átomo fechado $p\left(t_{1}, \ldots, t_{n}\right)$. Claramente, $\mathcal{A} \models p\left(t_{1}, \ldots, t_{n}\right): \mu$ para todo átomo anotado fechado $p\left(t_{1}, \ldots, t_{n}\right): \mu$, contradizendo a hipótese de que $\mathcal{A}$ é paraconsistente, e portanto não-trivial. Assim, se $Q_{\tau}$ é paraconsistente, então \# $|\tau| \geq 2$.

Suponha agora que $\#|\tau| \geq 2$. Logo, $\perp \neq \top$. Seja $p$ um símbolo predicativo $n$-ário de $L \tau$ e $\left(a_{1}, \ldots, a_{n}\right),\left(b_{1}, \ldots, b_{n}\right) \in|\mathcal{A}|^{n}$ tal que $\left(a_{1}, \ldots, a_{n}\right) \neq$ $\left(b_{1}, \ldots, b_{n}\right)$. Considere a estrutura $\mathcal{A}$ definida da seguinte forma:

$$
p^{\mathcal{A}}\left(a_{1}, \ldots, a_{n}\right)=\top \text { e } p^{\mathcal{A}}\left(b_{1}, \ldots, b_{n}\right)=\perp .
$$

Claramente, temos que $\mathcal{A} \models p\left(a_{1}, \ldots, a_{n}\right): \top$, e como $\top \geq \sim \top$, temos que $\mathcal{A} \models \neg p\left(a_{1}, \ldots, a_{n}\right)$ : T. Por outro lado, como $\perp \geq T$, segue que $\mathcal{A} \not \models p\left(b_{1}, \ldots, b_{n}\right): T$. Assim, $\mathcal{A}$ é uma estrutura paraconsistente para $L \tau$, e portanto $Q \tau$ é paraconsistente.

Teorema 2.5 Qualquer que seja $\tau$, existem sistemas $Q_{\tau}$ que não são paracompletos. Qualquer que seja $\tau$ tal que \# $|\tau|$, existem sistemas $Q_{\tau}$ que são paracompletos. Se $Q \tau$ é paracompleto, então \# $|\tau| \geq 2$.

Demonstração. Análoga à demonstração anterior.

Definição 2.12 Dizemos que uma estrutura $\mathcal{A}$ é não-alética se $\mathcal{A}$ é simultaneamente paraconsistente e paracompleta. O sistema $Q \tau$ é dito não-alético se existe uma estrutura $\mathcal{A}$ para $L \tau$ tal que $\mathcal{A}$ é não-alética.

\subsubsection{Princípios do 3ọ Excluído e da Não Contradição}

Como consequência das definições de paraconsistência e paracompletude, algumas características dos sistemas lógicos, invisíveis do ponto de vista das lógicas clássicas, tornamse visíveis sob o prisma das lógicas anotadas.

Considere, por exemplo, os princípios do 3 o excluído e da não-contradição. O primeiro diz que toda setença ou é verdadeira ou é falsa $(A \vee \neg A)$ e o último diz que nenhuma sentença é simultaneamente verdadeira e falsa $(\neg(A \wedge \neg A))$. Assim, o princípio do 3ọ excluído não é válido em um sistema paracompleto, enquanto que o princípio da não-contradição não é válido em um sistema paraconsistente.

Em um sistema clássico, derivamos o seguinte resultado:

Metateorema Clássico 2.1 (Lei de De Morgan) Sejam A e B fórmulas clássicas quaisquer. Então $(\neg A \vee \neg B) e \neg(A \wedge B)$ são intercambiáveis. 
A partir de uma interpretação errônea do metateorema acima, pode-se concluir indevidamente que o princípio do 3o excluído e o princípio da não contradição são o mesmo princípio. Por definição, tais conceitos expressam noções distintas. Mas por conta do metateorema 2.1, esta distinção não é caracterizada em um sistema clássico.

Do ponto de vista das lógicas anotadas, o metateorema acima não é válido. De fato, considere o seguinte exemplo, onde $\tau$ é o reticulado FOUR, cuja ordem é representada através do diagrama na figura 1.2 .

Exemplo 2.1 Seja $\sim:|\tau| \rightarrow|\tau|$ tal que $\sim \top=\perp e \sim v=f$. Sejam $\mathcal{A}$ uma estrutura para $L \tau$ e $A, B$ átomos fechados da linguagem tais que $A^{\mathcal{A}}=\top$ e $B^{\mathcal{A}}=v$. Considere as fórmulas anotadas $A: T$ e $B: v$.

Da definição de satisfatibilidade, temos que:

(i) $\mathcal{A} \models(\neg A: \top \vee \neg B: v)$ sse $\mathcal{A} \models \neg A: \top$ ou $\mathcal{A} \models \neg B: v$.

(ii) $\mathcal{A} \models \neg(A: \top \wedge B: v)$ sse $\mathcal{A} \not \forall(A: \top \wedge B: v)$ sse $\mathcal{A} \not \models A: \top$ ou $\mathcal{A} \not \models B: v$.

De (i) temos que $\mathcal{A} \models \neg A: \top$ sse $\mathcal{A} \models A: \sim \top$ sse $\mathcal{A} \models A: \perp$, o que é válido por definição. Portanto, $\mathcal{A} \models(\neg A: \top \vee \neg B: v)$.

De (ii), como temos que $\mathcal{A} \models A: T e \mathcal{A} \models B: v$, então temos que $\mathcal{A} \not \models \neg(A: \top \wedge B: v)$.

Neste caso, $(\neg A: \top \vee \neg B: v)$ e $\neg(A: \top \wedge B: v)$ não são intercambiáveis.

Assim, mostramos como os princípios acima são distintos, de acordo com a definição de lógicus anotadas. 


\section{Capítulo 3}

\section{Lógicas Anotadas e IA: Outra Abordagem}

As lógicas anotadas têm se mostrado de grande importância para a Inteligência Artificial, principalmente porque constituem um formalismo para sistemas dedutivos que tratam inconsistências. Neste capítulo, investigamos um outro aspecto de tais lógicas, que acreditamos ser também de grande interesse para pesquisadores nessa área.

\subsection{Fatos e Argumentos}

Existe uma diferença entre raciocinar com fatos da realidade e raciocinar com argumentos a respeito de fatos da realidade.

Não é nosso objetivo discutir aqui se temos ou não acesso a uma "realidade objetiva"; isto levaria a uma complexa questão filosófica que vem sendo considerada através dos séculos. Gostaríamos de apresentar, entretanto, uma forma precisa na qual a distinção acima possa ser analisada e caracterizada.

Para efeito de ilustração, vamos considerar a seguinte situação, bastante familiar para quem trabalha com computadores:

Exemplo 3.1 Quando um computador quebra e um técnico vem consertá-lo, ele efetua ações corretivas a partir da observação do problema. Neste caso, ele está raciocinando com fatos da realidade. Se, ao contrário, o técnico atua à distância através de uma "hot-line" de manutenção, as ações corretivas são efetuadas baseadas nos argumentos construídos pelo cliente a partir dos fatos. Desta forma, seu raciocínio não é mais guiado por fatos, e sim por argumentos a respeito dos fatos, e assim as várias possibilidades de relacionamento entre fatos e argumentos devem ser consideradas.

Neste capítulo, nossa intenção é caracterizar esta diferenciação de uma forma mais técnica, em termos de linguagens e sistemas lógicos. Como veremos, as linguagens 
clássicas não servirão para este propósito. De fato, a própria estrutura das lógicas clássicas não permite que tal diferenciação seja feita de modo claro. Esta é uma das razões porque pesquisadores em IA e raciocínio dedutivo muitas vezes recorrem às lógicas não-clássicas.

Definição 3.1 (Sistema Lógico Clássico) Chamaremos um sistema lógico de clássico se for:

1. bi-valorado; $e$

2. consistente em relação a um operador de negação $\neg$; i.e. se tiver um operador de negação $\neg$, então $\neg$ é uma negação forte (clássica). Ou seja, para fórmulas $A, B$ quaisquer, as seguintes propriedades são válidas:

(a) $A \vee \neg A$

(b) $(A \rightarrow B) \rightarrow((A \rightarrow \neg B) \rightarrow \neg A)$

(c) $A \rightarrow(\neg A \rightarrow B)$

$\mathrm{Na}$ lógica clássica, a diferença entre fatos e argumentos é geralmente negligenciada - e negligenciável. De fato, quando discutimos o conceito clássico de verdade [Tar69, GB93], vemos que um de seus fundamentos mais intuitivos aparenta ser extremamente simples e claro: se $p$ é uma sentença, então " $p$ " é verdadeira se e somente se $p^{1}$. Desta forma, as sentenças $p$ e " $p$ " é verdadeira são intercambiáveis no caso clássico.

Considerando a situação mencionada anteriormente, a sentença $p$ poderia representar, por exemplo, o fato de que o monitor está quebrado, enquanto que "o monitor está quebrado" é verdadeira representa um argumento construído pelo cliente a partir de sua própria observação do fato.

Em [Tar69], o autor faz questão de frisar que existe uma rigorosa distinção entre a linguagem que constitui o objeto da discussão em si (linguagem objeto), e a linguagem que usamos para formular definições e estudar suas implicações (metalinguagem). Como apresentado em [Hof79], temos uma espécie de hierarquia de linguagens: $p$ é uma sentença de uma linguagem objeto, que está na base de tal hierarquia. Neste nível, são feitas referências apenas a um domínio específico e nunca a aspectos da própria linguagem objeto. Desta forma, uma sentença como " $p$ " é verdadeira só pode ser expressa em uma metalinguagem; ou seja, uma linguagem que nos permite referenciar fatos da linguagem objeto. Seguindo tal hierarquia, poderíamos ter uma meta-metalinguagem para raciocinar com argumentos a respeito de fatos da metalinguagem, e assim sucessivamente.

\footnotetext{
${ }^{1}$ De acordo com [Tar69]. sempre que se fizer uma afirmação a respeito de um objeto, deve-se usar um nome deste objeto, e não o objeto em si. Denotamos aqui o nome de um objeto colocando-o entre aspas.
} 
Em particular, temos uma linguagem objeto para raciocinar com fatos (externos) e uma metalinguagem para raciocinar com argumentos a respeito de tais fatos. As sentenças $p$ e " $p$ " é verdadeira estão assim em níveis distintos de linguagem e a equivalência

$$
\text { " } p \text { " é verdadeira se e somente se } p
$$

está nou nível da metảininguaagem.

Segundo [Hof79], em se tratando de sistemas lógicos, esta distinção pode ser caracterizada em termos de se trabalhar no próprio sistema e de se pensar a respeito do sistema.

No caso das lógicas clássicas, tanto a linguagem objeto quanto a metalinguagem são bi-valoradas: apenas os valores verdadeiro $(v)$ e falso $(f)$ são associados às sentenças. Se considerarmos ainda as propriedades axiomáticas dos conectivos clássicos e a concepção clássica de verdade, temos como resultado a equivalência mencionada acima.

Esta é uma propriedade interessante e útil das lógicas clássicas. Porém, esta "supersimplificação" imposta aos processos de raciocínio pela própria estrutura algébrica de tais lógicas pode se tornar um fator limitante para certas aplicações. Como por exemplo no caso de raciocínio dedutivo usado para implementar certos sistemas de Inteligência Artificial.

Por conta desta "super-simplificação", alguns aspectos do próprio processo de raciocínio tornam-se invisíveis sob o prisma da lógica clássica. Vamos considerar por exemplo os princípios do 3 ọ excluído e da não contradição. Como vimos no capítulo 2, tais princípios são distintos, mas, pelo metateorema 2.1, são intercambiáveis no caso clássico.

Este resultado é um metateorema da lógica clássica; ou seja, um Teorema (um resultado provado) sobre um teorema (uma fórmula da linguagem objeto que pode ser provada - no caso, a linguagem objeto é a própria linguagem clássica) [Hof79]. Portanto, o metateorema 2.1 faz parte do conhecimento que temos sobre o sistema clássico.

Quando linguagem objeto e metalinguagem se confundem (como no caso clássico), raciocinar com argumentos a respeito de fatos passa a ser apenas mais uma forma de raciocinar com os fatos em si. Mas, mesmo que um sistema possa raciocinar sobre si mesmo dentro de si mesmo [Hof79], ainda existiria um fator externo que o "enxergaria" (raciocinaria sobre este) de uma maneira diferente. E portanto, existiria uma "visão externa" correspondente a uma outra metalinguagem que não mais se confunde com a linguagem objeto considerada.

Em [CdS96], o autor faz uma distinção semelhante no que diz respeito ao tratamento de incertezas em IA. Dos sistemas propostos para tal finalidade, alguns foram desenvolvidos para raciocinar com incertezas, enquanto outros foram desenvolvidos para raciocinar sobre incertezas. Neste trabalho, abordamos esta distinção em termos de raciocínio com fatos e sobre fatos; em outras palavras, raciocínio com fatos e com argumentos. 
Como vimos, sistemas clássicos não são apropriados para caracterizar as diferenças entre fatos e argumentos. Fica então a seguinte pergunta: será que sistemas anotados podem caracterizar (pelo menos em parte) esta diferenciação entre níveis de linguagem e raciocínio? A resposta nos parece ser positiva. Nas seções seguintes, partimos da idéia apresentada em [CdS96] e tentamos justificar esta resposta. Nesta seção, restringiremos nosso trabalho às linguagens proposicionais. De fato, tais linguagens são suficientes para ilustrar nosso ponto de vista.

\subsection{Uma Linguagem Objeto Clássica}

Intuitivamente, os fatos da realidade são ou não são. Eles representam o que é ou não é realmente verdadeiro no "mundo real". Nos parece razoável que, em termos de linguagens lógicas, as sentenças que representam fatos da realidade assumam então valores verdadeiro ou falso.

A linguagem objeto que definimos aqui é simplesmente uma linguagem proposicional clássica, digamos $L$, cujos símbolos primitivos são:

1. Um conjunto enumerável $\mathcal{P}=\left\{p_{1}, p_{2}, \ldots\right\}$ de símbolos proposicionais;

2. Os conectivos lógicos $\neg, \wedge, \vee, \rightarrow^{2}$;

3. Símbolos auxiliares: parênteses.

As fórmulas de $L$ são definidas da maneira usual.

A semântica usual das lógicas clássicas nos permite assim raciocinar com os fatos de uma forma "objetiva". Portanto, assumimos $L$ como a linguagem objeto da nossa hierarquia.

Exemplo 3.2 Suponha que um dos computadores de uma certa empresa não esteja funcionando adequadamente. O técnico que presta serviços de manutençâa a esta empresa trabalha diretamente no local e portanto, neste caso, ele tem acesso direto aos fatos. Ou seja, ele raciocina a partir da própria observação dos problemas apresentados pelo computador.

Desta forma, a linguagem usada para especificar o problema é a própria linguagem objeto clássica L. Podemos representar os fatos em questão, ou seja, algumas das características analisadas pelo técnico, pelas seguintes fórmulas de $L$ :

\section{Em relação ao monitor:}

\footnotetext{
${ }^{2}$ Sabemos que a lógica proposicional clássica pode ser definida a partir de apenas dois conectivos lógicos (por exemplo $\neg$ e $\wedge$ ). Neste caso, porém, para manter uma relação com as linguagens anotadas, assumimos que todos os conectivos lógicos são primitivos.
} 
(a) monitor_q denota que "o monitor está quebrado".

(b) placa_q denota que "a placa de vídeo está quebrada".

(c) liga denota que "a luz que indica se o monitor está ligado/desligado está funcionando".

2. Em relação ao mouse e teclado:

(a) mouse_q denota que "o mouse está quebrado".

(b) teclado_q denota que "o drive está quebrado".

3. Em relação a outros componentes:

(a) drive_q denota que "o drive está quebrado".

(b) cpu_q denota que "a cpu está quebrada".

4. Temos ainda a fórmula garantia, que denota que "a manutenção realizada é coberta pela garantia da máquina”.

Nota. Afirmamos que um componente está quebrado quando não está funcionando adequadamente; ou seja, quando está apresentando algum tipo de problema.

O técnico observou no computador que o monitor não estava funcionando, porém a luz indicadora acendia normalmente. Observou ainda que o restante dos componentes estava em ordem. Estas observações podem ser expressas a partir das seguintes fórmulas de $L$ :

1. monitor_q $_{-}$

2. $\operatorname{liga}$

3. $\neg$ mouse_q

4. ᄀteclado_q

5. $\neg$ drive $q$

6. ᄀсри-q

O técnico sabe ainda que se o monitor está quebrado, mas a luz indicadora está funcionando normalmente, então o problema reside na placa de vídeo. Se o problema for na placa, então a manutenção é coberta pela garantia. Outra situação que se encaixa na garantia é quando o mouse está quebrado, mas o teclado funciona normalmente. Neste caso, o mouse com problemas é substituído sem custo algum. Este conhecimento pode ser expresso pelas seguintes sentenças: 
1. monitor_q $\wedge$ liga $\rightarrow$ placa_q

2. placa_q $\rightarrow$ garantia

3. mouse_$_{-} \wedge \wedge$ teclado_ $q \rightarrow$ garantia

O técnico conclui então que a placa está com problemas e efetua as ações corretivas necessárias sem cobrar o serviço.

\subsubsection{Uma Questão de Notação}

A linguagem proposicional clássica não precisa, porém, ser apresentada de uma maneira "clássica". No presente trabalho, optamos por adotar uma nova formulação para esta linguagem, que se aproximasse da sintaxe das linguagens anotadas ${ }^{3}$.

Em [Abe92], o autor apresenta a lógica anotada como uma extensão da lógica clássica, definindo um novo conectivo, denominado negação forte ${ }^{4}$, que se prova ser um operador de negação clássico. Assim, a última pode ser obtida a partir da primeira. Além destes resultados, o principal fato que motivou a idéia de uma nova formulação foi a própria linguagem anotada e um de seus aspectos mais significativos: a possibilidade de incorporar o símbolo de negação $\neg$ à anotação através do operador $\sim$ quando a fórmula em questão for um hiper-literal ${ }^{5}$.

A negação $\neg$ pode se comportar de maneiras distintas para hiper-literais e fórmulas complexas. No primeiro caso reside a paraconsistência da linguagem anotada, enquanto que, de acordo com a definição 3.1 e a axiomatização apresentada no capítulo 2, o operador de negação $\neg$ é clássico em relação a fórmulas complexas.

Apresentar uma formulação da lógica clássica usando anotações significa ter que eliminar a paraconsistência da linguagem anotada. Para tanto, parece que devemos tratar fundamentalmente dos hiper-literais e do significado da negação neste caso em particular. Assim, nos parece razoável especificar o reticulado de valores-verdade $\tau$ e o operador $\sim$ associado, restringindo de certa forma as anotações no sistema e o próprio uso da negação em relação a hiper-literais.

Restringir o uso da negação na linguagem anotada para torná-la clássica faz com que ela perca algumas de suas principais características de linguagem anotada, como por exemplo a paraconsistência. Vale lembrar, porém, que nossa intenção é apresentar uma formulação da lógica clássica cuja sintaxe se aproxime da "sintaxe anotada"; ou seja, usando anotações.

Parece claro que, uma vez que queremos tratar dos hiper-literais em particular, o primeiro passo seja desmembrar o símbolo de negação em dois. Este procedimento nos parece natural, uma vez que $\neg$ funciona de formas distintas para hiper-literais e

\footnotetext{
${ }^{3}$ Uma definição da lógica proposicional anotada pode ser encontrada em [Abe92], entre outros.

${ }^{4} \mathrm{cf}$. Seção 2.1 , onde apresentamos a definição da negação forte.

${ }^{5}$ Capítulo 2, em particular os lemas 2.2 e 2.4 .
} 
fórmulas complexas. Para fins de clareza, nesta nova formulação $\neg$ é dividido nos seguintes símbolos:

1. Para fórmulas complexas, ᄀ é clássico, e portanto continuaremos usando o próprio símbolo.

2. Para hiper-literais, a negação virá implícita na anotação através do operador $\sim:|\tau| \rightarrow|\tau|$ e não mais usaremos o símbolo $\neg$.

No caso dos hiper-literais, a negação, agora absorvida pelo seu significado (o operador $\sim$ ), ainda acarreta a paraconsistência da linguagem. Para torná-la clássica, é preciso especificar o reticulado e, principalmente, o operador $\sim$. Mas antes gostaríamos de expor algumas considerações a respeito desta nova formulação.

Representar a negação de forma alternativa é um recurso que já foi utilizado em outros sistemas lógicos. Na lógica linear [Gir87, Gal91], por exemplo, a negação de uma fórmula $A$ é denotada por $A^{\perp}$. Ou seja, a negação pode ser interpretada como uma espécie de anotação associada à fórmula. Neste sistema em particular, as anotações correspondem aos valores-verdade clássicos $f$ e $v$ e, dada uma proposição $p$ qualquer, $p: v$ denota a fórmula $p$, e $p: f$ denota a fórmula $\neg p$.

A segunda providência que devemos tomar é em relação ao reticulado $\tau$ de valoresverdade e o respectivo operador $\sim$ associado. Como estamos formulando a linguagem proposicional clássica, a tentativa natural seria definir $\tau$ como sendo o reticulado booleano $|f, v|=<\{f, v\}, \leq>$, tal que $f, v$ são os únicos átomos e $f \leq v$. Além disso, $\sim$ representaria o próprio operador de complemento, ou seja, $\sim(f)=v$ e $\sim(v)=f$. Porém, não basta tornar a linguagem bivalorada para torná-la clássica: a paraconsistência continua presente (cf. teorema 2.4). De fato, considere a seguinte situação:

Seja $I$ uma interpretação ${ }^{6}$ para o sistema em questão, e seja $p$ um símbolo proposicional qualquer. Claramente, $I(p) \geq f$, qualquer que seja $I(p)$. De acordo com esta formulação, a fórmula $p: f$ (ou $\neg p$ ) é sempre válida. Isso naturalmente não corresponde àquilo que desejamos representar.

O terceiro passo é então remover a paraconsistência da linguagem. Para tanto, não basta restringir o reticulado de valores-verdade ao reticulado booleano e o operador $\sim$ ao operador de complemento. Basicamente, precisamos obter as seguintes propriedades:

1. Se $p: \mu$ é válido, então $p: \lambda$ não é válido, $\mu \neq \lambda$. Neste caso em particular, os únicos elementos do reticulado booleano são $f$ e $v$, donde segue que se $p: f$ é valido então $p: v$ não é válido, e se $p: v$ é valido então $p: f$ não é válido. Intuitivamente, isso significa a impossibilidade de se deduzir a inconsistência a partir da consistência.

\footnotetext{
${ }^{6}$ Equivalente ao conceito de estrutura para o cálculo de predicados. Uma definição mais precisa pode ser encontrada em [Abe92].
} 
2. Se $p: \mu_{1}$ e $p: \mu_{2}, \mu_{1} \neq \mu_{2}$, são válidos. então qualquer fórmula $A$ é válida. Em particular, se $p: f$ e $p: v$ (ou $\neg p$ e $p$ ) são válidos, então qualquer fórmula $A$ é válida. Intuitivamente, isso significa a impossibilidade de se obter a nãotrivialidade a partir da inconsistência.

Assim, teremos que todo sistema lógico consistente não permitirá a dedução de resultados inconsistentes; e todo sistema lógico inconsistente será trivial, não se podendo, portanto, construir sistemas paraconsistentes.

Na figura 3.1, apresentamos, a título de comparação, um sistema de axiomas e regra de inferência para o cálculo proposicional anotado ${ }^{7}$. Na figura 3.2, apresentamos um sistema de axiomas e regra de inferência para este caso em particular, obtido a partir do primeiro de forma que as propriedades mencionadas acima se tornem válidas. Para obtermos as propriedades desejadas, fizemos as seguintes alterações no sistema original:

1. Para que a propriedade 1 acima seja válida, o axioma 13 foi removido e o axioma 14 foi alterado.

2. Para que a propriedade 2 acima seja válida. o axioma 16 foi alterado.

\subsubsection{Uma Versão Consistente da Linguagem Anotada}

A linguagem objeto que adotaremos é a própria linguagem proposicional clássica, formulada como uma versão consistente (clássica) da linguagem proposicional anotada, e que será denotada por $L_{0}$. Como vimos na seção 3.1, $L_{0}$ está no início de uma hierarquia de linguagens, e é de fato a única que efetivamente faz referências a fatos externos à própria linguagem.

A linguagem $L_{0}$ é formada pelos seguintes símbolos primitivos:

1. Um conjunto enumerável $\mathcal{P}_{0}=\left\{p_{1}, p_{2}, \ldots\right\}$ de símbolos proposicionais;

2. Os conectivos lógicos $\neg, \wedge, \vee, \rightarrow$;

3. Cada elemento de $|f, v|$ se diz uma constante anotacional;

4. Símbolos auxiliares: parênteses.

Em $|f, v|$ fixamos o operador $\sim$ como sendo o próprio complemento. Assim,

$$
\begin{aligned}
& \sim(f)=v \mathrm{e} \\
& \sim(v)=f .
\end{aligned}
$$

\footnotetext{
${ }^{7}$ cf. [Abe92].
} 
Sejam $A, B, C$ fórmulas quaisquer, $F$. $G$ fórmulas complexas, $p$ um símbolo proposicional, e $\lambda, \mu, \mu_{i}, 1 \leq i \leq m$ constantes anotacionais da linguagem.

1. $A \rightarrow(B \rightarrow A)$

2. $(A \rightarrow(B \rightarrow C)) \rightarrow((A \rightarrow B) \rightarrow(A \rightarrow C))$

3. $((A \rightarrow B) \rightarrow A) \rightarrow A$

4. $(A \wedge B) \rightarrow A$

5. $(A \wedge B) \rightarrow B$

6. $A \rightarrow(B \rightarrow(A \wedge B))$

7. $A \rightarrow(A \vee B)$

8. $B \rightarrow(A \vee B)$

9. $(A \rightarrow C) \rightarrow((B \rightarrow C) \rightarrow((A \vee B) \rightarrow C))$

10. $(F \rightarrow G) \rightarrow((F \rightarrow \neg G) \rightarrow \neg F)$

11. $F \rightarrow(\neg F \rightarrow A)$

12. $F \vee \neg F$

13. $p: \perp$

14. $p: \mu \rightarrow p: \lambda, \mu \geq \lambda$

15. $\left(\neg^{k} p: \mu\right) \leftrightarrow\left(\neg^{k-1} p: \sim \mu\right), k \geq 1$

16. $\left(p: \mu_{1} \wedge \ldots \wedge p: \mu_{n}\right) \rightarrow p: \mu, \mu=\sqcup_{i=1}^{n} \mu_{i}$

Regra de Inferência: $\frac{A \quad A \rightarrow B}{B}$ (Modus Ponens)

Figura 3.1: Sistema de axiomas e regra de inferência para o Cálculo Proposicional Anotado 
Sejam $A, B, C$ fórmulas quaisquer, $F, G$ fórmulas complexas, $p$ um símbolo proposicional, e $\mu$ constante anotacional da linguagem.

1. $A \rightarrow(B \rightarrow A)$

2. $(A \rightarrow(B \rightarrow C)) \rightarrow((A \rightarrow B) \rightarrow(A \rightarrow C))$

3. $((A \rightarrow B) \rightarrow A) \rightarrow A$

4. $(A \wedge B) \rightarrow A$

5. $(A \wedge B) \rightarrow B$

6. $A \rightarrow(B \rightarrow(A \wedge B))$

7. $A \rightarrow(A \vee B)$

8. $B \rightarrow(A \vee B)$

9. $(A \rightarrow C) \rightarrow((B \rightarrow C) \rightarrow((A \vee B) \rightarrow C))$

10. $(F \rightarrow G) \rightarrow((F \rightarrow \neg G) \rightarrow \neg F)$

11. $F \rightarrow(\neg F \rightarrow A)$

12. $F \vee \neg F$

13. -

14'. $p: v \vee p: f$

15. $\left(\neg^{k} p: \mu\right) \leftrightarrow\left(\neg^{k-1} p: \sim \mu\right), k \geq 1$

16'. $(p: v \wedge p: f) \rightarrow A$

Regra de Inferência: $\frac{A \quad A \rightarrow B}{B}$ (Modus Ponens)

Figura 3.2: Sistema de axiomas e regra de inferência para a versão consistente do Cálculo Proposicional Anotado 
Definição 3.2 (Fórmulas) As fórmulas de $L_{0}$ sâo definidas indutivamente da seguinte forma:

1. Se p é um símbolo proposicional e $\mu \in \tau$ é uma constante anotacional, então $p: \mu$ é uma fórmula atômica.

2. Se A é uma fórmula, então $(\neg A)$ é uma fórmula. Se A for da forma $p: \mu$ (fórmula atômica), então denotamos $(\neg A)$ por $p: \sim \mu$.

3. Se $A$ e $B$ são fórmulas, então $(A \wedge B),(A \vee B) e(A \rightarrow B)$ são fórmulas.

Definição 3.3 (Interpretação e Valoração) Uma interpretação $I_{0}$ para a linguagem $L_{0}$ é uma função $I_{0}: \mathcal{P}_{0} \rightarrow\{f, r\}$. Seja $\mathcal{F}_{0}$ o conjunto de todas as fórmulas de $L_{0}$. A cada interpretação $I_{0}$ associamos uma valoração $v_{I_{0}}: \mathcal{F}_{0} \rightarrow\{f, v\}$, definida indutivamente da seguinte forma:

1. Se p é um símbolo proposicional, então $v_{I_{0}}(p: \mu)=v$ se e somente se $I_{0}(p)=\mu$. (Nota. Este caso cobre todos os hiper-literais, uma vez que os denotamos pela sua forma equivalente, onde a negação é incorporada à anotação.)

2. Se $A$ e $B$ são fórmulas, então

(a) $v_{I_{0}}(A \wedge B)=v$ se e somente se $v_{I_{0}}(A)=v$ e $v_{I_{0}}(B)=v$.

(b) $v_{I_{0}}(A \vee B)=v$ se e somente se $v_{I_{0}}(A)=v$ ou $v_{I_{0}}(B)=v$.

(c) $v_{I_{0}}(A \rightarrow B)=v$ se e somente se $v_{I_{0}}(A)=f$ ou $v_{I_{0}}(B)=v$.

3. Se $F$ é uma fórmula complexa, então $v_{I_{0}}(\neg F)=v$ se e somente se $v_{I_{0}}(F)=f$.

Dizemos que uma interpretação $I_{0}$ satisfaz um conjunto de fórmulas $\Gamma\left(I_{0} \models \Gamma\right)$ se $v_{I_{0}}(A)=v$ para toda fórmula $A$ em $\Gamma$.

Um sistema de axiomas e regra de inferência para esta linguagem está representado na figura 3.2 .

Definição 3.4 (Dedução) Seja $\Gamma$ um conjunto de fórmulas. Uma dedução ou prova a partir de $\Gamma$ é uma sequência finita $\left(B_{1}, \ldots, B_{n}\right)$ de fórmulas tal que, para cada $k \leq n$ vale:

1. ou $B_{k}$ é um axioma;

2. ou $B_{k} \in \Gamma$;

3. ou $B_{k}$ é consequência imediata de fórmulas precedentes da sequência pela aplicação da regra de Modus Ponens. 
Teorema 3.1 (Correção) Seja $\Gamma$ um conjunto de fórmulas e A uma fórmula qualquer. Se $\Gamma \vdash A$, então $\Gamma \models A$.

Teorema 3.2 (Completude) Seja $\Gamma$ um conjunto de fórmulas e A uma fórmula qualquer. $S e \Gamma \models A$, então $\Gamma \vdash A$.

Nota. As demonstrações dos teoremas de correção e completude para o sistema apresentado nesta seção são análogas às demonstrações dos teoremas correspondentes para o cálculo proposicional clássico. De fato, o sistema é consistente em relação à negação tanto para hiper-literais como para fórmulas complexas, e assim os procedimentos de demonstração funcionam da mesma forma.

Considerando esta axiomatização, proramos o seguinte resultado:

Proposição 3.1 O sistema apresentado nesta seção é clássico ${ }^{8}$ em relação ao operador de negação $\neg$.

Demonstração. Para esta demonstração, adotaremos a seguinte estratégia: para mostrar que o sistema aqui apresentado é clássico em relação ao operador $\neg$ (de acordo com a definição 3.1), vamos provar que este sistema é equivalente ao sistema proposicional clássico. Para isso, especificaremos uma funçâo de tradução entre estes dois sistemas lógicos. Como ambos são corretos e completos, basta provarmos que uma fórmula $A$ neste sistema é verdadeira se e somente se a sua tradução $A^{c}$ no sistema clássico também for verdadeira.

Seja $L$ a linguagem proposicional clássica correspondente a $L_{0}$, ou seja, tal que $\mathcal{P}_{0}=\mathcal{P}=\left\{p_{1}, p_{2}, \ldots\right\}$ é o conjunto de símbolos proposicionais de $L_{0}$ e $L$. Seja $\mathcal{F}$ o conjunto de todas as fórmulas da linguagem $L$ do cálculo proposicional clássico. Então a função de tradução $\mathcal{T}: \mathcal{F}_{0} \rightarrow \mathcal{F}$ aplicada a uma fórmula $A$ de $L_{0}$ é definida indutivamente da seguinte forma:

1. Se $A$ é uma fórmula atômica da forma $p: \mu$, então

$$
\mathcal{T}(p: \mu)= \begin{cases}p & \text { se } \mu=v \\ \neg p & \text { se } \mu=f .\end{cases}
$$

2. Se $A$ é da forma $(\neg B)$, então:

(a) Se $A$ é um hiper-literal $\neg^{k} p: \mu, k \geq 1$, então denotamos por $p: \sim^{k} \mu$. Desta forma, temos que

$$
\mathcal{T}\left(p: \sim^{k} \mu\right)=\neg \mathcal{T}\left(p: \sim^{k-1} \mu\right) .
$$

Note que $\mathcal{T}\left(p: \sim^{0} \mu\right)=\neg \mathcal{T}(p: \mu)$.

(b) Se $B$ é uma fórmula complexa, então

\footnotetext{
${ }^{8} \mathrm{cf}$. Definição 3.1 .
} 


$$
\mathcal{T}(\neg B)=\neg \mathcal{T}(B) .
$$

Note que neste caso as duas formas acima são equivalentes, e estão definidas separadamente apenas para manter a característica sintática das lógicas anotadas.

3. Se $A$ é da forma $(B \wedge C),(B \vee C)$ ou $(B \rightarrow C)$, então:

(a) $\mathcal{T}(B \wedge C)=\mathcal{T}(B) \wedge \mathcal{T}(C)$.

(b) $\mathcal{T}(B \vee C)=\mathcal{T}(B) \vee \mathcal{T}(C)$.

(c) $\mathcal{T}(B \rightarrow C)=\mathcal{T}(B) \rightarrow \mathcal{T}(C)$.

Estamos utilizando os mesmos símbolos para denotar os conectivos das duas linguagens. Como já discutimos anteriormente, exceto para a construção de hiper-literais, estes conєctivos funcionam da mesma forma tanto no sistema clássico quanto no anotado.

Para provar que função $\mathcal{T}$ de tradução é injetora e sobrejetora, basta aplicar uma simples indução sobre as fórmulas de $L_{0}$.

Para provar que os sistemas são equivalentes, precisamos ainda mostrar que, dada uma interpretação $I: \mathcal{P}_{0}(=\mathcal{F}) \rightarrow\{f, v\}$, e dada uma fórmula $A$ de $L_{0}$, então

$$
v_{I}(A)=v_{I}^{c}(\mathcal{T}(A))
$$

onde $v_{I}^{c}$ denota a valoração associada a $I$ em relação ao sistema proposicional clássico ${ }^{9}$.

Vamos provar por indução no comprimento ${ }^{10}$ de uma fórmula $A$ de $L_{0}$.

Base: Se $A$ é uma fórmula atômica da forma $p: \mu$, temos dois casos a considerar:

1. $\mu=v$

Assim, $v_{I}(p: v)=v$ sse $I(p)=v$.

$\mathrm{E} v_{I}^{c}(\mathcal{T}(p: v))=v_{I}^{c}(p)=v$ sse $I(p)=v$.

Portanto, $v_{I}(A)=v_{I}^{c}(\mathcal{T}(A))$.

2. $\mu=f$

Assim, $v_{I}(p: f)=v$ sse $I(p)=f$.

E $v_{I}^{c}(\mathcal{T}(p: f))=v_{I}^{c}(\neg p)=v$ sse $v_{I}^{c}(p)=f$ sse $I(p)=f$.

Portanto, $v_{I}(A)=v_{I}^{c}(\mathcal{T}(A))$.

Passo: Seja $A$ da forma $(\neg B),(B \wedge C),(B \vee C)$ ou $(B \rightarrow C)$.

\footnotetext{
${ }^{9}$ Sistema bivalorado com operação de complemento tal que $\bar{f}=v$ e $\bar{v}=f$.

${ }^{10}$ Conceito usual de comprimento de uma fórmula.
} 
1. Se $A$ é da forma $(\neg B)$ (onde $B$ pode ser tanto um hiper-literal quanto uma fórmula complexa), então $v_{I}(\neg B)=v$ sse $v_{I}(B)=f$.

E $v_{I}^{c}(\mathcal{T}(\neg B))=v_{I}^{c}(\neg \mathcal{T}(B))=v$ sse $v_{I}^{c}(\mathcal{T}(B))=f$.

Pela hipótese de indução, $v_{I}(B)=v_{I}^{c}(\mathcal{T}(B))$, e portanto temos que

$$
v_{I}(A)=v_{I}^{c}(\mathcal{T}(A)) \text {. }
$$

2. Se $A$ é da forma $(B \wedge C)$, então $v_{I}(B \wedge C)=v$ sse $v_{I}(B)=v$ e $v_{I}(C)=v$. $\mathrm{E} v_{I}^{c}(\mathcal{T}(B \wedge C))=v$ sse $v_{I}^{c}(\mathcal{T}(B))=v$ e $v_{I}^{c}(\mathcal{T}(C))=v$.

Pela hipótese de indução, $v_{I}(B)=v_{I}^{c}(\mathcal{T}(B))$ e $v_{I}(C)=v_{I}^{c}(\mathcal{T}(C))$, e portanto temos que

$$
v_{I}(A)=v_{I}^{c}(\mathcal{T}(A)) .
$$

3. Se $A$ é da forma $(B \vee C)$, então $v_{I}(B \vee C)=v$ sse $v_{I}(B)=v$ ou $v_{I}(C)=v$.

$\mathrm{E} v_{I}^{c}(\mathcal{T}(B \vee C))=v$ sse $v_{I}^{c}(\mathcal{T}(B))=v$ ou $v_{I}^{c}(\mathcal{T}(C))=v$

Pela hipótese de indução, $v_{I}(B)=v_{I}^{c}(\mathcal{T}(B))$ e $v_{I}(C)=v_{I}^{c}(\mathcal{T}(C))$, e portanto temos que

$$
v_{I}(A)=v_{I}^{c}(\mathcal{T}(A)) .
$$

4. Se $A$ é da forma $(B \rightarrow C)$, então $v_{I}(B \rightarrow C)=v$ sse $v_{I}(B)=f$ ou $v_{I}(C)=v$.

$\mathrm{E} v_{I}^{c}(\mathcal{T}(B \rightarrow C))=v$ sse $v_{I}^{c}(\mathcal{T}(B))=v$ ou $v_{I}^{c}(\mathcal{T}(C))=v$.

Pela hipótese de indução, $v_{I}(B)=v_{I}^{c}(\mathcal{T}(B))$ e $v_{I}(C)=v_{I}^{c}(\mathcal{T}(C))$, e portanto temos que

$$
v_{I}(A)=v_{I}^{c}(\mathcal{T}(A))
$$

Assim, provamos que o sistema apresentado nesta seção é equivalente ao sistema proposicional clássico, e portanto clássico em relação ao operador de negação $\neg$.

Exemplo 3.3 No exemplo 3.2, a linguagem adotada foi a proposicional clássica $L$. Considerando a linguagem proposicional anotada "classicalizada" $L_{0}$ ao invés de $L$, as sentenças representando o estado do equipamento analisado pelo técnico poderiam ser expressas da seguinte forma:

1. monitor_ $_{-}: v$

2. $\operatorname{lig} a: v$

3. mouse_q $_{-} f$

4. teclado_ $q: f$ 
5. drive_q $: f$

6. $c p u_{-} q: f$

7. monitor_q $: v \wedge$ liga $: v \rightarrow$ placa_q $: v$

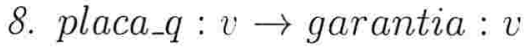

9. mouse_$: v \wedge$ teclado_q $: f \rightarrow$ garantia $: v$

As conclusões tiradas pelo técnico seriam as mesmas: a placa está com problemas e ele irá tomar as providências necessárias sem cobrar o serviço.

\subsection{Uma Metalinguagem Anotada}

Nosso ponto de partida para tratar argumentos a respeito de fatos são os próprios fatos; ou seja, a linguagem clássica $L_{0}$ apresentada na seção anterior. Estaremos definindo aqui a metalinguagem $L_{1}$, que referencia fatos da linguagem objeto $L_{0}$ e que está exatamente um nível "acima" de $L_{0}$ se considerarmos a hierarquia mencionada nas seções anteriores.

Quando falamos sobre fatos estamos em um outro nível de linguagem e raciocínio, onde não temos (necessariamente) acesso aos fatos em si. Para raciocinar neste nível, nos parece mais razoável investigar os possíveis valores-verdade dos fatos envolvidos e determinar as conclusões a partir destas investigações. Para representar tais investigações, definimos um reticulado completo $\tau_{1}=<\left|\tau_{1}\right|, \leq>$ de valores-verdade. Seus elementos representam ainda os valores-verdade na interpretação dos fatos da linguagem objeto. Assim, $\tau_{1}$ é usado tanto na sintaxe quanto na semântica da linguagem que estamos definindo.

Como exposto em [KL92, LL95], as anotações constituem um conjunto de conhecimentos que pode representar crenças do agente raciocinador sobre um fato, e daí temos um átomo anotado. Outras interpretações para as anotações também podem ser consideradas. Os elementos de $\tau_{1}$ podem ainda representar graus de incerteza ou de confiança associados aos fatos por este agente, que, como já mencionamos anteriormente, não tem acesso aos fatos em si.

Por exemplo, uma interpretação $I$ é um modelo de um hiper-literal $A: \mu$ se e somente se $I(A) \geq \mu$. Intuitivamente, se um agente acredita em $A$ com grau de crença $\mu$, então ele também acredita em $A$ com qualquer grau de crença menor.

Em $\tau_{1}$, definimos ainda um operador $\sim:|\tau| \rightarrow|\tau|$ que constituirá o "significado" do símbolo de negação da linguagem.

Assim, se o reticulado $\tau_{1}$ representa valores de confiança associados pelo agente raciocinador, o operador $\sim$ pode indicar a investigação de não confiar em [CdS96].

Apesar de investigarmos os fatos a partir de um conjunto de valores (graus de crença, incerteza ou confiança). as sentenças são sempre interpretadas como verdadeiras ou 
falsas. Aliás, a investigação sobre os possíveis valores associados a um fato vem da necessidade de interpretá-lo como verdadeiro ou falso, uma vez que nem sempre temos acesso ao nível dos fatos (linguagem objeto). No nível da metalinguagem, o raciocínio humano é essencialmente clássico [LMR].

Definimos em $\mathcal{F}_{0}$ (conjunto de fórmulas de $L_{0}$ ) a seguinte relação de equivalência:

$$
(A \equiv B) \stackrel{\text { def }}{\Leftrightarrow} \vdash A \rightarrow B \text { e } \vdash B \rightarrow A .
$$

Se $A \in \mathcal{F}_{0}$, então $|A|=\{B \mid A \equiv B\}^{11}$.

$\mathrm{O}$ conjunto das classes de equivalência em relação a $\equiv$ é o próprio conjunto das representações distintas dos fatos (fórmulas) da linguagem objeto. Desta forma, conseguimos uma certa "normalização" das fórmulas, o que simplifica consideravelmente o problema. Além disso, são estas representações dos fatos que serão referenciadas pela metalinguagem. Portanto, chamamos este conjunto de $\mathcal{P}_{1}$, que constituirá o conjunto dos símbolos proposicionais de $L_{1}$. Assim:

$$
\mathcal{P}_{1}=\left\{|A| \mid A \in \mathcal{F}_{0}\right\},
$$

onde $|A|$ também denota o representante da classe de equivalência $|A|$ de uma fórmula A.

Ao observarmos as regras de formação das fórmulas de $L_{0}$ (definição 3.2 ), vemos que estas são formadas pelos símbolos proposicionais, constantes anotacionais e conectivos da linguagem. O reticulado completo de valores verdade associado a $L_{0}$ é o próprio $|f, v|$, e portanto o número de constantes anotacionais é finito. O número de conectivos também é claramente finito. Caso o conjunto $\mathcal{P}_{0}$ não seja finito, o número de classes de equivalência (ou o número de símbolos proposicionais de $L_{1}$ ) também não será finito, e nem mesmo enumerável.

Como nosso interesse é computacional, e também para simplificar esta apresentação, podemos supor que o conjunto $\mathcal{P}_{0}$ de variáveis proposicionais de $L_{0}$ é finito. Desta forma, $\mathcal{P}_{1}$ também será finito ${ }^{12}$.

Da mesma forma, se considerarmos $\tau_{1}$ como sendo um reticulado completo infinito, teremos que definir algumas regras infinitárias para, por exemplo, calcular o supremo de um conjunto de elementos de $\tau^{13}$. Principalmente por motivos computacionais, podemos assumir que $\tau_{1}$ é finito.

Podemos então definir a metalinguagem $L_{1}$ para representação dos argumentos, que é constituída dos seguintes símbolos primitivos:

1. Um conjunto (finito) $\mathcal{P}_{1}$ de símbolos proposicionais;

\footnotetext{
${ }^{11}$ Construção análoga à da Álgebra de Lindenbaum do Cálculo Proposicional Clássico [BS71].

${ }^{12}$ Este tipo de simplificação também foi utilizado em [CdS96] para analisar as lógicas de incerteza.

${ }^{13}$ Ver axioma 16 para o Cálculo Proposicional Anotado (figura 3.1).
} 
2. Um conjunto (finito) $\left|\tau_{1}\right|$ de constantes anotacionais;

3. Os conectivos lógicos $\neg, \wedge, \vee, \rightarrow$;

(Nota. Os símbolos usados aqui para representar os conectivos da linguagem sâo os mesmos utilizados para especificar a linguagem objeto. De certa forma, esta é uma característica interessante, principalmente em casos como o da lógica clássica, onde os vários níveis de linguagem se confundem, e os conectivos desempenham os mesmos papéis nos diversos níveis. Em geral, a utilização dos símbolos estará clara pelo contexto; se necessário, conectivos em níveis diferentes de linguagem serão diferenciados.)

4. Símbolos auxiliares: parênteses.

Definição 3.5 (Fórmulas) As fórmulas de $L_{1}$ são definidas indutivamente da seguinte forma:

1. Se $p \in \mathcal{P}_{1}$ e $\mu \in\left|\tau_{1}\right|$, então $p: \mu$ é uma fórmula atômica.

2. Se A é uma fórmula, então $(\neg A)$ é uma fórmula.

3. Se $A, B$ são fórmulas, então $(A \wedge B),(A \vee B) e(A \rightarrow B)$ são fórmulas.

Note que esta linguagem é a própria linguagem proposicional anotada. No caso, estamos apenas especificando as variáveis proposicionais como os possíveis fatos a serem tratados. Intuitivamente, quando estamos raciocinando sobre fatos (em particular, proposições), investigamos o seu valor verdade através de uma anotação.

Como no capítulo anterior, chamaremos uma fórmula atômica ou a sua negação de hiper-literal. Da mesma forma, o símbolo de negação $\neg$ é, neste caso, intercambiável com o operador aplicado à anotação. Fórmulas que não são hiper-literais, ou seja, fórmulas com pelo menos uma ocorrência de algum dos conectivos $\wedge, \vee, \rightarrow$, são chamadas complexas.

Definição 3.6 (Interpretação e Valoração) Uma interpretação $I_{1}$ para a linguagem $L_{1}$ é uma função $I_{1}: \mathcal{P}_{1} \rightarrow\left|\tau_{1}\right|$. Seja $\mathcal{F}_{1}$ o conjunto de todas as fórmulas de $L_{1}$. A cada interpretação $I_{1}$ associamos uma valoração $v_{I}: \mathcal{F}_{1} \rightarrow\{f, v\}$, definida indutivamente da seguinte forma:

1. Se p é um símbolo proposicional, então

(a) $v_{I}(p: \mu)=v$ se e somente se $I(p) \geq \mu$.

(b) $v_{I}\left(\neg^{k} p: \mu\right)=v_{I}\left(\neg^{k-1} p: \sim \mu\right), k \geq 1$.

Note que $v_{I}\left(\neg^{0} p: \mu\right)=v_{I}(p: \mu)$.

2. Se $A$ e $B$ são fórmulas, então 
(a) $v_{I}(A \wedge B)=v$ se e somente se $v_{I}(A)=v$ e $v_{I}(B)=v$.

(b) $v_{I}(A \vee B)=v$ se e somente se $v_{I}(A)=v$ ou $v_{I}(B)=v$.

(c) $v_{I}(A \rightarrow B)=v$ se e somente se $v_{I}(A)=f$ ou $v_{I}(B)=v$.

3. Se $F$ é uma fórmula complexa, então $v_{I}(\neg F)=v$ se e somente se $v_{I}(F)=f$.

Na figura 3.1, apresentamos o sistema de axiomas e regra de inferência para o cálculo proposicional anotado. O conceito de dedução é definido da forma usual. Uma prova da correção e completude desta axiomatização em relação à semântica proposta pode ser encontrada em [Abe92], por exemplo.

Exemplo 3.4 Retomando o exemplo 3.1, suponha agora que um usuário de uma outra empresa, ao ver o seu micro com problemas, entre em contato com um técnico através de uma "hot-line" de manutenção. Temos então o seguinte diálogo entre usuário e técnico:

- Estou com um probleminha aqui com o meu micro: o monitor não está funcionando bem.

- Monitor quebrado... Mas a luz de liga/desliga do monitor está funcionandó?

- Não, ela não está acendendo.

- Mais algum problema?

- Não, tá tudo OK. O drive eu não sei, pois eu não testei.

Além dessas informações dadas pelo usuário via telefone, o técnico conta ainda com o seu conhecimento sobre o sistema: ele não tem acesso àquele micro em especial, mas sabe que en um equipamento desse tipo, se a luz liga/desliga do monitor não funciona, então o monitor não está quebrado: é um problema de instalação elétrica. E com relação à postura da empresa, se o cliente fornece informações erradas (ou seja, o técnico descobre que a informação fornecida não é válida), a manutenção não se encaixa na garantia.

Fatos sobre o micro quebrado são especificados na linguagem objeto $L_{0}$, e portanto os fatos em questão são representados por fórmulas desta linguagem (Exemplos $3.2 \mathrm{e}$ 3.3). Por exemplo, a fórmula que representa que o monitor está quebrado é denotada por monitor $q$ em $L$ e por monitor $q$ : $v$ em $L_{0}$. Como as linguagens $L$ e $L_{0}$ são equivalentes, e a título de simplificar a notação, vamos denotar aqui a fórmula monitor_q $: v$ apenas por monitor_q.

Neste caso, porém, o técnico não tem acesso aos fatos em si. Para efetuar os procedimentos necessários, ele conta com as informações fornecidas pelo cliente (argumentos), além do seu próprio conhecimento sobre o equipamento.

Para representar as informações obtidas e as investigações a respeito destas, podemos considerar como o conjunto de valores-verdade o reticulado FOUR (figura 1.2), onde $\perp, f, v, \top$ denotam, respectivamente, informação desconhecida, falsa, verdadeira $e$ contraditória. Assim, na metalinguagem $L_{1}$, temos as seguintes sentenças: 
1. monitor $\_q: v$

2. liga: $f$

3. drive_$_{-}: \perp$

4. liga: $f \rightarrow$ monitor_$_{-}: f$

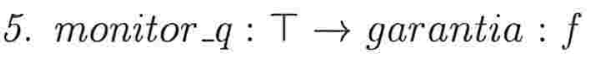

6. drive_q $: \top \rightarrow$ garantia $: f$

Pelo seu conhecimento, o técnico pode deduzir que, como a luz do monitor não está funcionando, então o monitor não está quebrado. Como o cliente pode ter dado uma informação contraditória em relação ao monitor ${ }^{14}$, essa manutenção será cobrada, pois não se encaixa mais na garantia. Isto faz com que os usuários verifiquem melhor o problema antes de ligar para o técnico: neste caso, pode ser um problema da parte elétrica, ou mesmo um fio fora da tomada.

\subsubsection{E Se a Metalinguagem Fosse Clássica?}

O que aconteceria se a metalinguagem fosse uma versão consistente da linguagem proposicional anotada? Ou seja, se aplicássemos à linguagem $L_{1}$ os mesmos processos executados na definição de $L_{0}$ ? Nesta seção, investigamos as consequências da aplicação dos seguintes passos sobre a metalinguagem anotada $L_{1}$ :

1. desmembramento do símbolo de negação em dois;

2. especificação do reticulado $\tau_{1}$ como sendo o reticulado booleano $|f, v|$ e do operador $\sim$ como o próprio operador de complemento; e

3. eliminação da paraconsistência da linguagem.

Nos parece natural esperar que, sendo a linguagem objeto e a metalinguagem clássicas, voltamos à situação "clássica", onde níveis distintos de linguagem se confundem. Afinal, já provamos na seção 3.2.2 (proposição 3.1) que o processo acima citado aplicado a uma linguagem proposicional anotada (e paraconsistente) transforma-a em uma linguagem clássica.

Exemplo 3.5 Suponha que o técnico responsável pela "hot-line" do exemplo 3.4 seja absolutamente crédulo. Ou seja, ele acredita sempre nas informações fornecidas pelo usuário, e é incapaz de detectar uma mentira ou uma informação contraditória. De acordo com as informações do exemplo anterior, teríamos as seguintes sentenças:

\footnotetext{
${ }^{14}$ De fato, de 1 . temos que $I($ monitor $q$. $) \geq v$. De 2. e 4 . temos que $I$ (monitor $\left.q\right) \geq f$. Isto representa uma inconsistência (no sentido bi-valorado). e portanto associamos o valor-verdade $T$ à sentença monitor_q.
} 


\section{1. monitor_$_{-} q: v$ \\ 2. liga: $f$ \\ 3. liga: $f \rightarrow$ monitor_q $: f$}

Sendo um técnico crédulo acima de tudo, para ele as conclusões são sempre verdadeiras ou falsas: se a resposta do cliente é sim, a proposição é verdadeira; se a resposta é não, falsa. No exemplo acima, ao ter que lidar com uma inconsistência em relaçấo ao estado do vídeo, o técnico passa a não distinguir entre o que já era falso e verdadeiro, trivializando o seu raciocínio (axioma 16' na figura 3.2). A partir daí, o técnico pode chegar à conclusấo de que seria necessário mandar um novo computador para a empresa, quando o problema era apenas um fio fora da tomada.

Isso é o que acontece quando o raciocínio do técnico é representado por uma lógica anotada "classicalizada" e é preciso lidar com inconsistências.

Assim, se $L_{1}^{\prime}$ é a linguagem obtida de $L_{1}$ pela aplicação dos passos definidos acima ("classicalização"), provamos o seguinte resultado:

Proposição 3.2 As linguagens $L_{0}{ }^{15}$ e $L_{1}^{\prime}$ são logicamente equivalentes.

Demonstração. A demonstração de que $L_{0}$ e $L_{1}^{\prime}$ são logicamente equivalentes pode ser organizada nos seguintes passos, uma vez que os dois sistemas lógicos em questão são corretos e $\operatorname{completos}^{16}$ :

1. Existe uma função que traduz fórmulas de $L_{1}^{\prime}$ para fórmulas de $L_{0}$.

2. Uma fórmula de $L_{1}^{\prime}$ é válida se e somente se a sua tradução para $L_{0}$ for válida.

3. Existe uma função que traduz fórmulas de $L_{0}$ para fórmulas de $L_{1}^{\prime}$.

4. Uma fórmula de $L_{0}$ é válida se e somente se a sua tradução para $L_{1}^{\prime}$ for válida.

Em primeiro lugar, vamos especificar uma função de tradução $\mathcal{T}^{\prime}: \mathcal{F}_{1}^{\prime} \rightarrow$ $\mathcal{F}_{0}$ das fórmula de $L_{1}^{\prime}$ para as fórmulas de $L_{0}$. Para uma fórmula $A$ de $L_{1}^{\prime}$, $\mathcal{T}^{\prime}$ é definida indutivamente da seguinte forma:

1. Se $A$ é uma fórmula atômica da forma $p: \mu$, onde $p \in \mathcal{P}_{1}^{\prime}$, então

$$
\mathcal{T}^{\prime}(p: \mu)= \begin{cases}p & \text { se } \mu=v \\ \neg p & \text { se } \mu=f .\end{cases}
$$

\footnotetext{
${ }^{15} L_{0}$ é a linguagem objeto anotada e "classicalizada" apresentada na Seçāo 3.2.2.

${ }^{16}$ cf. Seção 3.2.2.
} 
(Nota. Por construção, $\mathcal{P}_{1}^{\prime}=\mathcal{P}_{1} \subseteq \mathcal{F}_{0}$, e $p$ (e portanto $\neg p$ ) é uma fórmula de $L_{0}$.)

2. Se $A$ é da forma $(\neg B),(B \wedge C),(B \vee C)$ ou $(B \rightarrow C)$, então:

(a) $\mathcal{T}^{\prime}(\neg B)=\neg \mathcal{T}^{\prime}(B)$

(b) $\mathcal{T}^{\prime}(B \wedge C)=\mathcal{T}^{\prime}(B) \wedge \mathcal{T}^{\prime}(C)$.

(c) $\mathcal{T}^{\prime}(B \vee C)=\mathcal{T}^{\prime}(B) \vee \mathcal{T}^{\prime}(C)$.

(d) $\mathcal{T}^{\prime}(B \rightarrow C)=\mathcal{T}^{\prime}(B) \rightarrow \mathcal{T}^{\prime}(C)$.

Por abuso de notação, usamos os mesmos símbolos lógicos para denotar os conectivos das duas linguagens em questão. Afinal, estamos tratando de duas linguagens anotadas, construídas da mesma forma, cuja única diferença é o conjunto de símbolos proposicionais.

Para provarmos o segundo passo, vamos antes introduzir a noção de uma interpretação para $L_{1}^{\prime}$ baseada em uma interpretação para $L_{0}$. Seja $I_{0}: \mathcal{P}_{0} \rightarrow\{f, v\}$ uma interpretação para $L_{0}$, e seja $v_{I_{0}}: \mathcal{F}_{0} \rightarrow\{f, v\}$ a valoração de $L_{0}$ associada a $I_{0}$. A interpretação $I_{1}^{\prime}: \mathcal{P}_{1}^{\prime}\left(\subseteq \mathcal{F}_{0}\right) \rightarrow\{f, v\}$ baseada em $I_{0}$ é a própria função valoração $v_{I_{0}}$. Ou seja, se $p$ é um símbolo proposicicnal de $\mathcal{P}_{1}^{\prime}$, então $I_{1}^{\prime}(p)=v_{I_{0}}(p)$.

Vamos provar que, dada uma interpretação $I_{0}$ para $L_{0}$ e uma fórmula $A$ de $L_{1}^{\prime}, A$ é válida se e somente se $\mathcal{T}^{\prime}(A)$ for válida. Assim, vamos mostrar por indução no comprimento de $A$ que

$$
v_{I_{1}^{\prime}}(A)=v_{I_{0}}\left(\mathcal{T}^{\prime}(A)\right) .
$$

Base: Se $A$ é uma fórmula atômica da forma $p: \mu$, temos dois casos a considerar:

1. $\mu=v$

Assim, $v_{I_{1}^{\prime}}(p: v)=v$ sse $I_{1}^{\prime}(p)=v_{I_{0}}(p)=v$.

$\mathrm{E} v_{I_{0}}\left(\mathcal{T}^{\prime}(p: v)\right)=v \operatorname{sssev}_{I_{0}}(p)=v$.

Portanto, $v_{I_{1}^{\prime}}(A)=v_{I_{0}}(\mathcal{T}(A))$.

2. $\mu=f$

Assim, $v_{I_{1}^{\prime}}(p: f)=v$ sse $I_{1}^{\prime}(p)=v_{I_{0}}(p)=f$.

$\mathrm{E} v_{I_{0}}\left(\mathcal{T}^{\prime}(p: f)\right)=v_{I_{0}}(\neg p)=v$ sse $v_{I_{0}}(p)=f$.

Portanto, $v_{I_{1}^{\prime}}(A)=v_{I_{0}}(\mathcal{T}(A))$.

Passo: Seja $A$ da forma $(\neg B),(B \wedge C),(B \vee C)$ ou $(B \rightarrow C)$.

1. Se $A$ é da forma $(\neg B)$, então $v_{I_{1}^{\prime}}(\neg B)=v$ sse $v_{I_{1}^{\prime}}(B)=f$.

$\mathrm{E} v_{I_{0}}\left(\mathcal{T}^{\prime}(\neg B)\right)=v_{I_{0}}\left(\neg \mathcal{T}^{\prime}(B)\right)=v$ sse $v_{I_{0}}\left(\mathcal{T}^{\prime}(B)\right)=f$.

Pela hipótese de indução, $v_{I_{1}^{\prime}}(B)=v_{I_{0}}\left(\mathcal{T}^{\prime}(B)\right)$, e portanto temos que

$$
v_{I_{1}^{\prime}}(A)=v_{I_{0}}\left(\mathcal{T}^{\prime}(A)\right) \text {. }
$$


2. Se $A$ é da forma $(B \wedge C)$, então $v_{I_{1}^{\prime}}(B \wedge C)=v$ sse $v_{I_{1}^{\prime}}(B)=v \mathrm{e}$ $v_{I_{1}^{\prime}}(C)=v$.

$\mathrm{E} v_{I_{0}}\left(\mathcal{T}^{\prime}(B \wedge C)\right)=v$ sse $v_{I_{0}}\left(\mathcal{T}^{\prime}(B)\right)=v$ e $v_{I_{0}}\left(\mathcal{T}^{\prime}(C)\right)=v$

Pela hipótese de indução, $v_{I_{1}^{\prime}}(B)=v_{I_{0}}\left(\mathcal{T}^{\prime}(B)\right)$ e $v_{I_{1}^{\prime}}(C)=v_{I_{0}}\left(\mathcal{T}^{\prime}(C)\right)$, e portanto temos que

$$
\eta_{I_{1}^{\prime}}(A)=v_{I_{0}}\left(\mathcal{T}^{\prime}(A)\right) .
$$

3. Se $A$ é da forma $(B \vee C)$, então $v_{I_{1}^{\prime}}(B \vee C)=v$ sse $v_{I_{1}^{\prime}}(B)=v$ ou $v_{I_{1}^{\prime}}(C)=v$.

$\mathrm{E} v_{I_{0}}\left(\mathcal{T}^{\prime}(B \vee C)\right)=v$ sse $v_{I_{0}}\left(\mathcal{T}^{\prime}(B)\right)=v$ ou $v_{I_{0}}\left(\mathcal{T}^{\prime}(C)\right)=v$

Pela hipótese de indução, $v_{I_{1}^{\prime}}(B)=v_{I_{0}}\left(\mathcal{T}^{\prime}(B)\right)$ e $v_{I_{1}^{\prime}}(C)=v_{I_{0}}\left(\mathcal{T}^{\prime}(C)\right)$, e portanto temos que

$$
v_{I_{1}^{\prime}}(A)=v_{I_{0}}\left(\mathcal{T}^{\prime}(A)\right) .
$$

4. Se $A$ é da forma $(B \rightarrow C)$, então $v_{I_{1}^{\prime}}(B \rightarrow C)=v$ sse $v_{I_{1}^{\prime}}(B)=f$ ou $v_{I_{1}^{\prime}}(C)=v$.

$\mathrm{E} v_{I_{0}}\left(\mathcal{T}^{\prime}(B \rightarrow C)\right)=v$ sse $v_{I_{0}}\left(\mathcal{T}^{\prime}(B)\right)=f$ ou $v_{I_{0}}\left(\mathcal{T}^{\prime}(C)\right)=v$.

Pela hipótese de indução, $v_{I_{1}^{\prime}}(B)=v_{I_{0}}\left(\mathcal{T}^{\prime}(B)\right)$ e $v_{I_{1}^{\prime}}(C)=v_{I_{0}}\left(\mathcal{T}^{\prime}(C)\right)$, e portanto temos que

$$
v_{I_{1}^{\prime}}(A)=v_{I_{0}}\left(\mathcal{T}^{\prime}(A)\right) .
$$

Assim, provamos que existe uma função de tradução das fórmulas de $L_{1}^{\prime}$ para fórmulas de $L_{0}$, e que uma fórmula em $L_{1}^{\prime}$ é válida se e somente se sua tradução for válida.

A demonstração dos passos 3 e 4 é análoga. Para o passo 3, por exemplo, basta considerar a função que, dada uma fórmula $F$ de $L_{0}$, associa a fórmula $F^{\prime}: v$ de $L_{1}^{\prime}$, onde $F^{\prime}$ é o representante da classe de equivalência de $F$ definida na construção de $L_{1}$. Prova-se o passo 4 também por indução, agora no comprimento das fórmulas de $L_{0}$.

Note que podemos aplicar a função de tradução $\mathcal{T}$ à $\mathcal{T}^{\prime}$, obtendo a função composta $\mathcal{T}^{\prime} \circ \mathcal{T}: \mathcal{F}_{1}^{\prime} \rightarrow \mathcal{F}$, que traduz fórmulas da metalinguagem proposicional anotada "classicalizada" para fórmulas da linguagem proposicional clássica.

Um ponto desta demonstração que gostaríamos de retomar é o do uso dos mesmos símbolos para representar os conectivos das duas linguagens em questão. Isto foi feito por uma questão de clareza na notação, e também porque não existe ambiguidade neste caso. Porém, poderíamos obter como corolário da proposição acima o resultado de que os conectivos são intercambiáveis entre $L_{0}$ e $L_{1}^{\prime}$.

Para fins de clareza, vamos considerar o seguinte exemplo (onde os conectivos são diferenciados), ilustrando a proposição 3.2 . 
Exemplo 3.6 Considere neste exemplo a seguinte notação: os simbolos assinalados com ${ }^{0}$ representam os conectivos da linguagem $L_{0}$. Analogamente, aqueles assinalados com ${ }^{1}$ representam os conectivos da linguagem $L_{1}^{\prime}$.

Considere as seguintes fórmulas de $L_{0}$, apresentadas no exemplo 3.3, agora representadas através dos conectivos assinalados.

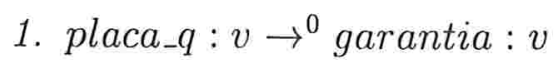

2. mouse_$_{-}: v \wedge^{0}$ teclado_$q: f \rightarrow^{0}$ garantia $: v$

Considere agora a seguinte fórmula em $L_{1}^{\prime}$ :

$\left(\right.$ placa_q $: v \rightarrow^{0}$ garantia $\left.: v\right): v \wedge^{1}\left(\right.$ mouse $_{-} q: v \wedge^{0}$ teclado_$q: f \rightarrow^{0}$ garantia $\left.: v\right): v$

Podemos aplicar a função de tradução definida na proposição 3.2 à fórmula acima, obtendo a seguinte fórmula de $L_{0}$ :

$\left(\right.$ placa $_{-} q: v \rightarrow^{0}$ garantia $\left.: v\right) \wedge^{0}\left(\right.$ mouse_$_{-} q: v \wedge^{0}$ teclado_ $_{-}: f \rightarrow^{0}$ garantia $\left.: v\right)$

o que ilustra a equivalência entre os conectivos destas linguagens.

\subsection{Meta-metalinguagens, Meta-meta-metalinguagens,}

Se pensarmos em termos da hierarquia de linguagens mencionada nas seções anteriores, podemos seguir adiante definindo uma meta-metalinguagem para raciocinar com argumentos a respeito de fatos da metalinguagem, uma meta-meta-metalinguagem para raciocinar com argumentos a respeito de fatos da meta-metalinguagem, e assim sucessivamente.

Assim, é possível formular uma sequência $L_{0}, L_{1}, \ldots, L_{n}, \ldots$ de linguagens tal que cada linguagem $L_{i}$ é usada para raciocinar sobre fatos (ou raciocinar com argumentos a respeito de fatos) da linguagem $L_{i-1}$. De fato, tal sequência pode ser caracterizada como a hierarquia de linguagens descrita na seção 3.1 .

Teríamos, por exemplo, a seguinte sequência de sentenças, onde $p$ é o único fato externo às linguagens:

$$
\begin{aligned}
& L_{0}: p \\
& L_{1}: \text { : } p \text { " é verdadeira } \\
& L_{2}: \text { " } p \text { " é verdadeira" é verdadeira } \\
& L_{3}: \text { " " } p \text { " é verdadeira" é verdadeira" é verdadeira }
\end{aligned}
$$


Tais linguagens não precisam ser necessariamente clássicas, mas podem vir a ser através do processo definido na seção 3.2.2. Se todas as linguagens mencionadas acima forem clássicas, os níveis de linguagem objeto, metalinguagem, meta-metalinguagem, etc. se colapsam em um único. Da proposição 3.2, derivamos o corolário de que quaisquer duas linguagens clássicas (ou classicalizadas) consecutivas na sequência são logicamente equivalentes. Portanto, basta aplicarmos esta proposição às linguagens da sequência, obtendo assim os seguintes resultados:

$L_{0}$ é logicamente equivalente a $L_{1}$

$L_{1}$ é logicamente equivalente a $L_{2}$

$L_{2}$ : é logicamente equivalente a $L_{3}$

$\cdots$

Assimı, os níveis de linguagem são todos intercambiáveis. Teríamos, por exemplo, uma série de equivalências da forma:

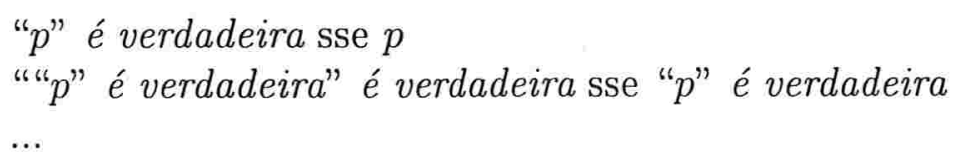

Este tipo de formulação se torna interessante quando temos lógicas não-clássicas envolvidas, como por exemplo uma lógica anotada. Caso contrário, a diferenciação se torna inútil, uma vez que todas as linguagens se colapsam em uma só.

Nas seções anteriores, estudamos o caso onde temos apenas dois níveis de linguagem na hierarquia: $L_{0}$ e $L_{1}$. Resta saber até que ponto da sequência nos seria útil especificar os vários níveis de linguagem.

Em primeiro lugar, vale a pena considerar as questões de complexidade. A linguagem $L_{i}$ na sequência é obtida a partir das fórmulas de $L_{i-1}$, que por sua vez é obtida a partir das fórmulas de $L_{i-2}$, e assim sucessivamente. Mesmo considerando um conjunto normalizado de fórmulas a cada nível e partindo de um conjunto finito de proposições em $L_{0}$, o número de fórmulas cresce exponencialmente a cada nível. Assim, o raciocínio em níveis de linguagem mais altos na hierarquia é computacionalmente muito mais complexo.

Em segundo lugar, consideremos a seguinte situação:

Exemplo 3.7 Retomando os exemplos anteriores, um usuário, ao detectar um problema em seu micro, liga para a secretária e pede a ela para contactar um técnico através de uma "hot-line" de manutenção. No telefone, ele a informa que o monitor está quebrado, mas o teclado não apresenta problemas.

No diálogo entre a secretária e o técnico, ela repassa estas informações. Suponha, porém, que o técnico faça a seguinte pergunta:

- A luz liga/desliga do monitor está funcionando?

Provavelmente, a secretária não saberá responder.

Formalizando o raciocínio do técnico, teríamos então as seguintes sentenças: 
1. (monitor_q $: v): v$

2. (teclado_q :v) : $f$

3. $($ liga $: v): \perp$

Neste caso, o raciocínio do técnico não é guiado por fatos, nem por argumentos a respeito dos fatos, mas sim por argumentos a respeito dos argumentos a respeito dos fatos. Ou seja, pelo quê a secretária disse que o cliente disse. O formalismo das lógicas anotadas permite apenas que o técnico investigue os valores-verdade associados aos argumentos, e não aos fatos. Assim, ele precisa considerar as várias possibilidades de relacionamento entre argumentos e argumentos a respeito de argumentos, raciocinando no nível da meta-metalinguagem.

A questão é o quanto uma situação deste tipo pode ser interessante no nível prático para a construção de sistemas em IA. Além da desvantagem de complexidade computacional, que cresce exponencialmente conforme subimos um nível na sequência, casos como este nos parecem pouco freqüentes, e até mesmo sem sentido. Portanto, não é interessante tratar situações assim, uma vez que o objetivo maior deste trabalho é apresentar uma ferramenta para o desenvolvimento de aplicações, principalmente na área de Inteligência Artificial.

De qualquer forma, no nível da metalinguagem e do raciocínio com argumentos, as lógicas anotadas parecem ser um formalismo adequado. Acreditamos que resultados bastante interessantes possam surgir de um estudo mais profundo dessa abordagem das lógicas anotadas em IA. 


\section{Capítulo 4}

\section{Programação em Lógica Anotada}

Apresentamos aqui a teoria original da programação em lógica anotada, introduzida em [BS88]. Esta foi a primeira apresentação nesta área onde o conjunto de valores-verdade, e conseqüentemente de anotações, não era especificado na definição. Inicialmente, expomos um breve resumo da teoria da programação em lógica clássica, que será útil no decorrer da leitura deste capítulo.

Dentro desta área, apresentamos vários desses resultados já desenvolvidos. Entre eles, um método de prova correto e completo para a programação em lógica anotada, tendo em vista a implementação de um sistema de raciocínio dedutivo para tais lógicas.

\subsection{Programação em Lógica Clássica}

Nesta seção, fazemos um breve apanhado da teoria da programação em lógica usual [Apt90]. Essa teoria é baseada em uma linguagem de primeira ordem clássica, com sintaxe e semântica definidas usualmente. Assim, adotaremos os conceitos usuais de termos, fórmulas, estruturas, modelos, satisfatibilidade e dedução.

\subsubsection{Sintaxe}

Definição 4.1 (Literal) Se $A$ é um átomo, então $A e \neg A$ são ditos literais positivo $e$ negativo, respectivamente, ou apenas literais.

Definição 4.2 (Cláusula) Se $L_{1}, L_{2}, \ldots, L_{n}$ são literais, então a fórmula

$$
(\forall) L_{1} \vee \ldots \vee L_{n}
$$

é uma cláusula. Uma cláusula pode ser escrita na forma clausal:

$$
A_{1} \vee \ldots \vee A_{k} \leftarrow B_{1} \wedge \ldots \wedge B_{r}
$$


onde $A_{1}, \ldots, A_{k}$ são os literais positivos de $L_{1}, \ldots, L_{n}$ e $\neg B_{1}, \ldots, \neg B_{r}$ são os literais negativos.

Neste caso, $A_{1}, \ldots, A_{k}$ e $B_{1}, \ldots, B_{r}$ são chamadas conclusões e premissas, respectivamente. Se $k=1$, dizemos que $A_{1} \leftarrow B_{1} \wedge \ldots \wedge B_{r}$ é uma cláusula de programa ou definida ou ainda cláusula de Horn. Se $k=0$, dizemos que $\leftarrow B_{1} \wedge \ldots \wedge B_{r}$ é uma consulta.

Uma consulta é na verdade ı̇ma conjunção de átomos existencialmente fechada da forma $(\exists) B_{1} \wedge \ldots \wedge B_{r}$, que tentamos provar que é uma consequência do programa em questão.

A representação de fórmulas na forma clausal é sintaticamente mais simples. Ao contrário do que se poderia imaginar, a linguagem das cláusulas não implica em uma perda de expressividade em relação às fórmulas, se definirmos esta noção da seguinte forma:

Definição 4.3 Um conjunto de cláusulas $\mathcal{C}$ é uma representação clausal para uma fórmula $A$ se e somente se $A$ é satisfativel se e somente se $\mathcal{C}$ é satisfativel.

Uma representação clausal $\mathcal{C}$ pode ser definida como uma conjunção de disjunções.

A representação clausal de um fórmula pode ser obtida através de um algoritmo de representação clausal [CGF87]. Baseados nesta noção de expressividade, temos o seguinte resultado:

Teorema 4.1 (Teorema da Representação Clausal) Sejam A uma fórmula e C a representação clausal obtida para A pela aplicação do algoritmo. Então A é satisfatível se e somente se $\mathcal{C}$ é satisfativel.

Ou seja, a linguagem das cláusulas é tão expressiva quanto a própria linguagem de primeira ordem.

Definição 4.4 (Programa em Lógica) Um programa em lógica é um conjunto finito de cláusulas de programa.

\subsubsection{Substituições e Unificadores}

Fixada a linguagem de primeira ordem a ser adotada, apresentamos aqui alguns conceitos fundamentais para a programação em lógica.

Definição 4.5 (Substituição) Uma substituição é um mapeamento finito de variáveis para termos, representado da seguinte forma:

$$
\theta=\left\{v_{1} / t_{1}, \ldots, v_{n} / t_{n}\right\} .
$$

Se $t_{1}, \ldots, t_{n}$ são termos fechados (livres da ocorrência de variáveis), dizemos que $\theta$ é fechada. 
Substituições são aplicadas a expressões da linguagem, ou seja, termos, literais ou cláusulas de $L \tau$. Se e é uma expressão e $\theta$ uma substituição, então $e \theta$ denota a aplicação de $\theta$ a $e$, obtida pela substituição simultânea de todas as ocorrências de cada variável no domínio de $\theta$ pelo termo correspondente. Dizemos que $E \theta$ é uma instância de $e$.

Definição 4.6 (Composição) $S e \theta=\left\{v_{1} / t_{1}, \ldots, v_{n} / t_{n}\right\}$ e $\eta=\left\{u_{1} / s_{1}, \ldots, u_{m} / s_{m}\right\}$ são substituições, entâa a composiçấo $\theta n$ pode ser obtida a partir do conjunto

$$
\left\{v_{1} / t_{1} \eta, \ldots, v_{n} / t_{n} \eta, u_{1} / s_{1}, \ldots, u_{m} / s_{m}\right\},
$$

removendo-se os pares $v_{i} / t_{i} \eta$ tais que $v_{i} \equiv t_{i} \eta$, bem como os pares $u_{i} / s_{i}$ tais que $u_{i} \in$ $\left\{v_{1}, \ldots, v_{n}\right\}$.

Desta forma, dizemos que uma substituição $\theta$ é mais geral que uma substituição $\eta$ se existe uma substituição $\gamma$ tal que $\eta=\theta \gamma$.

Definição 4.7 (Unificador) $S e e_{1}, e_{2}$ são expressões, uma substituição $\theta$ é dita um unificador de $e_{1}$ e e e e somente se $e_{1} \theta$ e e $e_{2} \theta$ são a mesma expressão $\left(e_{1} \theta \equiv e_{2} \theta\right)$. Neste caso, dizemos que $e_{1}$ e e $e_{2}$ são unificáveis.

Definição 4.8 (umg) Um unificador $\theta$ de $e_{1} e e_{2}$ é dito um unificador mais geral (umg) se $\theta$ é mais geral que qualquer outro unificador de $e_{1}$ e $e_{2}$.

Um importante resultado envolvendo unificadores foi provado em [Rob65], e diz que, se duas expressões são unificáveis, então elas possuem um único unificador mais geral. De fato, em [Apt90] encontramos uma demonstração do seguinte resultado:

Teorema 4.2 (Teorema da Unificação) Existe um algoritmo (algoritmo de unificação) tal que, para quaisquer dois átomos, produz seu umg caso eles sejam unificáveis, e caso contrário afirma a não-existência de um unificador.

\subsubsection{Semântica Declarativa}

A semântica declarativa de um programa nos fornece o significado do próprio programa. Ou seja, estuda as consequências do programa sem analisar os mecanismos computacionais envolvidos. Segundo [Apt90], explica o quê deveria ser computado pelo programa.

Baseados na noção de satisfatibilidade, estudamos a semântica declarativa dos programas em lógica relacionando os modelos destes programas aos pontos-fixos de operadores monotônicos associados.

Estudamos assim o conceito de interpretação de um programa em lógica $\mathcal{P}$. Consideramos apenas as interpretações de Herbrand, que têm como domínio a base de Herbrand $B_{\mathcal{P}}$ (conjunto de todos os átomos da linguagem que são livres da ocorrência de variáveis).

Introduzimos assim o operador de consequência imediata $T_{\mathcal{P}}$ associado ao programa $\mathcal{P}$, que mapeia interpretações de Herbrand a interpretações de Herbrand: 


$$
\begin{array}{r}
T_{\mathcal{P}}(I)=\left\{A \mid A \leftarrow A_{1} \wedge \ldots \wedge A_{n}\right. \text { é uma instância fechada } \\
\text { de uma cláusula em } \left.\mathcal{P} \text { e } I \models A_{1} \wedge \ldots \wedge A_{n}\right\} .
\end{array}
$$

Teorema 4.3 Sejam $\mathcal{P}$ um programa em lógica e I uma interpretação de Herbrand. para $\mathcal{P}$. Então, I é um modelo de $\mathcal{P}$ se e somente se $T_{\mathcal{P}}(I) \subseteq I$.

\subsubsection{Semântica Operacional}

Enquanto a semântica declarativa esclarece o quê deve ser computado por um programa, a semântica operacional esclarece como isso deve ser feito e quais os processos computacionais envolvidos.

Basicamente, para desenvolver uma semântica operacional, apresenta-se uma teoria de demonstração para a linguagem dos programas em lógica, provando que existe um procedimento de demonstração computável que seja correto e completo em relação à semântica declarativa.

Poderíamos apresentar um método na forma de árvores e/ou, mas existe uma preocupação presente no âmbito computacional de que o procedimento apresentado seja o mais eficiente possível. O caráter prático da Inteligência Artificial (e da computação em geral) é a principal fonte desta preocupação.

No caso da programação em lógica usual, o método de resolução foi proposto [Rob65] como um procedimento de demonstração correto e completo para a lógica de primeira ordem. A partir de então, estratégias de refinamento e simplificação têm sido propostas para tornar o método mais eficiente [Bit96]. Para o fragmento das cláusulas definidas, que compõe os programas em lógica clássica, o procedimento de resolução foi refinado e melhorado, dando origem ao método de resolução-SLD ${ }^{1}$.

Podemos definir brevemente este procedimento.

Definição 4.9 (Resolvente) Sejam $\mathcal{P}$ um programa em lógica, $Q$ a consulta

$$
\leftarrow A_{1} \wedge \ldots \wedge A_{k}
$$

e $C$ a cláusula de $\mathcal{P}$

$$
B \leftarrow B_{1} \wedge \ldots \wedge B_{r}
$$

tal que, para algum $1 \leq i \leq k, B$ e $A_{i}$ são unificáveis via umg $\theta$. Entâo, o resolvente de $Q$ e $C$ com umg $\theta$ em relação a $A_{i}$ é a consulta

$$
\leftarrow\left(A_{1} \wedge \ldots \wedge A_{i-1} \wedge B_{1} \wedge \ldots \wedge B_{r} \wedge A_{i+1} \wedge \ldots \wedge A_{k}\right) \theta
$$

Definição 4.10 (Dedução-SLD) Uma dedução-SLD de uma consulta inicial $Q_{0} a$ partir de um programa em lógica $\mathcal{P}$ é uma sequência

\footnotetext{
${ }^{1}$ SLD abrevia resolução Linear com regra de Seleçâo para cláusulas Definidas.
} 


$$
<Q_{0}, C_{1}, \theta_{1}>, \ldots,<Q_{i}, C_{i+1}, \theta_{i+1}>, \ldots
$$

onde cada $Q_{j+1}$ é o resolvente de $Q_{j}$ e $C_{j+1}^{2}$.

Definição 4.11 (Refutação-SLD) Uma refutação-SLD (de comprimento $n$ ) de uma consulta inicial $Q_{0}$ a partir de um programa em lógica $\mathcal{P}$ é uma dedução-SLD

$$
<Q_{0}, C_{1}, \theta_{1}>, \ldots,<Q_{n} \cdot C_{n+1}, \theta_{n+1}>,
$$

onde $Q_{n+1}$ é a cláusula vazia .

Chamamos uma refutação-SLD de irrestrita quando $\theta_{1}, \ldots, \theta_{n+1}$ são unificadores quaisquer, não necessariamente mais gerais.

Podemos partir agora para a programação em lógica anotada.

\subsection{Programação em Lógica Anotada: Sintaxe}

A teoria da programação em lógica anotada é baseada na linguagem anotada de primeira ordem $L \tau$, apresentada no capítulo 2.

Como na teoria da programação em lógica clássica, aqui também nos baseamos em uma linguagem clausal. Neste caso, porém, pagamos um "preço" pelas vantagens que a lógica anotada oferece em relação à lógica clássica.

Em relação à noção de expressividade apresentada na seção anterior, não conseguimos obter um resultado semelhante ao teorema da representação clausal (4.1) para a lógica anotada. Isto porque no caso clássico existe um algoritmo que, para cada fórmula, devolve um conjunto de cláusulas que é uma representação clausal da fórmula dada. Um conjunto de cláusulas pode ser visto como uma conjunção de disjunções que é obtido através de manipulação dos conectivos e suas equivalências.

No caso anotado, porém, não é possível fazer uma manipulação semelhante. Conforme discussão no capítulo 2, cada conectivo é definido como símbolo primitivo, e não em função de outros, como na lógica clássica. Equivalências entre conectivos da linguagem, como por exemplo

$$
A \rightarrow B \equiv \neg A \vee B
$$

não são válidas na lógica anotada.

Isto acontece porque a negação funciona de formas distintas para hiper-literais e fórmulas complexas ${ }^{4}$. Considere, a título de ilustração, o seguinte exemplo:

\footnotetext{
${ }^{2}$ Assumimos que $Q_{j}$ e $C_{j+1}$ não têm nenhuma variável em comum. Basta considerar uma cópia de $C_{j+1}$ para obter o resolvente-a; ou seja, uma cláusula $C_{j+1}^{\prime}$ obtida da renomeação das variáveis de $C_{j+1}$ de forma que $C_{j+1}^{\prime}$ e $Q_{0}, \ldots, Q_{j}, C_{1}, \ldots, C_{j}$ não tenham nenhuma variável em comum.

${ }^{3}$ Conjunção vazia de átomos, que denotamos por $\square$.

${ }^{4}$ cf. Capítulo 3.
} 
Exemplo 4.1 Considere as seguintes fórmulas anotadas sobre FOUR (figura 1.2), onde $p$ e q são átomos da linguagem:

$$
p: v \rightarrow q: v \quad \neg p: v \vee q: v
$$

Seja I uma interpretação para esta linguagem tal que $I(p)=\top$ e $I(q)=f$. Seja ainda $\sim$ o operador definido da seguinte forma:

$$
\sim \perp=\perp \quad \sim f=v \quad \sim v=f \quad \sim \top=\top
$$

Assim, temos que $v_{I}(p: v \rightarrow q: v)=v$ sse $I(p) \geq v$ ou $I(q) \geq v$.

Analogamente, $v_{I}(\neg p: v \vee q: v)=v$ sse $I(p) \geq \sim v$ ou $I(q) \geq v$.

Claramente, temos que $p: v \rightarrow q: v e \neg p: v \vee q: v$ não são equivalentes.

Desta forma, vamos simplesmente considerar o subconjunto de fórmulas da linguagem anotada que estão na forma clausal. A perda de expressividade se deve ao fato de que este é um subconjunto próprio do conjunto de fórmulas, e portanto existem fórmulas que não conseguiremos representar em um programa.

\subsubsection{Programas em Lógica Anotada}

Nesta seção, definimos a notação e terminologia que adotaremos daqui por diante.

Definição 4.12 (Literal Anotado sobre $\tau$ ) Se $A$ é um hiper-literal da linguagem $L \tau$, então $A$ é dito um literal anotado sobre $\tau$. Se $A$ é um átomo anotado de $L \tau$, então $A$ é dito um átomo anotado sobre $\tau$.

Vale lembrar que os elementos do reticulado $\tau$ de valores-verdade não são átomos da linguagem.

Definição 4.13 (Cláusula Anotada sobre $\tau$ ) Se $A, A_{1}, \ldots, A_{n}$ são literais anotados sobre $\tau$, então

$$
(\forall) A \leftarrow A_{1} \wedge \ldots \wedge A_{n}
$$

é uma cláusula anotada sobre $\tau$. Vamos assumir que o fecho universal está implicitamente presente e denotar uma cláusula apenas por

$$
A \leftarrow A_{1} \wedge \ldots \wedge A_{n}
$$

Neste caso, $A$ e $A_{1}, \ldots, A_{n}$ são ditos cabeça (ou conclusão) e corpo (ou premissas) da cláusula, respectivamente. Cláusulas desta forma são também chamadas definidas ou de programa. Se $n=0$, dizemos que é uma cláusula unitária. 
Definição 4.14 (Consulta Anotada sobre $\tau$ ) Se a conclusão de uma cláusula de programa é vazia, então

$$
\leftarrow A_{1} \wedge \ldots \wedge A_{n}
$$

é uma consulta anotada sobre $\tau$.

Definição 4.15 (PLA) Um programa em lógica anotada sobre $r$ (PLA) é um conjunto finito de cláusulas de programa anotadas sobre $\tau$.

A menos que não esteja claro pelo próprio contexto, daqui pra frente passaremos a omitir na terminologia a expressão "anotado sobre $\tau$ ". Por exemplo, cláusulas anotadas sobre $\tau$ serão referenciadas apenas como cláusulas.

\subsubsection{Substituições e Unificadores}

Fixada a linguagem de primeira ordem a ser adotada (no caso, $L \tau$ ), generalizamos as noções da programação em lógica usual, como por exemplo substituições e unificadores.

Estes conceitos são apenas extensões simples dos conceitos usuais para a programação em lógica clássica ${ }^{5}$.

Dizemos que dois literais anotados $A_{1}: \mu_{1}$ e $A_{2}: \mu_{2}$ são unificáveis se $A_{1}$ e $A_{2}$ são unificáveis. Assim, uma substituição não é aplicável às anotações de uma expressão e os conceitos definidos na seção 4.1 .2 se aplicam diretamente ao caso anotado.

\subsection{Programação em Lógica Anotada: Semântica}

Nesta seção, definimos uma interpretação de um PLA. O conceito é equivalente ao de uma estrutura ${ }^{6}$ para uma linguagem de primeira ordem anotada $L \tau$. Porém, fazemos aqui uma restrição quanto ao universo das interpretações e consideramos apenas as interpretações de Herbrand; ou seja, aquelas que têm como domínio a base de Herbrand da linguagem associada.

A base de Herbrand $B_{L}$ de uma linguagem $L$ constitui o conjunto de todos os átomos (não anotados) fechados de $L$. Em relação a um PLA $\mathcal{P}$, consideremos a base de Herbrand $B_{\mathcal{P}}$ da linguagem associada a $\mathcal{P}$.

Definição 4.16 (Interpretação de um PLA) Uma interpretação de Herbrand de um $P L A \mathcal{P}$ pode ser definida como uma função $I: B_{\mathcal{P}} \rightarrow|\tau|$ e a ordem subjacente a $\tau$ pode ser estendida da seguinte forma:

$$
I_{1} \leq I_{2} \text { se e somente se } I_{1}(A) \leq I_{2}(A) \text { para todo átomo } A \text { em } B_{\mathcal{P}} .
$$

\footnotetext{
${ }^{5}$ cf. Seção 4.1.2.

${ }^{6} \mathrm{cf}$. Definição 2.5 na seção 2.2 .
} 
Neste caso, estamos consideramos como domínio específico o conjunto de todos os átomos fechados da linguagem. Isso nos permite particularizar o conceito original de estrutura, definindo a função associada a cada símbolo funcional de $L \tau$ como a função identidade. Desta forma, podemos considerar uma interpretação como a função descrita acima.

Para definir satisfatibilidade, assumimos ainda a existência de uma função $\sim: \tau \rightarrow \tau$.

Definição 4.17 (Satisfatibilidade) Seja I uma interpretação e $F$ uma fórmula. Então $I \models F(I$ satisfaz $F)$ é definido da seguinte forma:

1. Se $F$ é um átomo anotado fechado $A: \mu$, então $I \models A: \mu$ se e somente se $I(A) \geq \mu$.

2. Se $F$ é um literal anotado fechado da forma $\neg A: \mu$, então $I \models \neg A: \mu$ se $e$ somente se $I \models A: \sim \mu$.

3. Se $F$ é da forma $\left(F_{1} \wedge F_{2}\right),\left(F_{1} \vee F_{2}\right)$ ou $\left(F_{1} \leftarrow F_{2}\right)$, onde $F_{1}, F_{2}$ são fórmulas fechadas, então:

(a) $I \models F_{1} \wedge F_{2}$ se e somente se $I \models F_{1}$ e $I \models F_{2}$.

(b) $I \models F_{1} \vee F_{2}$ se e somente se $I \models F_{1}$ ou $I \models F_{2}$.

(c) $I \models F_{1} \leftarrow F_{2}$ se e somente se $I \models F_{1}$ ou não é o caso que $I \models F_{2}\left(I \not \models F_{2}\right)$.

4. Se $F$ é a fórmula fechada $(\exists v) F_{1}$, então $I \models F$ se e somente se existe um termo fechado $t$ tal que $I \models F_{1}[t / v]$, onde $F_{1}[t / v]$ denota a substituição de todas as ocorrências livres de $v$ por $t$ em $F_{1}$.

5. Se $F$ é a fórmula fechada $(\forall v) F_{1}$, então $I \models F$ se e somente $I \models F_{1}[t / v]$, para todo termo fechado $t$.

6. I satisfaz uma fórmula qualquer $F$ se e somente se I satisfaz toda instância fechada de $F$.

Neste ponto, vale a pena introduzir algumas considerações iniciais ${ }^{7}$ sobre o operador $\sim$ que, como vimos no capítulo 2, constitui o significado do símbolo de negação do sistema.

Nas lógicas anotadas, existem pelo menos duas noções distintas de negação: a negação ontológica, que se aproxima da negação clássica; e a negação epistêmica, que se aproxima da negação de lógicas multivaloradas. A vantagem da negação epistêmica é que esta pode ser absorvida pela anotação de um átomo através do operador $\sim$, e portanto é computacionalmente mais eficiente. Por outro lado, a negação ontológica de uma

\footnotetext{
${ }^{7}$ A questão da negação em lógicas anotadas é tratada em vários artigos (cf. [KS92] e [KL92]) e será retomada posteriormente neste trabalho (cf. Capítulos 5 e 6).
} 
fórmula é definida em termos da não-satisfatibilidade desta fórmula. Por exemplo, a implicação poderia ser definida em função de uma negação ontológica $(A \rightarrow B \equiv \bar{A} \rightarrow \mathrm{V} B)$, mas como a negação considerada aqui é epistêmica, introduzimos um novo símbolo para definir a implicação.

Assim, a programação em lógica anotada é definida originalmente apenas com a negação epistêmica. A ontológica será introduzida em algumas de suas extensões.

Vale ressaltar que $\sim$ é um operador qualquer, e a teoria desenvolvida sobre lógicas anotadas independe de sua definição. Porém, algumas propriedades desejáveis podem ser obtidas a partir da especificação de $\sim^{8}$.

Dizemos que uma interpretação $I$ é um modelo de um PLA $\mathcal{P}$ se $I$ satisfaz todas as cláusulas de $\mathcal{P}$.

Definição 4.18 (Modelo de Herbrand) Um modelo de Herbrand para um PLA $P$ é uma interpretação de Herbrand que é modelo de $\mathcal{P}$.

A principal propriedade do operador de negação $\neg$ de uma lógica de primeira ordem anotada - a de ser absorvido pela anotação através do operador - nos garante um dos mais importantes resultados da programação em lógica anotada.

Lema 4.1 Se I é uma interpretação, então $I \models(\exists) \neg A: \mu$ se e somente se $I \models(\exists) A: \sim$ $\mu$.

Demonstração. Ver [BS88].

Teorema 4.4 Seja $\mathcal{P}$ um PLA. Seja $\mathcal{P}^{\prime}$ o PLA obtido a partir de $\mathcal{P}$ pela substituição de todos os literais anotados da forma $\neg A: \mu$ por $A: \sim \mu$. Então $I$ é um modelo de $\mathcal{P}$ se e somente se $I$ é um modelo de $\mathcal{P}^{\prime}$.

Demonstração. Por definição, $I$ é um modelo de um programa $\mathcal{P}$ se satisfaz todas as cláusulas de $\mathcal{P}$.

Seja $\mathcal{C}_{\mathcal{P}}$ uma cláusula de $\mathcal{P}$ e seja $\mathcal{C}_{\mathcal{P}^{\prime}}$ a cláusula de $\mathcal{P}^{\prime}$ assocind $\cdots$ Vamos provar que $I \models \mathcal{C}_{\mathcal{P}}$ sse $I \models \mathcal{C}_{\mathcal{P}^{\prime}}$.

Como cláusulas são universalmente fechadas, pela definição de sát bilidade,

$$
I \models \mathcal{C}_{\mathcal{P}} \text { sse } I \models \mathcal{C}_{\mathcal{P}}[t / v] \text { para todo } t,
$$

onde $t$ é uma lista de termos fechados e $v$ é a lista de todas as variáveis que ocorrem livres em $\mathcal{C}_{\mathcal{P}}$.

Claramente, a lista de variáveis livres $v^{\prime}$ referente à cláusula $\mathcal{C}_{\mathcal{P}^{\prime}}$ é idêntica à lista $v$, e portanto cada instância fechada $\mathcal{C}_{\mathcal{P}}[t / v]$ de $\mathcal{C}_{\mathcal{P}}$ equivale à instância fechada $\mathcal{C}_{\mathcal{P}^{\prime}}\left[t / v^{\prime}\right]$ de $\mathcal{C}_{\mathcal{P}^{\prime}}$

\footnotetext{
${ }^{8}$ cf. Capítulo 6.
} 
Seja $C_{\mathcal{P}} \equiv A \leftarrow A_{1} \wedge \ldots \wedge A_{n}$ uma instância fechada de $\mathcal{C}_{\mathcal{P}}$ e seja $C_{\mathcal{P}^{\prime}} \equiv$ $A^{\prime} \leftarrow A_{1}^{\prime} \wedge \ldots \wedge A_{n}^{\prime}$ a instância fechada de $\mathcal{C}_{\mathcal{P}^{\prime}}$ equivalente a $C_{\mathcal{P}}$.

Novamente pela definição 4.17 ,

$$
I \models C_{\mathcal{P}} \text { sse } I \models A \text { ou } I \not \models A_{1} \wedge \ldots \wedge A_{n} .
$$

Temos dois casos a considerar:

1. $I \models A$

Assim,

(a) Se em $A$ não ocorre o símbolo de negação $\neg$, então $A^{\prime} \equiv A$, por definição. Claramente,

$$
I \models A \text { sse } I \models A^{\prime} \text {. }
$$

Pela definição de satisfatibilidade, $I \models C_{\mathcal{P}^{\prime}}$.

(b) Se $A$ é da forma $\neg B: \mu$, então $A^{\prime}$ é $B: \sim \mu$. Desta forma, pela definição de satisfatibilidade,

$$
I \models \neg B: \mu \text { sse } I \models B: \sim \mu \text {. }
$$

Ainda pela definição, $I \models C_{\mathcal{P}^{\prime}}$.

2. $I \not \forall A$. Assim,

$$
I \not \forall A_{1} \wedge \ldots \wedge A_{n} \text { sse } I \not \models A_{i} \text {, para algum } i \text {. }
$$

(a) Se em $A_{i}$ não ocorre o símbolo de negação $\neg$, então $A_{i}^{\prime} \equiv A_{i}$, por definição. Claramente,

$$
I \not \models A_{i} \text { sse } I \not \models A_{i}^{\prime} \text {. }
$$

Pela definição de satisfatibilidade, $I \not \models A_{1}^{\prime} \wedge \ldots \wedge A_{n}^{\prime}$, e $\operatorname{assim} I \models$ $C_{\mathcal{P}^{\prime}}$.

(b) Se $A_{i}$ é da forma $\neg B_{i}: \mu$, então $A_{i}^{\prime}$ é $B_{i}: \sim \mu$. Desta forma, pela definição de satisfatibilidade,

$$
I \not \models \neg B_{i}: \mu \text { sse } I \not \forall B_{i}: \sim \mu \text {. }
$$

Ainda pela definição, $I \not \forall A_{i}^{\prime}$, donde segue que $I \not \models A_{1}^{\prime} \wedge \ldots \wedge A_{n}^{\prime}$. Assim, $I \models C_{\mathcal{P}^{\prime}}$.

Provamos assim que, para qualquer instância fechada

$$
I \models C_{\mathcal{P}} \text { sse } I \models C_{\mathcal{P}^{\prime}} \text {. }
$$

Portanto,

$$
I \models \mathcal{C}_{\mathcal{P}} \text { sse } I \models \mathcal{C}_{\mathcal{P}^{\prime}} .
$$

Por conta deste resultado, podemos assumir que os PLA's não contêm ocorrência explícita da negação. 


\subsubsection{Semântica Declarativa}

Como no caso da programação em lógica usual, para estudar os modelos de Herbrand de um PLA $\mathcal{P}$, introduzimos um operador de consequência imediata $T_{\mathcal{P}}$. $T_{\mathcal{P}}$ é uma função associada a $\mathcal{P}$ que mapeia interpretações de Herbrand a interpretações de Herbrand da seguinte forma:

$$
\begin{gathered}
T_{\mathcal{P}}(I)(A)=\sqcup\left\{\mu \mid A: \mu \leftarrow A_{1} \wedge \ldots \wedge A_{n}\right. \text { é uma instância fechada } \\
\text { de uma cláusula em } \left.\mathcal{P} \text { e } I \models A_{1} \wedge \ldots \wedge A_{n}\right\} .
\end{gathered}
$$

Como esperado, caracterizamos os modelos de Herbrand de $\mathcal{P}$ em função do operador $T_{\mathcal{P}}$ associado, relacionando-os através do teorema abaixo.

Teorema 4.5 Sejam $\mathcal{P}$ um PLA e I uma interpretação de Herbrand para $\mathcal{P}$. Então, $I$ é um modelo de $\mathcal{P}$ se e somente se $T_{\mathcal{P}}(I) \leq I$.

Demonstração. Ver [BS88].

Quando $T_{\mathcal{P}}(I) \leq I$, dizemos que $I$ é um pré-ponto-fixo de $T_{\mathcal{P}}$. Assim, os modelos de Herbrand de um PLA são os pré-pontos-fixos do operador de consequência imediata associado.

Um outro resultado importante (e esperado) em relação a $T_{\mathcal{P}}$ é a monotonicidade. Pela definição, $T_{\mathcal{P}}$ é monotônico; ou seja, se $I_{1} \leq I_{2}$, então $T_{\mathcal{P}}\left(I_{1}\right) \leq T_{\mathcal{P}}\left(I_{2}\right)$.

$\mathrm{Na}$ verdade, não precisamos diretamente desta característica para provar o teorema acima, mas sem ela não garantimos a existência de um pré-ponto-fixo. De fato, temos o seguinte resultado:

Teorema 4.6 (Teorema do Ponto Fixo) (Knaster e Tarski [Tar55]) Um operador monotônico $T$ tem um ponto-fixo mínimo p $\mathrm{fm}(T)$ que coincide com o pré-ponto-fixo mínimo.

Definição 4.19 (Modelo Mínimo) Um modelo de Herbrand I é modelo mínimo de um PLA $\mathcal{P}$ se $I(A) \leq I^{\prime}(A)$, para todo átomo $A$ em $B_{\mathcal{P}}$ e para todo modelo de Herbrand $I^{\prime}$ de $\mathcal{P}$.

Teorema 4.7 Um PLA $\mathcal{P}$ tem um modelo minimo que coincide com o ponto-fixo mínimo de $T_{\mathcal{P}}$.

Demonstração. Como $T_{\mathcal{P}}$ é um operador monotônico de um reticulado completo para um reticulado completo (formado naturalmente pelas interpretações de Herbrand de $\mathcal{P}$ ), pelo teorema 4.6, $T_{\mathcal{P}}$ tem um pré-ponto-fixo mínimo, digamos $I$. Ou seja, $T_{\mathcal{P}}(I) \leq I$. Pelo teorema $4.5, I$ é um modelo de $\mathcal{P}$. Como $I$ é pré-ponto-fixo mínimo de $T_{\mathcal{P}}$, e uma interpretação de $\mathcal{P}$ é modelo sse for pré-ponto-fixo, então $I$ é modelo mínimo de $\mathcal{P}$. 
Associado a cada reticulado finito $\tau$ e a cada programa anotado sobre $\tau$, existe sempre uma interpretação $\Delta$ que associa o valor-verdade $\perp$ a todo $A$ em $B_{\mathcal{P}}$.

Definição 4.20 Se P é um PLA sobre $\tau$, então a iteração ascendente de $T_{\mathcal{P}}$ é definida indutivamente da seguinte forma:

$$
\begin{aligned}
& T_{\mathcal{P}} \uparrow 0=\Delta \\
& T_{\mathcal{P}} \uparrow(n+1)=T_{\mathcal{P}}\left(T_{\mathcal{P}} \uparrow n\right) \\
& T_{\mathcal{P}} \uparrow \omega=\sqcup_{n<\omega} T_{\mathcal{P}} \uparrow n .
\end{aligned}
$$

Definimos a iteração ascendente como em [Apt90], e não como em [BS89, BS88]. Nestes últimos, a definição envolve todos os ordinais sucessores e todos os ordinais limite. Por outro lado, este trabalho tem como um dos objetıvos principais apresentar uma ferramenta de uso prático para pesquisadores em IA, e por isso nos limitamos a apresentar a definição equivalente envolvendo apenas os naturais finitos e seu limite $\omega$. Aqui não nos interessa ir além de $\omega$.

Um operador $T$ sobre um reticulado é dito contínuo se é monotônico e finitário. $T$ é finitário se, para toda sequência infinita $I_{0} \leq I_{1} \leq \ldots$,

$$
T\left(\sqcup_{n=0}^{\omega} I_{n}\right) \leq \sqcup_{n=0}^{\omega} T\left(I_{n}\right) .
$$

Ao contrário da programação em lógica usual, não podemos garantir a continuidade do operador $T_{\mathcal{P}}$, exceto quando $\tau$ for finito. Mesmo assim, temos o seguinte resultado:

Teorema 4.8 $T_{\mathcal{P}} \uparrow \omega$ coincide com o ponto-fixo mínimo de $T_{\mathcal{P}}\left(p f m\left(T_{\mathcal{P}}\right)\right)$.

Demonstração.

$\left[T_{\mathcal{P}} \uparrow \omega \leq p f m\left(T_{\mathcal{P}}\right)\right]$ Segue da monotonicidade de $T_{\mathcal{P}}$.

$\left[p f m\left(T_{\mathcal{P}}\right) \leq T_{\mathcal{P}} \uparrow \omega\right]$ Neste caso, pelo teorema 4.7 , basta provarmos que $T_{\mathcal{P}} \uparrow \omega$ é um modelo de $\mathcal{P}$.

Seja $A: \mu \leftarrow A_{1}: \mu_{1} \wedge \ldots \wedge A_{n}: \mu_{n}$ uma instância fechada de uma cláusula em $\mathcal{P}$.

Suponha que $T_{\mathcal{P}} \uparrow \omega \models A_{1}: \mu_{1} \wedge \ldots \wedge A_{n}: \mu_{n}$.

Para qualquer átomo $A$ em $B_{\mathcal{P}}$, como $T_{\mathcal{P}}$ é monotônico, temos que

$$
T_{\mathcal{P}} \uparrow 0(A) \leq T_{\mathcal{P}} \uparrow 1(A) \leq T_{\mathcal{P}} \uparrow 2(A) \leq \cdots
$$

Pelas definições de $T_{\mathcal{P}}$ e da iteração ascendente, cada $T_{\mathcal{P}} \uparrow m(A)$ pode ser:

1. o menor elemento do reticulado $\tau(\perp)$; ou

2. o supremo de um conjunto (finito) de valores-verdade referentes às anotações nas cabeças de certas cláusulas em $\mathcal{P}$. 
Existe assim um número finito de tais conjuntos. Desta forma, a cadeia acima é composta por um número finito de valores-verdade, e portanto contém o seu próprio supremo.

Assim, deve existir um número natural $m<\omega$ tal que

$$
T_{\mathcal{P}} \uparrow m \models A_{1}: \mu_{1} \wedge \ldots \wedge A_{n}: \mu_{n} .
$$

Pela detinição de $T_{\mathcal{P}}$, temos que $T_{\mathcal{P}} \uparrow(m+1)(A) \geq \mu$, e portanto $T_{\mathcal{P}} \uparrow$ $(m+1) \models A: \mu$. Pela definição de $T_{\mathcal{P}} \uparrow \omega, T_{\mathcal{P}} \uparrow \omega \geq T_{\mathcal{P}} \uparrow(m+1)$. Como $T_{\mathcal{P}} \uparrow(m+1)(A) \geq \mu$, segue que $T_{\mathcal{P}} \uparrow \omega \geq \mu$, e portanto $T_{\mathcal{P}} \uparrow \omega \models A: \mu$.

Assim, $T_{\mathcal{P}} \uparrow \omega$ é modelo de $T_{\mathcal{P}}$, e $p f m\left(T_{\mathcal{P}}\right) \leq T_{\mathcal{P}} \uparrow \omega$.

Podemos ainda caracterizar mais uma classe de modelos:

Definição 4.21 Um modelo I de um PLA P é dito suportado se e somente se, para todo átomo fechado $A$, temos que

$$
\begin{gathered}
I(A)=\sqcup\left\{\mu \mid A: \mu \leftarrow A_{1} \wedge \ldots \wedge A_{n}\right. \text { é uma instância fechada } \\
\text { de uma cláusula em } \left.\mathcal{P} \text { e } I \models A_{1} \wedge \ldots \wedge A_{n}\right\} .
\end{gathered}
$$

Teorema 4.9 ([BS88]) I é um ponto-fixo de $T_{\mathcal{P}}$ se e somente se I é um modelo suportado de $\mathcal{P}$.

Corolário 4.1 ([BS88]) $T_{\mathcal{P}} \uparrow \omega$ é um modelo suportado de $\mathcal{P}$.

\subsubsection{Semântica Operacional}

Enquanto a semântica declarativa se preocupa em definir o significado de um programa, a semântica operacional se preocupa em apresentar um método de demonstração de teoremas para a linguagem associada, que seja computável, correto e completo em relação ao significado definido.

O método de prova que apresentaremos aqui é baseado no método clássico de resolução-SLD. Este método, que chamamos de resolução-SLDa, é, como veremos, um mecanismo computacional eficiente apenas uma certa classe de PLAs.

Em primeiro lugar, definimos o procedimento de resolução-SLDa para um PLA $\mathcal{P}$.

Definição 4.22 (Resolvente-a) Seja $Q$ a consulta

$$
\leftarrow A_{1}: \mu_{1} \wedge \ldots \wedge A_{k}: \mu_{k}
$$

e C a cláusula anotada

$$
B: \rho \leftarrow B_{1}: \rho_{1} \wedge \ldots \wedge B_{r}: \rho_{r}
$$


em $\mathcal{P}$ tal que, para algum $1 \leq i \leq k, B$ e $A_{i}$ são unificáveis via umg $\theta$ e $\rho \geq \mu_{i}$, então o resolvente-a de $Q$ e $C$ com relação $a A_{i}: \mu_{i}$ é a consulta.

$$
\leftarrow\left(A_{1}: \mu_{1} \wedge \ldots \wedge A_{i-1}: \mu_{i-1} \wedge B_{1}: \rho_{1} \wedge \ldots \wedge B_{r}: \rho_{r} \wedge A_{i+1}: \mu_{i+1} \wedge \ldots \wedge A_{k}: \mu_{k}\right) \theta .
$$

Definição 4.23 (Dedução-SLDa) Uma dedução-SLDa de uma consulta inicial $Q_{0} a$ partir de um PLA $\mathcal{P}$ é uma sequência

$$
<Q_{0}, C_{1}, \theta_{1}>, \ldots,<Q_{i}, C_{i+1}, \theta_{i+1}>, \ldots,
$$

onde cada $Q_{j+1}$ é o resolvente-a de $Q_{j}$ e $C_{j+1}$.

Definição 4.24 (Refutação-SLDa) Uma refutação-SLDa (de comprimento $n$ ) de uma consulta inicial $Q_{0}$ a partir de um PLA $\mathcal{P}$ é uma dedução-SLDa

$$
<Q_{0}, C_{1}, \theta_{1}>, \ldots,<Q_{n}, C_{n+1}, \theta_{n+1}>,
$$

onde $Q_{n+1}$ é a cláusula vazia, denotada por $\square^{9}$.

A árvore-SLDa associada a uma refutação-SLDa pode ser representada pela figura 4.1. Como no caso usual, chamamos uma refutação-SLDa de irrestrita quando $\theta_{1}, \ldots, \theta_{n+1}$ são unificadores quaisquer, não necessariamente mais gerais.

Neste ponto, apresentamos um exemplo simples, apenas para ilustrar o método de resolução-SLDa.

Exemplo 4.2 Seja $\tau$ o reticulado FOUR, cuja ordem é representada através do diagrama na figura 1.2. Considere o seguinte PLA:

$$
\begin{aligned}
& C_{1}: p(X, Y): v \leftarrow q(X): v \wedge r(Y): f \\
& C_{2}: q(a): v \leftarrow \\
& C_{3}: r(a): f \leftarrow
\end{aligned}
$$

e a consulta $\leftarrow p(a, a): v$. A sequência abaixo é uma refutação-SLDa de comprimento 2 desta consulta, onde $\epsilon$ denota a substituição identidade.

$$
<\leftarrow p(a, a): v, C_{1},\{X / a, Y / a\}>,<\leftarrow q(a): v \wedge r(a): f, C_{2}, \epsilon>,<\leftarrow r(a): f, C_{3}, \epsilon>
$$

O procedimento de resolução deve ser correto em completo no que diz respeito a $T_{\mathcal{P}} \uparrow \omega$, e portanto deve refletir o cálculo deste. Para obter $T_{\mathcal{P}} \uparrow \omega$, além de uma busca em largura, é preciso calcular o supremo de um conjunto de anotações. Para que isto seja possível a partir de um procedimento tipo resolução-SLD, as anotações das cabeças de cláusulas em $\mathcal{P}$ que são unificáveis devem ser comparáveis. Assim, a resolução-SLDa é aplicável à seguinte classe de PLAs:

\footnotetext{
${ }^{9} \mathrm{O}$ procedimento de resolução-SLDa não nos fornece nenhuma anotação como medida associada a uma determinada refutação-SLDa. Para tanto, a anotação de uma consulta não poderia se restringir apenas a constantes anotacionais, mas também a variáveis. Esta idéia é formalizada por uma das extensões da programação em lógica anotada a ser apresentada no Capítulo j.
} 


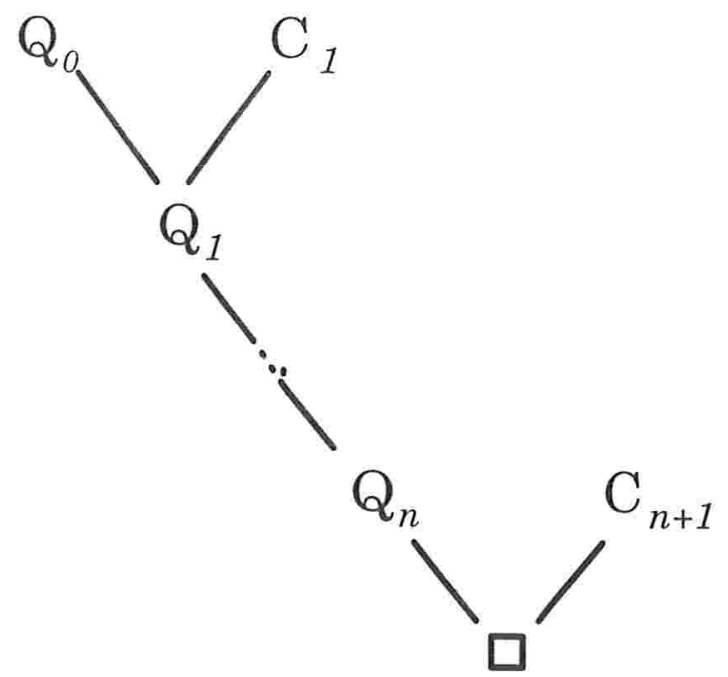

Figura 4.1: Árvore associada a uma Refutação-SLDa

Definição 4.25 (PLA Bem-definido) Dizemos que um PLA $\mathcal{P}$ é bem-definido se e somente se, se $C_{1}, C_{2}$ são cláusulas de $\mathcal{P}$ cujas cabeças são, respectivamente, $A_{1}: \mu_{1} e$ $A_{2}: \mu_{2}$ e $A_{1}$ e $A_{2}$ são unificáveis, então $\mu_{1}$ e $\mu_{2}$ são comparáveis (i.e., ou $\mu_{1} \leq \mu_{2}$ ou $\left.\mu_{2} \leq \mu_{1}\right)$.

Em [BS88], porém, foi proposto um método para aplicar o procedimento de resolução a um PLA qualquer. Se $\mathcal{P}$ não é um PLA bem-definido, aplicamos a resolução sobre o fecho de $\mathcal{P}$, que definimos a seguir.

Definição 4.26 (PLA Fechado) Um PLA P é fechado se e somente se, para quaisquer cláusulas distintas $C_{1}, C_{2}$ em $\mathcal{P}$ da forma

$$
\begin{gathered}
A_{1}: \rho_{1} \leftarrow B_{1}: \mu_{1} \wedge \ldots \wedge B_{k}: \mu_{k} \\
A_{2}: \rho_{2} \leftarrow D_{1}: \psi_{1} \wedge \ldots \wedge D_{r}: \psi_{r}
\end{gathered}
$$

tal que $A_{1}$ e $A_{2}$ sejam unificáveis via umg $\theta$ e $\rho_{1}$ e $\rho_{2}$ sejam incomparáveis $\left(\rho_{1} \not \rho_{2} e\right.$ $\left.\rho_{2} \not \rho_{1}\right)$, existe em $\mathcal{P}$ uma renomeação da cláusula

$$
\left(A_{1}: \sqcup\left\{\rho_{1}, \rho_{2}\right\} \leftarrow B_{1}: \mu_{1} \wedge \ldots \wedge B_{k}: \mu_{k} \wedge D_{1}: \psi_{1} \wedge \ldots \wedge D_{r}: \psi_{r}\right) \theta,
$$

denotada por $\lambda\left(C_{1}, C_{2}\right)$.

Definição 4.27 (Fecho) Seja $\mathcal{P}$ um PLA. Então:

$$
\begin{aligned}
& \mathcal{A}_{1}(\mathcal{P})=\mathcal{P} \\
& \mathcal{A}_{n+1}(\mathcal{P})=\left\{\lambda\left(C_{1}, C_{2}\right) \mid C_{1}, C_{2} \in \mathcal{A}_{n}(\mathcal{P})\right\} \cup \mathcal{A}_{n}(\mathcal{P}) .
\end{aligned}
$$


Existe algum inteiro $n$ tal que $\mathcal{A}_{n}(\mathcal{P})=\mathcal{A}_{n+1}(\mathcal{P}) . \mathcal{A}_{n}$ é dito o fecho de $\mathcal{P}$ e é denotado por $C L(\mathcal{P})$.

Considere o exemplo abaixo:

Exemplo 4.3 Seja $\tau$ o reticulado FOUR da figura 1.2, e seja $\mathcal{P}$ o programa

$$
\begin{aligned}
& p: v \leftarrow \\
& p: f \leftarrow
\end{aligned}
$$

Claramente, o programa não é bem-definido. Acrescentando a cláusula $p: \top \leftarrow$, obtemos o fecho de $\mathcal{P}$. Observe que $\mathcal{A}_{2}(\mathcal{P})=\mathcal{A}_{3}(\mathcal{P})$.

Teorema 4.10 Seja $\mathcal{P}$ um PLA. Então:

1. I é modelo de $\mathcal{P}$ sse $I$ é modelo de $C L(\mathcal{P})$;

2. $T_{\mathcal{P}}=T_{C L(\mathcal{P})}$.

Demonstração. Ver [BS90].

Desta forma, $\mathcal{P}$ e $C L(\mathcal{P})$ são logicamente equivalentes.

Teorema 4.11 Seja $\mathcal{P}$ um PLA fechado e $A \in B_{\mathcal{P}}$. Se $T_{\mathcal{P}} \uparrow \omega \models A: \mu$ (onde $\mu \neq \perp$ ), então existe uma uma instância fechada de uma cláusula em $\mathcal{P}$ da forma

$$
A: \mu^{\prime} \leftarrow A_{1}: \mu_{1} \wedge \ldots \wedge A_{k}: \mu_{k},
$$

onde $\mu^{\prime} \geq \mu$ e $T_{\mathcal{P}} \uparrow \omega \models A_{1}: \mu_{1} \wedge \ldots \wedge A_{k}: \mu_{k}$.

Demonstração. Ver [BS88].

Para que o resultado acima seja sempre válido, assumimos sem perda de generalidade que quaisquer duas cláusulas distintas em $\mathcal{P}$ não têm variáveis em comum.

Daqui por diante, podemos assumir que todo PLA $\mathcal{P}$ é fechado. De fato, se $\mathcal{P}$ não é fechado, basta considerarmos o fecho $C L(\mathcal{P})$ logicamente equivalente a $\mathcal{P}$.

Temos, assim, os teoremas de correção e completude da resolução-SLDa para um PLA fechado [BS88, BS90].

Teorema 4.12 (Correção) Seja $\mathcal{P}$ um PLA fechado e $Q_{0}$ a consulta

$$
\leftarrow A_{1}: \mu_{1} \wedge \ldots \wedge A_{r}: \mu_{r} .
$$

Se $Q_{0}$ tem uma refutação-SLDa a partir de $\mathcal{P}$, então

$$
I_{\mathcal{P}} \uparrow \omega \models(\exists) Q_{0},
$$


onde $(\exists) Q_{0} \equiv(\exists) A_{1}: \mu_{1} \wedge \ldots \wedge A_{r}: \mu_{r}$.

Demonstração. Seja

$$
<Q_{0}, C_{1}, \theta_{1}>, \ldots,<Q_{n}, C_{n+1}, \theta_{n+1}>
$$

uma refutação-SLDa de $Q_{0}$ a partir de $\mathcal{P}$. Vamos provar por indução no comprimento $n$ da re.utação que

$$
T_{\mathcal{P}} \uparrow \omega \models(\exists) Q_{0} .
$$

Base: $n=0$

Neste caso, $Q_{1}$ é a cláusula vazia, e portanto

$$
\begin{aligned}
& Q_{0} \equiv \leftarrow A_{1}: \mu_{1}, \\
& C_{1} \equiv A: \mu \leftarrow, \mu \geq \mu_{1} \mathrm{e} \\
& A_{1} \theta_{1} \equiv A \theta_{1} .
\end{aligned}
$$

Como $T_{\mathcal{P}} \uparrow \omega \models \mathcal{P}$, então $T_{\mathcal{P}} \uparrow \omega \models A^{\prime}: \mu$ para toda instância fechada $A^{\prime}$ de $A$. Em particular, $T_{\mathcal{P}} \uparrow \omega \models A_{1} \theta_{1}^{\prime}: \mu$ para toda instância fechada $A_{1} \theta_{1}^{\prime}$ de $A_{1} \theta_{1}$. Então, $T_{\mathcal{P}} \uparrow \omega \models A_{1} \theta_{1}: \mu$ e como $\mu \geq \mu_{1}$, segue que $T_{\mathcal{P}} \uparrow \omega \models A_{1} \theta_{1}: \mu_{1}$. Portanto,

$$
T_{\mathcal{P}} \uparrow \omega \models(\exists) A_{1}: \mu_{1} .
$$

Passo: $n+1$

Seja

$$
<Q_{0}, C_{1}, \theta_{1}>, \ldots,<Q_{n+1}, C_{n+2}, \theta_{n+2}>
$$

uma refutação-SLDa de $Q_{0}$ de comprimento $n+1$. Seja agora

$$
<Q_{1}, C_{2}, \theta_{2}>, \ldots,<Q_{n+1}, C_{n+2}, \theta_{n+2}>
$$

uma refutação-SLDa de $Q_{1}$ de comprimento $n$. Pela hipótese de indução, $T_{\mathcal{P}} \uparrow \omega \models(\exists) Q_{1}$. Mas $Q_{1}$ é da forma

$$
\begin{aligned}
& \quad \leftarrow\left(A_{1}: \mu_{1} \wedge \ldots \wedge A_{i-1}: \mu_{i-1} \wedge B_{1}: \rho_{1} \wedge \ldots \wedge B_{m}: \rho_{m} \wedge A_{i+1}:\right. \\
& \left.\mu_{i+1} \wedge \ldots \wedge A_{r}: \mu_{r}\right) \theta_{1}
\end{aligned}
$$

e $C_{1}$ é a cláusula

$$
A: \mu \leftarrow B_{1}: \rho_{1} \wedge \ldots \wedge B_{m}: \rho_{m}
$$

tal que $A \theta_{1} \equiv A_{i} \theta_{1}$ e $\mu \geq \mu_{i}$. Como $T_{\mathcal{P}} \uparrow \omega \models \mathcal{P}$, em particular $T_{\mathcal{P}} \uparrow \omega \models$ $C_{1} \theta_{1}$. Como $T_{\mathcal{P}} \uparrow \omega \models A \theta_{1}: \mu$, segue que $T_{\mathcal{P}} \uparrow \omega \models A_{i} \theta_{1}: \mu$. Já que $\mu \geq \mu_{i}$, temos que $T_{\mathcal{P}} \uparrow \omega \models A_{i} \theta_{1}: \mu_{i}$ e portanto

$$
T_{\mathcal{P}} \uparrow \omega \models(\exists)\left(A_{1}: \mu_{1} \wedge \ldots A_{r}: \mu_{r}\right) \theta_{1} .
$$


Logo, $T_{\mathcal{P}} \uparrow \omega \models(\exists)\left(A_{1}: \mu_{1} \wedge \ldots A_{r}: \mu_{r}\right)$.

Lema 4.2 ("mgu lemma") (cf. [Llo87]) Seja $\mathcal{P}$ um PLA e seja $Q_{0}$ uma consulta. Se $Q_{0}$ tem uma refutação-SLDa irrestrita.

$$
<Q_{0}, C_{1}, \theta_{1}>, \ldots,<Q_{n}, C_{n+1}, \theta_{n+1}>
$$

a partir de $\mathcal{P}$, então $Q_{0}$ tem uma refutação-SLDa

$$
<Q_{0}, C_{1}, \theta_{1}^{\prime}>, \ldots,<Q_{n}, C_{n+1}, \theta_{n+1}^{\prime}>
$$

a partir de $\mathcal{P}$ e existe uma substituição $\gamma$ tal que $\theta_{1} \ldots \theta_{n+1}=\theta_{1}^{\prime} \ldots \theta_{n+1}^{\prime} \gamma$.

Lema 4.3 ("Lifting lemma") (cf. [Llo87]) Sejam $\mathcal{P}$ um PLA, Q $Q_{0}$ uina consulta e $\theta$ uma substituição. Se $Q_{0} \theta$ tem uma refutação-SLDa a partir de $\mathcal{P}$, então $Q_{0}$ tem uma refutação-SLDa a partir de $\mathcal{P}$ de mesmo comprimento. Se $\theta_{1}, \ldots, \theta_{n+1}$ são os umg's da refutação-SLDa de $Q_{0} \theta$ e $\theta_{1}^{\prime}, \ldots, \theta_{n+1}^{\prime}$ são os umg's da refutação-SLDa de $Q_{0}$, então existe uma substituição $\gamma$ tal que $\theta \theta_{1} \ldots \theta_{n+1}=\theta_{1}^{\prime} \ldots \theta_{n+1}^{\prime} \gamma$.

Teorema 4.13 (Completude) Seja $\mathcal{P}$ um PLA fechado e $Q_{0}$ a consulta

$$
\leftarrow A_{1}: \mu_{1} \wedge \ldots \wedge A_{r}: \mu_{r} .
$$

Se

$$
T_{\mathcal{P}} \uparrow \omega \models(\exists) Q_{0},
$$

onde $(\exists) Q_{0} \equiv(\exists) A_{1}: \mu_{1} \wedge \ldots \wedge A_{r}: \mu_{r}$, então $Q_{0}$ tem uma refutação-SLDa a partir de $\mathcal{P}$.

Demonstraçẫo.

$T_{\mathcal{P}} \uparrow \omega \models(\exists) Q_{0}$, então $T_{\mathcal{P}} \uparrow \omega \models Q_{0} \theta$, onde $\theta$ é uma substituição tal que $Q_{0} \theta$ é uma instância fechada de $Q_{0}$. Logo, existe $n<\omega$ tal que $T_{\mathcal{P}} \uparrow n \models Q_{0} \theta$.

Vamos provar por indução em $n$ que existe uma refutação-SLDa para $\leftarrow A_{1}: \mu_{1} \wedge \ldots \wedge A_{r}: \mu_{r}$ a partir de $\mathcal{P}$.

Base: $n=1$

Para cada $A_{i} \theta: \mu_{i}, 1 \leq i \leq r$, existe uma cláusula $C_{i}$ em $\mathcal{P}$ com uma instância fechada da forma

$$
A_{i}^{\prime}: \rho_{i} \leftarrow
$$

tal que $\rho_{i} \geq \mu_{i}$. Então 


$$
\begin{gathered}
<\left(\leftarrow A_{1}: \mu_{1} \wedge \ldots \wedge A_{r}: \mu_{r}\right) \theta, C_{1}, \theta_{1}>, \\
<\left(\leftarrow A_{2}: \mu_{2} \wedge \ldots \wedge A_{r}: \mu_{r}\right) \theta \theta_{1}, C_{2}, \theta_{2}> \\
\quad \ldots \\
<\left(\leftarrow A_{r}: \mu_{r}\right) \theta \theta_{1} \ldots \theta_{r-1}, C_{r}, \theta_{r}>
\end{gathered}
$$

é uma refutação-SLDa irrestrita de $Q_{0} \theta$ a partir de $\mathcal{P}$. Pelo lema 4.2 , existe uma refutação-SLDa de $Q_{0} \theta$ a partir de $\mathcal{P}$. Pelo lema 4.3, existe uma refutaçã s-SLDa de $Q_{0}$ a partir de $\mathcal{P}$.

Passo: $n+1$

Suponha que $T_{\mathcal{P}} \uparrow(n+1) \models Q_{0} \theta$. Então, para cada $A_{i} \theta: \mu_{i}, 1 \leq i \leq r$, temos dois casos a considerar:

1. $T_{\mathcal{P}} \uparrow n \models A_{i} \theta: \mu_{i}$. Pela hipótese de indução, existe uma refutaçãoSLDa para $A_{i} \theta: \mu_{i}$.

2. Caso contrário, pelo teorema 4.11 , existe em $\mathcal{P}$ uma cláusula $C_{i}$ com uma instância fechada $C_{i} \theta_{i}$ da forma

$$
A_{i} \theta: \rho_{i} \leftarrow B_{1}: \beta_{1} \wedge \ldots \wedge B_{m}: \beta_{m},
$$

tal que $\rho_{i} \geq \mu_{i}$ e $T_{\mathcal{P}} \uparrow n \models B_{1}: \beta_{1} \wedge \ldots \wedge B_{m}: \beta_{m}$. Pela hipótese de indução, $B_{1}: \beta_{1} \wedge \ldots \wedge B_{m}: \beta_{m}$ tem uma refutação-SLDa $R_{i}$ a partir de $\mathcal{P}$. Assim,

$$
<\leftarrow A_{i} \theta: \mu_{i}, C_{i}, \theta_{i}>, R_{i}
$$

é uma refutação-SLDa irrestrita de $A_{i} \theta: \mu_{i}$ a partir de $\mathcal{P}$. Pelo lema 4.2 , existe uma refutação-SLDa de $A_{i} \theta: \mu_{i}$ a partir de $\mathcal{P}$.

Portanto, para cada $1 \leq i \leq r$, existe uma refutação-SLDa para $A_{i} \theta: \mu_{i}$ a partir de $\mathcal{P}$. Tais refutações combinadas fornecem uma refutação-SLDa para $Q_{0} \theta$ a partir de $\mathcal{P}$. Pelo lema 4.3 , existe uma refutação-SLDa para $Q_{0}$ a partir de $\mathcal{P}$.

\subsection{Um Meta-Interpretador Anotado}

A relação entre o princípio da resolução e as lógicas anotadas ficou bem definida nas seções anteriores. Nesta seção, apresentamos a especificação de um meta-interpretador para a lógica anotada que construímos baseado nos resultados deste capítulo.

Um dos aspectos da linguagem anotada é que esta pode ser programada como um meta-interpretador PROLOG de forma muito natural. É possível assim identificar um termo, um predicado ou uma cláusula da linguagem em função da linguagem usual. Por esta razão, implementamos o meta-interpretador em SICStus(c) PROLOG.

Nossa maior preocupação aqui é mostrar a viabilidade de se operacionalizar a lógica anotada, e portanto a implementação apresentada é a mais natural possível. Considerações sobre a eficiência desta implementação estão fora do escopo deste trabalho. 
Porém. dado o caráter prático do mesmo. tais considerações permanecem como motivação para trabalhos futuros.

Sempre que consultamos um PLA no meta-interpretador, também consultamos um outro arquivo auxiliar contendo as informações necessárias a respeito do reticulado em questão. Neste arquivo, representamos a ordem do reticulado através de pares de elementos. Apenas os pares que formam as arestas no diagrama de Hasse associado ${ }^{10}$ são explicitamente representadas. As demais relações entṛe os outros elementos são obtidas através de uma função do próprio meta-interpretador. Temos ainda uma função que fornece o supremo de dois valores dados. Da mesma forma, a função $\sim$ é representada no arquivo auxiliar. Pelo teorema 4.4, assumimos que não existe ocorrència explícita de negação nas cláusulas de um PLA. Porém, se necessário, pode-se aplicar a negação à anotação. Por exemplo, podemos ter uma cláusula da forma

$$
A: \operatorname{not}(v) \leftarrow
$$

onde not denota a função que representa o operador $\sim$ no meta-interpretador e que calcula seu resultado baseada na definição fornecida no arquivo. Desta forma, a aplicação sucessiva de $\sim$ à uma anotação é calculada por uma função do meta-interpretador baseada na definição de $\sim$ fornecida anteriormente.

Assim, seja $\mathcal{P}$ um PLA bem-definido ou fechado e $Q$ uma consulta. A figura 4.2 especifica a implementação do meta-interpretador, baseado no precedimento de resolução-SLDa. A notação $Q R \theta$ denota que o procedimento retornou com sucesso, tal que $Q$ é consequência de $\mathcal{P}$ com resposta/substituição $\theta$. Caso contrário, denotamos por $Q F$.

Se $\mathcal{P}$ é um PLA que não é bem-definido nem fechado e caso não seja possível verificar uma destas propriedades, então antes de efetuar o procedimento de resolução-SLDa é necessário gerar o fecho ${ }^{11}$ de $\mathcal{P}$, procedimento que está especificado na figura 4.3.

Outros meta-interpretadores para a lógica anotada já foram desenvolvidos. Por exemplo, há duas implementações que diferem fundamentalmente do meta-interpretador aqui apresentado pelo mesmo motivo: ambas já definem na própria implementação os valores-verdade que serão utilizados.

Uma destas implementações é o QUANTLOG [SU88], baseada na teoria que deu origem às lógicas anotadas [Sub87a, Sub88]. O conjunto de valores-verdade considerado neste caso é definido pelo reticulado apresentado em [Sub87a] e já discutido neste trabalho ${ }^{12}$.

\footnotetext{
${ }^{10}$ Por exemplo, as figuras $1.2,1.3$ e 4.4 .

${ }^{11} \mathrm{O}$ fecho também pode ser realizado durante a própria computação, o que é menos ineficiente do que o procedimento apresentado aqui. Além disso, outras estratégias têm sido estudadas em termos de eficiência [LL95].

Novamente, ressaltamos que nosso intuito aqui é apenas ilustrar a possibilidade de implementação do procedimento de refutação-SLDa, e portanto apresentamos uma implementação o mais natural possível.

${ }^{12} \mathrm{cf}$. Introdução (Capítulo 1).
} 
Para resolver $Q$ :

1. Assuma que $Q$ é da forma $Q_{a} \wedge Q^{\prime}$, onde $Q_{a}$ é um átomo anotado e $Q^{\prime}$ é uma consulta. (Note que $Q_{a} \equiv Q_{a} \wedge$ true.)

2. Resolva $Q_{a}$. Se $Q_{a} F$, então retorne $Q F$.

3. Se $Q_{a} R \theta$, então resolva $Q^{\prime} \theta$. Se $Q^{\prime} \theta F$, então retorne $Q F$.

4. Se $Q^{\prime} \theta R \pi$, então retorne $Q R \theta \pi$.

$\underline{\text { Para resolver } Q_{a} \equiv A: \mu \text { : }}$

1. Se $Q_{a} \equiv$ true, então retorne true $R$ yes, onde yes denota a substituição identidade.

2. Se $Q_{a} \equiv A: \mu$, então verifique se existe uma cláusula em $\mathcal{P}$ da forma $A^{\prime}: \mu^{\prime} \leftarrow B$, onde $B$ é uma conjunção de literais anotados, tal que $\mu \leq \mu^{\prime}$ e com $u m g\left(A, A^{\prime}\right)=\theta$. Se não existe tal cláusula em $\mathcal{P}$, então retorne $Q_{a} F$.

3. Caso exista uma cláusula assim em $\mathcal{P}$, então resolva $B \theta$. Se $B \theta F$, então retorne $Q_{a} F$.

4. Se $B \theta R \pi$, então retorne $Q_{a} R \theta \pi$.

Figura 4.2: Implementação da Resolução-SLDa para um PLA $\mathcal{P}$ Bem-definido ou Fechado

Para gerar o fecho de um PLA $\mathcal{P}$ :

1. Seja $C \equiv A: \mu \leftarrow B$. Verifique se existe alguma cláusula em $\mathcal{P}$ da forma $A^{\prime}: \mu^{\prime} \leftarrow B^{\prime}$ tal que $\mu \not \leq \mu^{\prime}$ e $\mu^{\prime} \not \leq \mu$ e tal que $u m g\left(A, A^{\prime}\right)=\theta$. Se não existe tal cláusula em $\mathcal{P}$, então retorne.

2. Caso exista tal cláusula, verifique se existe uma cláusula em $\mathcal{P}$ da forma $(A$ : $\left.\sqcup\left\{\mu, \mu^{\prime}\right\} \leftarrow B \wedge B^{\prime}\right) \theta$. Caso não exista, armazene-a em $\mathcal{P}$.

3. Caso exista, retorne.

Figura 4.3: Implementação do Procedimento de Fecho de um PLA $\mathcal{P}$ 


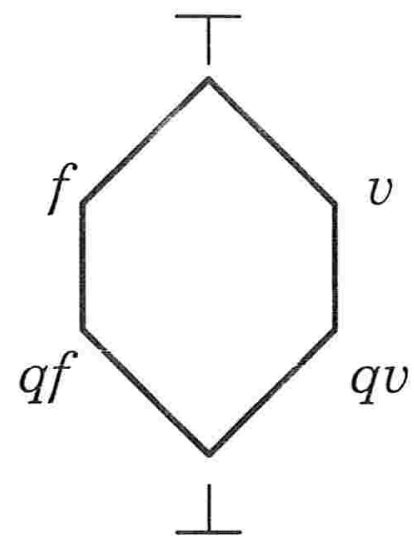

Figura 4.4: O Reticulado SIX

Um outro meta-interpretador para a lógica anotada, o PARALOG ${ }^{13}$, foi desenvolvido mais recentemente. O PARALOG [dCPA+95] considera como conjunto de valoresverdade o reticulado SIX, cuja ordem é definida pelo diagrama da figura 4.4. Intuitivamente, os valores $q f$ e $q v$ representam quase falso e quase verdadeiro, respectivamente.

Esta área ainda está em constante desenvolvimento e outras implementações vêm sendo construídas. As implementações mais recentes, porém, são baseadas em várias extensões da programação em lógica anotada, algumas das quais veremos a seguir.

Nossa implementação encontra-se disponível nas estações de trabalho da Rede do IME-USP e pode ser acessada e copiada mediante autorização da autora.

\footnotetext{
${ }^{13}$ Gostaríamos de apresentar aqui o PARALOG. a título de análise e comparação com relação ao presente trabalho. Isto não foi possível, porém, pois tentamos obtê-lo junto aos autores, sem sucesso.
} 


\section{Capítulo 5}

\section{Extensões da Programação em Lógica Anotada}

Neste capítulo, trataremos brevemente de duas das principais abordagens que dão continuidade ao estudo da programação em lógica anotada, especialmente com relação às aplicações para a Inteligência Artificial.

A teoria que apresentamos nas seções anteriores já é um formalismo suficientemente poderoso para representar várias formas de raciocínio dedutivo em IA, em particular sistemas inconsistentes ${ }^{1}$. As extensões que surgiram posteriormente foram desenvolvidas no sentido de generalizar mais ainda o poder de representação destas lógicas, principalmente no que se refere a raciocínio temporal e não-monotônico.

\subsection{Programação em Lógica Anotada Generalizada}

Esta extensão foi proposta em [KS92], e a diferença fundamental em relação à apresentação original é que as anotações não são apenas elementos de um reticulado completo, mas sim variáveis e funções sobre um semi-reticulado de valores-verdade.

Assim, $\tau=<|\tau|, \leq>$ é um semi-reticulado superior, não necessariamente completo. Em geral, assumimos a existência de um elemento máximo em $\tau$, denotado por $T$. $\mathrm{O}$ operador de supremo é denotado por $\sqcup$, enquanto o operador de ínfimo, se existir, será denotado por $\sqcap$.

A linguagem dos programas em lógica anotada generalizada é constituída pelos símbolos lógicos e não-lógicos usuais, pelos elementos de $\tau$, e ainda por um conjunto de funções $\mathcal{F}=\cup_{i \geq 1} \mathcal{F}_{i}$. Para cada $i \geq 1, \mathcal{F}_{i}$ é uma família de funções contínuas (e portanto monotônicas) da forma $|\tau|^{i} \rightarrow|\tau|$. Assumimos também que todas as funções $f$ em $\mathcal{F}$ são computáveis. Em particular, temos dois conjuntos disjuntos de símbolos de variáveis: variáveis objeto e variáveis anotacionais.

\footnotetext{
${ }^{1} \mathrm{cf}$. Capítulo 6.
} 
Definição 5.1 Uma anotação pode ser um elemento de $\tau$, uma variável anotacional, ou ainda um termo anotacional complexo. Termos anotacionais são definidos recursivamente da seguinte forma:

1. Constantes anotacionais (elementos de $\tau$ ) são termos anotacionais;

2. Variáveis anotacionais são termos anotacionais;

3. Se $f$ é uma função em $\mathcal{F}_{n}$ e $t_{1}, \ldots, t_{n}$ são termos anotacionais, então $f\left(t_{1}, \ldots, t_{n}\right)$ é um termo anotacional complexo.

A noção de átomo anotado é uma simples extensão da noção apresentada neste trabalho, apenas considerando anotações como termos anotacionais. Se um átomo anotado $A: \mu$ é tal que $\mu$ é uma constante anotacional, $A: \mu$ é dito c-anotado. Se $\mu$ é uma variável anotacional, $A: \mu$ é dito $v$-anotado. Se $\mu$ é um termo anotacional complexo, $A: \mu$ é dito t-anotado.

Definição 5.2 Se $A: \mu$ é um átomo anotado e $A_{1}: \mu_{1}, \ldots, A_{n}: \mu_{n}$ são átomos $c$ - ou $v$-anotados, então

$$
(\forall) A \leftarrow A_{1} \wedge \ldots \wedge A_{n}
$$

é uma cláusula anotada. Vamos assumir que o fecho universal está implicitamente presente, e denotar uma cláusula apenas por

$$
A \leftarrow A_{1} \wedge \ldots \wedge A_{n} .
$$

Um programa em lógica anotada generalizada (PLAG) é qualquer conjunto de cláusulas anotadas.

Para definir a semântica dos PLAG's, precisamos antes introduzir o seguinte conceito:

Definição 5.3 Um ideal de um semi-reticulado superior é qualquer subconjunto $S$ tal que:

1. $S$ é fechado por baixo, i.e. se $t \leq s$ para $s$ em $S$, então $t$ está em $S$.

2. $S$ é fechado em relação ao operador supremo finitário, i.e. para $s, t$ em $S, s \sqcup t$ está em $S$.

Um ideal $S$ é principal se, para algum elemento $p$ do reticulado, $S=\{s \mid s \leq p\}$. Os conjuntos de todos os ideais e de todos os ideais principais de $\tau$ são denotados por $\mathcal{I}(\tau)$ e $\mathcal{I}_{P}(\tau)$, respectivamente. $\mathcal{I}(\tau)$ define um reticulado completo sob a ordem de inclusão $(\subseteq)$, e com operadores $\cap$ e $\cup$ de ínfimo e supremo, respectivamente.

Se $L$ é a linguagem anotada associada a um PLAG, a base de Herbrand $B_{L}$ de $L$ é o conjunto de todas as instâncias fechadas de átomos de $L$ sem anotações. Neste caso, temos duas noções de interpretação: 
Definição 5.4 Uma interpretação geral de Herbrand (ou apenas interpretação) I é um mapeamento $I: B_{L} \rightarrow \mathcal{I}(\tau)$.

Uma interpretação restrita de Herbrand (ou r-interpretação) I é um mapeamento qualquer $I: B_{L} \rightarrow|\tau|$, ou, equivalentemente, um mapeamento da forma $I: B_{L} \rightarrow$ $\mathcal{I}_{P}(\tau)$.

Assim, toda r-interpretação é uma interpretação.

T'emos ainda um operador unário $\sim:|\tau| \rightarrow|\tau|$ que constitui o significado da negação, como no caso original.

Definição 5.5 (Satisfatibilidade) Seja I uma interpretação e $F$ uma fórmula. Então, $I \models F$ (I satisfaz $F)$ é definido da seguinte forma:

1. Se $F$ é um átomo anotado fechado $A: \mu$ e $\mu$ é uma c-anotação, então $I \models A: \mu$ se e somente se $\mu \in I(A)$.

2. Se $F$ é um literal anotado fechado da forma $\neg A: \mu$, então $I \models \neg A: \mu$ se $e$ somente se $I \models A: \sim \mu$.

3. Se $F$ é da forma $\left(F_{1} \wedge F_{2}\right),\left(F_{1} \vee F_{2}\right)$ ou $\left(F_{1} \leftarrow F_{2}\right)$, onde $F_{1}, F_{2}$ são fórmulas fechadas, então:

(a) $I \models F_{1} \wedge F_{2}$ se e somente se $I \models F_{1}$ e $I \models F_{2}$.

(b) $I \models F_{1} \vee F_{2}$ se e somente se $I \models F_{1}$ ou $I \models F_{2}$.

(c) $I \models F_{1} \leftarrow F_{2}$ se e somente se $I \models F_{1}$ ou não é o caso que $I \models F_{2}\left(I \not \models F_{2}\right)$.

4. Se $F$ é a fórmula fechada $(\exists v) F_{1}$, então $I \models F$ se e somente se existe um termo fechado $t$ tal que $I \models F_{1}[t / v]$, onde $F_{1}[t / v]$ denota a substituição de todas as ocorrências livres de $v$ por $t$ em $F_{1}$. Neste caso, $v$ pode ser tanto uma variável objeto quanto uma variável anotacional, desde que o termo t seja do mesmo tipo de $v$ (objeto ou anotacional).

5. Se $F$ é a fórmula fechada $(\forall v) F_{1}$, então $I \models F$ se e somente $I \models F_{1}[t / v]$, para todo termo fechado $t$.

6. I satisfaz uma fórmula qualquer $F$ se e somente se I satisfaz toda instância fechada de $F$.

Definição 5.6 (r-Satisfatibilidade) Seja $I$ uma r-interpretação e $F$ uma fórmula. Então, $I \models_{r} F(I$ satisfaz $F)$ é definido da seguinte forma:

1. Se $F$ é um átomo anotado fechado $A: \mu$ e $\mu$ é uma c-anotação, então $I \models_{r} A: \mu$ se e somente se $I(A) \geq \mu$. 
Os casos restantes sấo idênticos aos da definiçâa anterior.

O conceito de r-satisfatibilidade é definido exatamente como no caso original (definição 4.17), apenas com as restrições de $\mu$ ser uma c-anotação e $v$ poder ser tanto uma variável objeto quanto uma variável anotacional.

Os modelos e r-modelos de um PLAG $\mathcal{P}$ são estudados a partir de operadores monotônicos associados, $T_{\mathcal{P}}$ e $R_{\mathcal{P}}$, respectivamente.

- $T_{\mathcal{P}}(I)(A)$ é o menor ideal de $\tau$ contendo o conjunto $\left\{f\left(\mu_{1}, \ldots, \mu_{n}\right) \mid A: f\left(\mu_{1}, \ldots \mu_{n}\right) \leftarrow\right.$ $B_{1}: \mu_{1} \wedge \ldots B_{n}: \mu_{n}$ é uma instância fechada de uma cláusula em $\mathcal{P}$ (contendo apenas c-anotações) e $\left.I \models B_{1}: \mu_{1} \wedge \ldots \wedge B_{n}: \mu_{n}\right\}$.

- $R_{\mathcal{P}}(I)(A)=\sqcup\left\{f\left(\mu_{1}, \ldots, \mu_{n}\right) \mid A: f\left(\mu_{1}, \ldots, \mu_{n}\right) \leftarrow B_{1}: \mu_{1} \wedge \ldots B_{n}: \mu_{n}\right.$ é uma instância fechada de uma cláusula em $\mathcal{P}$ (contendo apenas c-anotações) e $I \models_{r} B_{1}: \mu_{1} \wedge$ $\left.\ldots \wedge B_{n}: \mu_{n}\right\}$.

Uma interpretação (r-interpretação) é um modelo (r-modelo) de um PLAG $\mathcal{P}$ se e somente se $T_{\mathcal{P}}(I) \leq I\left(R_{\mathcal{P}}(I) \leq I\right)$.

A grande diferença entre $T_{\mathcal{P}}$ e $R_{\mathcal{P}}$ é que o primeiro é contínuo e $T_{\mathcal{P}} \uparrow \omega$ coincide com o ponto-fixo mínimo de $T_{\mathcal{P}}$, enquanto que $R_{\mathcal{P}}$ não possui nenhuma dessas duas propriedades. $R_{\mathcal{P}}$ é definido analogamente ao operador de consequência imediata associado a um PLA e, como este, não é contínuo. Porém, um PLA é anotado sobre um reticulado completo (neste caso, finito) e possui apenas c-anotações. Neste caso, é possível provar a propriedade acima, mesmo sem a continuidade do operador associado.

Em [KS92], é apresentado um método de prova tipo resolução-SLD correto e completo (para uma certa classe de consultas), onde são usados conceitos e propriedades de programação em lógica sobre restrições. A afirmação dos autores de que no futuro existe esperança de se desenvolver uma única caracterização para programação em lógica sobre restrições, temporal e anotada reflete a sensação de que as lógicas anotadas constituem um formalismo que pode generalizar ainda mais várias formas de raciocínio dedutivo, motivando estudo e desenvolvimento desta área.

Algumas aplicações desta extensão foram apresentadas em [KS92], como por exemplo conjuntos de regras quantitativas, programas em lógica multivalorada sobre bi-reticulados, e ainda alguns fragmentos de lógicas temporais. Além disso, a programação em lógica anotada generalizada constitui ainda um formalismo para sistemas inconsistentes [LL95] e outras aplicações continuam sendo desenvolvidas.

\subsection{Uma Lógica Para Raciocínio com Inconsistência}

Esta lógica foi proposta em [KL92], com o objetivo de refinar o tratamento de inconsistências. A questão é se devemos ou não tirar conclusões a partir de premissas 
inconsistentes. Baseado nisto, propôs-se uma teoria onde podemos raciocinar das duas formas. Afinal, cada caso é um caso: às vezes é interessante continuar raciocinando a partir de uma inconsistência, às vezes não.

Esta abordagem se torna possível a partir da introdução de um novo operador de negação nas lógicas anotadas - a negação ontológica - e do desenvolvimento dos conceitos relativos às duas negações. A motivação deste estudo não era apenas tratar inconsistência, mas também tratá-la em sistemas não-monotônicos.

Ćomo base para esta linguagem de programação, podemos considerar as lógicas apresentadas no capítulo 2 acrescida do operador de negação forte, que se provou ser clássico.

A lógica apresentada é denominada $\mathrm{APC}^{2}$. O conjunto de valores-verdade associados constituem um reticulado, $\tau$. Neste caso, $\tau$ contém pelo menos os valores $v$ (verdadeiro), $f$ (falso), $\top$ (contraditório) e $\perp$ (desconhecido), onde $\sqcup\{f, v\}=\top$ e $\top$ e $\perp$ são os elementos mínimo e máximo de $\tau$, respectivamente.

Novamente, vale lembrar que $\tau$, diferentemente das lógicas multi-valoradas sobre um reticulado, faz parte da própria linguagem, e não apenas da sua interpretação.

A sintaxe do APC difere das lógicas anotadas originais apenas pela introdução de mais um símbolo de negação, a negação ontológica $\overline{7}$. Neste caso, se $A: \mu$ é um átomo

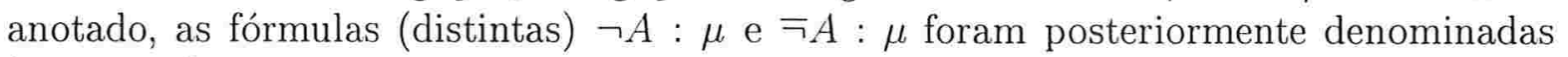
[LHSdC91] hiper-literal e mega-literal, respectivamente.

$\mathrm{Na}$ definição apresentada em [KL92], a negação epistêmica $\neg$ é definida unicamente para cada $\tau$ como um isomorfismo entre semi-reticulados possuindo certas propriedades, como por exemplo a involução. O operador é indutivamente estendido para fórmulas da maneira usual, tal que no caso base é absorvido pela anotação. Por esta propriedade, a negação epistêmica funciona como a ontológica para o caso de fórmulas complexas. A diferença está no tratamento dos átomos.

Em posteriores aplicações desta extensão, $\tau$ é considerado como um reticulado completo qualquer, e a negação epistêmica não obedece nenhuma propriedade em particular para o caso de hiper-literais (cf. [LHSdC91]). Portanto, $\neg$ pode ser reduzida a uma função qualquer sobre $\tau$. Pela propriedade de absorção, $\neg$ se torna aplicável apenas a átomos anotados.

A definição de satisfatibilidade é análoga, estendida apenas para o caso de fórmulas com ocorrência da negação ontológica. Uma interpretação $I$ é um modelo para a negação ontológica de uma fórmula $F(I \models \bar{F} F)$ se e somente se $I$ não for um modelo para $F$ $(I \not \forall F)$. Para um hiper-literal, a satisfatibilidade é definida como no caso original.

Introduzindo a negação ontológica, não é mais necessário definir todos os símbolos da linguagem como primitivos. A partir da negação (ontológica) e da conjunção, por exemplo, é possível definir implicação e disjunção. Como consequência, podemos desenvolver uma linguagem clausal e o respectivo teorema da representação clausal ${ }^{3}$.

\footnotetext{
${ }^{2}$ APC abrevia Annotated Predicate Calculus.

${ }^{3} \mathrm{cf}$. Seção 4.2 , onde discutimos a impossibilidade de se desenvolver um resultado semelhante para
} 
Assim, a teoria original de programação em lógica anotada foi desenvolvida a partir de um subconjunto de uma lógica e foi estendida em sua totalidade a partir da introdução da negação ontológica. Isto vem enriquecer bastante esta teoria, uma vez que o tratamento dos dois tipos de negação resulta em uma linguagem de programação em lógica bem mais abrangente.

\subsubsection{Inconsistência}

A existência das negações ontológica e epistêmica nesta lógica nos leva a estudar outros conceitos, intimamente ligados à noção de negação.

O primeiro deles é a inconsistência. Neste trabalho, o conceito de inconsistência foi sempre tratado no nível epistêmico. Considerando as anotações como graus de crença de um agente raciocinador, uma inconsistência neste nível reflete "informação inadequada sobre o mundo real". Modelos de um programa em APC pode ser então vistos como possíveis estados de crenças deste agente. Segundo [KL92], é justamente a separação entre realidade e crenças sobre a realidade que nos permite tolerar este tipo de inconsistência (cf. nossa discussão sobre níveis de raciocínio no capítulo 3).

Temos assim dois tipos de inconsistências naturalmente associadas a esta lógica: e-inconsistência (epistêmica) e o-inconsistência (ontológica).

Um conjunto de fórmulas $S$ é dito e-inconsistente se $S \models A$ : T, onde $A$ é um átomo da linguagem. Caso contrário, $S$ é dito e-consistente. Intuitivamente, se $S$ é e-inconsistente, então existe pelo menos uma crença inconsistente considerando todos os possíveis estados de crenças do agente raciocinador em questão.

A noção de ordem do reticulado pode ser estendida a interpretações:

$$
I_{1} \leq I_{2} \text { se e somente se } I_{1}(A) \leq I_{2}(A) \text { para todo átomo } A \text {. }
$$

A noção de e-inconsistência sugere ainda uma comparação entre modelos:

Definição 5.7 Uma interpretação $I_{1}$ é mais (ou igualmente) e-consistente que uma interpretação $I_{2}\left(I_{2} \leq_{\mathrm{T}} I_{1}\right)$ se e somente se, sempre que $I_{1} \models A: \mathrm{T}$, então $I_{2} \models A: \mathrm{T}$, para todo átomo $A$.

$O$ valor-verdade $T$ pode não ser o único a denotar inconsistência. Considere, por exemplo, o reticulado SEVEN (figura 1.3), onde o valor-verdade $d \top$ denota uma conclusão "default" inconsistente. Portanto, se $\Delta$ é o conjunto de valores-verdade que representam inconsistência, o conceito de comparação de modelos introduzido acima pode ser estendido a partir da definição 5.7, considerando-se todos os elementos de $\Delta$, e não apenas o valor-verdade $T$.

Por outro lado, um conjunto de fórmulas $S$ é dito o-inconsistente se não existem modelos para $S$. Neste caso, a noção de inconsistência é semelhante à da lógica clássica.

a programação em lógica anotada original. 
Exemplo 5.1 ([KL92]) Seja $S=\{$ chove : v, chove: $f \vee$ leve_guarda_chuva: $v\}$. $O$ conjunto $S$ tem dois modelos minimais $I_{1}$ e $I_{2}$ (de acordo com a noção de ordem definida acima):

1. $I_{1}($ chove $)=v$ e $I_{1}($ leve_guarda_chuva $)=v$

2. $I_{2}($ chove $)=\top$ e $I_{2}($ leve_guarda_chuva $)=\perp$

Intuitivamente, o primeiro modelo é mais natural: leve um guarda-chuva quando estiver chovendo.

O que gostaríamos de ilustrar, porém, é que não existe uma relação entre modelos minimais e modelos mais e-consistentes. Um modelo minimal pode não ser e-consistente e vice-versa.

\subsubsection{Implicação}

Outro conceito diretamente ligado à negação é a implicação. Novamente, para cada negação, temos uma noção distinta de implicação: a implicação epistêmica e a implicação ontológica.

Na apresentação original das lógicas anotadas, a negação é epistêmica, porém a implicação é ontológica. De fato, na definição de satisfatibilidade, se $I$ é uma interpretação, temos:

$$
I \models F_{1} \rightarrow F_{2} \text { sse } I \not \models F_{1} \text { ou } I \models F_{2} \text {. }
$$

Em termos da negação ontológica, temos agora a equivalência

$$
F_{1} \rightarrow F_{2} \equiv=F_{1} \vee F_{2} .
$$

A implicação epistêmica $\gg$ é definida analogamente:

$$
F_{1} \gg F_{2} \equiv \neg F_{1} \vee F_{2}
$$

A diferença fundamental entre os dois tipos de implicação está na propagação da inconsistência. Considere o seguinte exemplo:

Exemplo 5.2 ([KL92]) Seja $S_{1}=\{B: v, A: v \leftarrow B: v\}$. Claramente, $S_{1} \models A: v$. De fato, mesmo para um modelo $I$ de $S_{1}$ tal que $I(B)=T$, temos que $I \models A: v$.

Seja $S_{2}=\{B: v, A: v \ll B: v\}$. Neste caso, temos que $S_{2} \not \forall A: v$. Basta considerar um modelo $I$ de $S_{2}$ tal que $I(B)=\top$ e $I(A)=\perp$.

Assim, a implicação ontológica nos permite tirar conclusões a partir de crenças inconsistentes, ao contrário da implicação epistêmica, que não deduz nada de crenças inconsistentes ou de premissas que possam vir a ser inconsistentes. 
Porém, a definição natural de implicação epistêmica não traduz o conceito de um "mundo possível canônico". Ou seja. uma interpretação onde $p$ e $q$ são desconhecidos (têm valor-verdade $\perp$ ) não é um modelo para $p: v \ll q: f$, quando este seria o mundo possível mais natural associado a esta implicação. Para que $\gg$ corresponda a esta interpretação intuitiva de implicação, sua definição pode ser estendida da seguinte forma:

$$
F_{1} \leadsto F_{2} \equiv \neg F_{1} \vee \neg F_{1} \vee F_{2}
$$

Temos ainda outros conceitos de modus ponens e consequência semântica associados às noções de implicação.

Da implicação ontológica, por exemplo, definimos o operador $\models$ e a regra de modus ponens usuais.

A partir da implicação epistêmica, estes conceitos são um pouco diferenciados. A consequência semântica epistêmica, denotada por $\approx$, pode ser definida simplesmente como $\models$ restrito aos modelos mais e-consistentes em questão. Já a regra de modus ponens se torna um pouco limitada em relação a esta implicação, o que já era de se esperar, uma vez que $\leadsto$ não propaga inconsistências.

Considere, por exemplo, a seguinte situação:

Exemplo 5.3 ([KL92]) Temos que $\{p: \mu, p: \lambda \rightarrow q: \beta\} \models q: \beta$ se e somente se $\mu \geq \lambda$.

Porém, se $\mu \geq \lambda$, então $\{p: \mu, p: \lambda \gg q: \beta\} \not Æ q: \beta$ se e somente se $\mu \geq$ $\sqcup\{\lambda, \sim \lambda\}$. Note que $\sqcup\{\lambda, \sim \lambda\}$ é o menor grau de crença inconsistente maior ou igual a $\lambda$ em relação à ordem do reticulado em questão.

\subsubsection{Raciocínio Não-Monotônico e Crenças Inconsistentes}

Em [KL92] é apresentada uma série de exemplos característicos do raciocínio nãomonotônico, ilustrando a teoria desenvolvida.

Aqui, apresentamos um fragmento de um desses exemplos, que acreditamos ser suficiente para esclarecer uma das idéias centrais da extensão apresentada.

Exemplo 5.4 Considere o seguinte programa em APC sobre o reticulado SEVEN (figura 1.3):

1. $\operatorname{voa}(X): d v \leftarrow \operatorname{ave}(X): d v$

2. $\operatorname{voa}(X): d f \leftarrow \operatorname{pinguim}(X): d v$

3. $\operatorname{voa}(X): f \ll \operatorname{pinguim}(X): v$

4. ave (tweety) $: v$ 
Podemos então concluir, pela regra 1, que:

$$
\text { voa(tweety) : dv. }
$$

Posteriormente, adicionamos a seguinte informação sobre Tweety:

$$
\text { pinguim(tweety) : } v \text {. }
$$

Pelas regras 2 e 3 podemos concluir que:

$$
\text { voa(tweety): } f \text {, }
$$

uma vez que $d f \leq f$ e $d v \leq f$ no reticulado em questão.

Se considerarmos que posteriores observaçôes sobre a classificação de Tweety nos levam a concluir que:

$$
\text { pinguim(tweety) : } \top \text {, }
$$

não podemos mais deduzir que voa(tweety): $f$. Isto porque, pela regra 3 , não podemos tirar conclusões a partir de premissas inconsistentes. Das regras 1 e 2 temos que:

$$
\text { voa(tweety) : } d \top \text {. }
$$

Assim, se Tweety pode ser ou não um pingüim, ele também pode ou não voar, e portanto não podemos concluir efetivamente que ele não voa (ou seja, que voa(tweety) : $f$ ).

\subsection{Outras Extensões}

Várias extensões da programação em lógica anotada vêm sendo propostas continuamente: variações ou combinações de teorias já existentes, ou ainda generalizações envolvendo relações com outros sistemas lógicos.

Em [Thi95], o autor apresenta uma outra extensão e suas relações com formalismos para raciocínio não-monotônico. Em especial, faz um paralelo com a teoria apresentada na seção 5.2, mostrando ainda que a implicação definida neste novo sistema não é nem ontológica nem epistêmica.

Outra extensão foi desenvolvida em [NS89] para implementar uma forma de raciocínio probabilista, onde é possível anotar conjunções e disjunções.

Citamos estas extensões aqui apenas para dar um exemplo da produtividade associada a estas lógicas. O objetivo deste trabalho não é apresentar todas as pesquisas e todos os resultados na área - se é que isto seria possível aqui -, mas sim situar as lógicas anotadas dentro de um contexto de aplicações, ressaltando a sua importância para a IA. O fato de que existem várias linhas de desenvolvimento nesta área vem confirmar a idéia de que as lógicas anotadas são realmente um formalismo bastante poderoso no campo do raciocínio dedutivo e representação de conhecimento. 
90 CAPÍTULO 5. EXTENSÕES DA PROGR.AMAÇÃO EM LÓGICA ANOTADA 


\section{Capítulo 6}

\section{Aplicações}

Um dos pontos centrais deste trabalho é avaliar a importância das lógicas anotadas para a Inteligência Artificial. Já vimos que tais lógicas constituem um formalismo para tratar inconsistências (cf. capítulo 2), e também investigamos sua capacidade de caracterizar adequadamente o raciocínio com argumentos (cf. capítulo 3 ).

Estas aplicações já são suficientemente importantes para fazer com que estas lógicas sejam de grande interesse (e utilidade) para pesquisadores na área de raciocínio dedutivo. Porém, as lógicas anotadas parecem ser um formalismo suficientemente forte para caracterizar e generalizar várias formas de raciocínio em IA.

Neste capítulo, nos dedicamos ao estudo de algumas aplicações das lógicas anotadas no campo da IA. Para isso, especificamos várias instâncias das lógicas anotadas como PLA's, apresentando alguns exemplos que podem ser desenvolvidos no meta-interpretador apresentado. Dentre estas instâncias, podemos citar lógicas multivaloradas, lógicas paraconsistentes e a própria lógica clássica.

Uma outra abordagem que adotaremos neste estudo é a especificação do significado da negação fraca, analisando casos especiais da linguagem quando o operador $\sim$ goza de certas propriedades.

\subsection{A Negação $\neg$ e o Operador}

Como vimos em capítulos anteriores, o conectivo de negação fraca $\neg$ é absorvido por seu significado $\sim$ no caso de hiper-literais, onde $\sim:|\tau| \rightarrow|\tau|$ é um operador qualquer na definição da linguagem $L \tau$.

Nesta seção, investigamos o comportamento da linguagem sob vários aspectos quando este operador possui certas propriedades. Dentre estes aspectos, podemos citar, por exemplo, o poder de expressividade da linguagem [CdS96].

Nas próximas seções, consideramos três abordagens ao especificarmos algumas propriedades do operador $\sim$ : 
1. A primeira abordagem diz respeito às características da aplicação do operador a um elemento de $\tau$.

2. Na segunda, discutimos a manutenção (ou não) da ordem quando aplicamos o operador a dois elementos de $\tau$.

3. E, por último, definimos $\tau$ como um tipo especial de reticulado e investigamos algumas características e propriedades do operador $\sim$ associado.

\subsubsection{Propriedades Clássicas e Intuicionistas}

Aqui investigamos algumas consequências de se especificar o operador $\sim$ com certas características em relação à aplicação a um elemento de $\tau$.

Se pensarmos na negação em um sistema lógico, esta é geralmente um operador unário obedecendo algumas propriedades. $\mathrm{O}$ operador $\sim$ constitui, na verdade, o significado da negação em uma lógica anotada, porém sem nenhuma propriedade préestabelecida.

Desta forma, nos parece razoável especificar algumas propriedades para $\sim$, baseados nas propriedades de operadores de negação de outros sistemas lógicos.

Se pensarmos no operador de negação $\neg$ do sistema clássico, a primeira propriedade que exploramos é a involução.

Definição 6.1 Um operador $*: S \rightarrow S$ é dito involutivo se e somente se $* * x=x$ para todo $x$ em $S$.

Assim, se $\sim$ é um operador involutivo, $\sim \sim \mu=\mu$ para todo $\mu \mathrm{em}|\tau|$.

Intuitivamente, a aplicação consecutiva de duas negações a um hiper-literal da linguagem não altera a crença (o conhecimento) associada à sentença. De fato,

$$
\neg \neg A: \mu \equiv A: \sim \sim \mu \equiv A: \mu .
$$

Ou seja, se aplicarmos duas vezes consecutivas o operador $\sim$ sobre $\tau$, a ordem relativa dos elementos do reticulado não se altera. Lm exemplo é o operador associado ao reticulado FOUR ${ }^{1}$ (figura 1.2).

Neste caso, conseguimos derivar o seguinte resultado para a linguagem $L \tau$ :

Lema 6.1 Se : $\tau|\rightarrow| \tau \mid$ é um operador involutivo, então:

1. $\neg^{k} A: \mu \leftrightarrow A: \mu, k$ par;

2. $\neg^{k} A: \mu \leftrightarrow \neg A: \mu, k$ impar.

\footnotetext{
${ }^{1} \mathrm{cf}$. capítulos anteriores.
} 
Se considerarmos o operador de negação intuicionista, este diverge do clássico em vários sentidos. Em um sistema lógico intuicionista, por exemplo, o princípio do 30 excluído não é válido, bem como a equivalência $F \leftrightarrow \neg \neg F$. A equivalência só é válida em uma direção: $F \rightarrow \neg \neg F$ [dC 77$]$.

Assim, um operador * intuicionista não é involutivo, mas tem a seguinte característica [Fit91]:

$$
x \leq * * x .
$$

Portanto, se o operador $\sim$ tem a propriedade $\mu \leq \sim \sim \mu$, para todo $\mu$ em $|\tau|$, pode ser caracterizado como intuicionista.

O que isso quer dizer intuitivamente? Um hiper-literal $A: \mu$ é válido se o valorverdade de $A$ for pelo menos $\mu$. A fórmula negada duas vezes será válida se o valorverdade de $A$ for pelo menos $\sim \sim \mu$. Pela propriedade intuicionista de $\sim, \mu \leq \sim \sim \mu$. Assim, a cada duas aplicações consecutivas de $\sim$, a afirmação a respeito de $A$ é feita com maior (ou igual) força; ou seja, a crença de um agente associada a $A$ não diminui. Assim, derivamos o seguinte resultado:

Lema $6.2 S e \sim:|\tau| \rightarrow|\tau|$ é um operador intuicionista, então:

$$
\neg^{k+k^{\prime}} A: \mu \rightarrow \neg^{k} A: \mu, k^{\prime} \text { par, } k \geq 0 .
$$

Podemos ainda analisar o caso oposto. Ou seja, $\sim$ é um operador tal que $\sim \sim \mu \leq \mu$. Intuitivamente, aplicando o operador $\neg$ duas vezes consecutivas, a afirmação a respeito de $A$ é feita com menos (ou igual) força. Se negarmos muitas (um número par de) vezes, podemos chegar na seguinte afirmação:

$$
A: \perp
$$

que é sempre válida e quer dizer apenas que não sabemos nada sobre $A$. Cada dupla aplicação simplesmente não acrescenta nenhum novo conhecimento ao sistema em relação a $A$. De fato, desta propriedade derivamos o resultado abaixo.

Lema 6.3 Se $\sim:|\tau| \rightarrow|\tau|$ é um operador tal que $\sim \mu \leq \mu$, para todo $\mu \in|\tau|$, então: $A: \mu \rightarrow \neg^{k} A: \mu, k$ par.

Podemos generalizar um pouco mais este resultado, obtendo:

$$
\neg^{k} A: \mu \rightarrow \neg^{k+k^{\prime}} A: \mu, k^{\prime} \text { par, } k \geq 0 .
$$

Vale ressaltar que, em todos os casos anteriores, nada podemos afirmar sobre uma única aplicação (ou um número ímpar de aplicações) do operador $\sim$ a um elemento de $\tau$. Neste caso, $\sim$ pode ser estritamente (ou não) crescente ou decrescente, característica que independe deste tipo de propriedade.

Podemos ainda considerar $\sim$ como sendo um operador constante. Ou seja, para todo $\mu \mathrm{em}|\tau| \sim \mu=\lambda$, onde $\lambda$ é um elemento específico de $|\tau|$.

Considere, por exemplo, o caso especial onde $\lambda=\perp$. Assim, 


$$
\sim \mu=\perp
$$

Intuitivamente, negando um hiper-literal $A: \mu$ da linguagem, não teremos mais nenhuma informação a respeito de $A$. De fato,

$$
\neg A: \mu \equiv A: \perp,
$$

que é sempre válido. Disto segue o resultado abaixo:

Lema 6.4 Se : $|\tau| \rightarrow|\tau|$ é tal que $\sim \mu=\perp$ para todo $\mu$ em $|\tau|$, então:

$$
\neg^{k} A: \mu, k \geq 1 \text {. }
$$

Se $\sim$ é um operador constante qualquer, podemos generalizar o lema acima da seguinte forma:

Lema 6.5 Seja $\lambda$ um elemento de $|\tau|$. Se $\sim:|\tau| \rightarrow|\tau|$ é tal que $\sim \mu=\lambda$ para todo $\mu$ em $|\tau|$, então:

$$
\neg^{k} A: \mu \leftrightarrow A: \lambda, k \geq 1 .
$$

Uma outra classe de funções unárias pode ser particularizada para o caso de reticulados completos e definida da seguinte forma:

Definição 6.2 Uma função $f$ de um reticulado completo a um reticulado completo é dita estrita se e somente se $f(\perp)=\perp$.

A interpretação intuitiva neste caso é bem natural. Se $\sim$ é um operador estrito e se considerarmos um fato sobre o qual não temos nenhuma informação, a sua negação também não acrescentaria nenhuma nova informação ao sistema (ao agente). Assim,

$$
\neg A: \perp \equiv A: \perp \text {. }
$$

Em [BS88], encontramos a seguinte observação:

Teorema 6.1 Seja $\mathcal{P}$ é um PLA sobre $\tau$, onde $\tau$ tem pelo menos dois elementos, $e$ seja uma função estrita. Então existe um PLA $\mathcal{P}^{\prime}$ sobre $\tau$, tal que

1. Se A pertence à linguagem de $\mathcal{P}$, então $T_{\mathcal{P}} \uparrow \omega \models A: \mu$ se e somente se $T_{\mathcal{P}^{\prime}} \uparrow$ $\omega \models A: \mu$;

2. $\mathcal{P}^{\prime}$ é paraconsistente ${ }^{2}$.

\footnotetext{
${ }^{2}$ Extensão da noção de paraconsistência (definição 2.10).
} 
Neste trabalho, apresentamos uma pequena extensão do resultado acima. Considere a classe de funções unárias $f$ de um reticulado completo a um reticulado completo que associam pelo menos um elemento a ele mesmo. Ou seja, $f(\mu)=\mu$ para algum elemento $\mu$ do reticulado.

Lema 6.6 Seja P é um PLA sobre $\tau$. onde $\tau$ tem pelo menos dois elementos, e seja uma função como definida acima. Então existe um PLA $\mathcal{P}^{\prime}$ sobre $\tau$, tal que

1. Se $A$ pertence à linguagem de $\mathcal{P}$. então $T_{\mathcal{P}} \uparrow \omega \models A: \mu$ se e somente se $T_{\mathcal{P}^{\prime}} \uparrow$ $\omega \models A: \mu$;

2. $\mathcal{P}^{\prime}$ é paraconsistente.

Demonstração. De acordo com a noção introduzida na seção 2.4 , um programa $\mathcal{P}$ é paraconsistente se for simultaneamente inconsistente e nãotrivial.

Pela definição de $\sim$, existe $\mu$ em $|\tau|$ tal que $\sim \mu=\mu$. Assim, para todo átomo $A$ em $B_{\mathcal{P}}, T_{\mathcal{P}} \uparrow \omega \models A: \mu$ e $T_{\mathcal{P}} \uparrow \omega \models \neg A: \mu$. Portanto, $\mathcal{P}$ é inconsistente (de acordo com a definição 2.9).

Se $\mathcal{P}$ é não-trivial (de acordo com a definicao 2.8), considere $\mathcal{P}^{\prime}$ como sendo o próprio programa $\mathcal{P}$. Caso contrário, seja $\mathcal{P}^{\prime}$ o programa $\mathcal{P} \cup$ $\{q: \perp \leftarrow\}$, onde $q$ é um símbolo de predicado 0-ário que não pertence à linguagem de $\mathcal{P}$. Neste caso, $T_{\mathcal{P}^{\prime}} \uparrow \omega \not \neq q: \lambda$, onde $\lambda \neq \perp$ é um elemento de $|\tau|$. Assim, $\mathcal{P}^{\prime}$ é não-trivial, e portanto é paraconsistente.

Todo PLA sobre $\tau$ tal que $\sim$ é definida como acima pode ser considerado um programa paraconsistente. De fato, para todo PLA $\mathcal{P}$ desta forma, existe um PLA $\mathcal{P}^{\prime}$ paraconsistente cujo significado é o mesmo de $\mathcal{P}$.

\subsubsection{Monotonicidade e Antitonicidade}

Outras características que podemos explorar a respeito do operador $\sim$ são as de manutenção (ou não) da ordem quando aplicado a elementos que são relacionados em $\tau$.

Considere, por exemplo, a monotonicidade:

Definição 6.3 Dizemos que um operador unário * é monotônico em relação à uma ordem $\leq$ se, para quaisquer elementos $x, y$ do dominio, se $x \leq y$ então $* x \leq * y$.

Se $\sim$ é um operador monotônico, então a intuição por trás da aplicação de $\sim$ é de que a negação não altera o conhecimento que temos do sistema. Neste caso, a aplicação de $\sim$ sobre $\tau$ não altera a ordem relativa dos elementos do reticulado.

Temos assim o seguinte resultado: 
Lema 6.7 Se $\sim:|\tau| \rightarrow|\tau|$ é um operador monotônico, então:

$$
\neg^{k} A: \mu \rightarrow \neg^{k} A: \lambda, \mu \geq \lambda, k \geq 0 .
$$

Por exemplo, o operador $\sim$ associado ao reticulado FOUR é monotônico.

Podemos considerar ainda uma outra propriedade:

Definição 6.4 Dizemos que um operador unário * é antitônico em relação à uma ordem leq se, para quaisquer elementos $x, y$ do domínio, se $x \leq y$ então $* y \leq * x$.

Neste caso, o operador $\sim$ aplicado sobre $\tau$ simplesmente inverte a ordem relativa dos elementos do reticulado. Se considerássemos que a ordem definida em $\tau$ representa verdade, e não conhecimento, esta propriedade seria intuitivamente clara: a negação inverte a noção de verdade.

Lema 6.8 Se $\sim:|\rightarrow| \tau \mid$ é um operador antitônico, então:

1. $\neg^{k} A: \mu \rightarrow \neg^{k} A: \lambda, \mu \geq \lambda, k$ par.

2. $\neg^{k} A: \mu \rightarrow \neg^{k} A: \lambda, \lambda \geq \mu, k$ impar.

Considere o reticulado FOUR e o operador $\sim^{\prime}$ definido da seguinte forma:

$$
\begin{aligned}
& \sim^{\prime} \perp=\top \\
& \sim^{\prime} \top=\perp \\
& \sim^{\prime} f=f \\
& \sim^{\prime} v=v .
\end{aligned}
$$

Neste caso, $\sim^{\prime}$ é antitônico.

É claro que existem operadores não-monotônicos que não são antitônicos, e viceversa. Por exemplo, se $x \leq y$, a aplicação de $\sim$ poderia resultar que $\sim x \leq \sim y$, ou $\sim x \geq \sim y$, ou ainda que $\sim x$ e $\sim y$ não são comparáveis. Nestes casos, não conseguimos estabelecer nenhum resultado para a relação entre a negação $\neg$ e o operador $\sim$, além daquela fornecida pela própria definição.

\subsubsection{Bi-reticulados}

As noções introduzidas na seção anterior serão úteis para a definição dos conceitos envolvidos nesta seção. Aqui, consideramos como sendo o operador de negação associado a $\tau$, quando este é um bi-reticulado.

Os bi-reticulados foram introduzido por M. Ginsberg (cf. [Fit91]) como famílias de valores-verdade que permitem tratar, por exemplo. informações incompletas ou conflitantes. O reticulado FOLR constitui o mais simples dos bi-reticulados. 
Posteriormente, propôs-se uma semântica declarativa para programas em lógica sobre um bi-reticulado de valores-verdade [Fit91]. Para tanto, introduziu-se a noção de bireticulados entrelaçados, um pouco mais restrita do que a original, na qual nos baseamos nesta seção e que apresentamos brevemente a seguir ${ }^{3}$.

Definição 6.5 (Bi-reticulado Entrelaçado) Um bi-reticulado entrelaçado é um conjunto $S$ com duas ordens parciais $\leq_{k} e \leq_{t}$ tais que:

1. Cada uma das ordens $\leq_{k}$ e $\leq_{t}$ define $S$ como sendo um reticulado completo.

2. Os operadores de ínfimo e supremo para cada ordem parcial sâo monotônicos em relação à outra ordem.

A segunda condição é a que restringe o bi-reticulado, definindo-o como entrelaçado.

A ordem $\leq_{k}$ é definida na direção que representa informação ou conhecimento, enquanto que $\leq_{t}$ é definida na direção que representa verdade ${ }^{4}$.

Em um bi-reticulado $\tau=<|\tau|, \leq_{k}, \leq_{t}>$, temos pelo menos quatro elementos:

- $\perp$ e T são, respectivamente, os elementos mínimo e máximo de $\tau$ sob a ordem $\leq_{k}$.

- $f$ e $v$ são, respectivamente, os elementos mínimo e máximo de $\tau$ sob a ordem $\leq_{t}$.

Um bi-reticulado pode ter um operador de negação associado, definido da seguinte forma:

Definição 6.6 Um bi-reticulado entrelaçado $S$ tem um operador de negação fraca se existe um mapeamento $\sim: S \rightarrow S$ tal que:

1. Se $x \leq_{k} y$, então $\sim x \leq_{k} \sim y$;

2. Se $x \leq_{t} y$, então $\sim y \leq_{t} \sim x$.

Note que estas noções são as mesmas definidas na seção anterior. Neste caso, $\sim$ é monotônico em relação a $\leq_{k}$ e antitônico em relação a $\leq_{t}$. A intuição é a mesma já discutida anteriormente.

Porém, no caso das lógicas anotadas, trabalhamos com reticulados, e portanto com apenas uma ordem. Se tomarmos alguns dos reticulados das seções anteriores, como por exemplo os (bi-)reticulados FOUR e SEVEN (figuras 1.2 e 1.3), é fácil verificar que a ordem considerada é a de conhecimento; ou seja, $\leq_{k}$. Portanto, se $\sim$ assume o papel do operador de negação em um bi-reticulado, ele é monotônico em relação à ordem considerada pela lógica anotada. Portanto, vale o resultado apresentado no lema 6.7.

A título de ilustração, as figuras 6.1 e 6.2 mostram as duas ordens existentes nos (bi-)reticulados FOUR e SEVEN, respectivamente. 


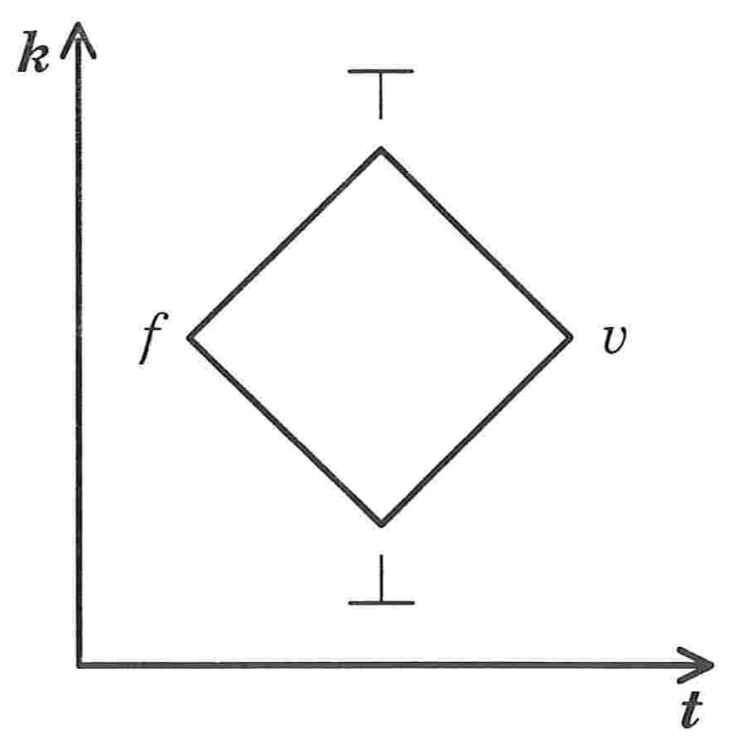

Figura 6.1: O Bi-reticulado FOUR

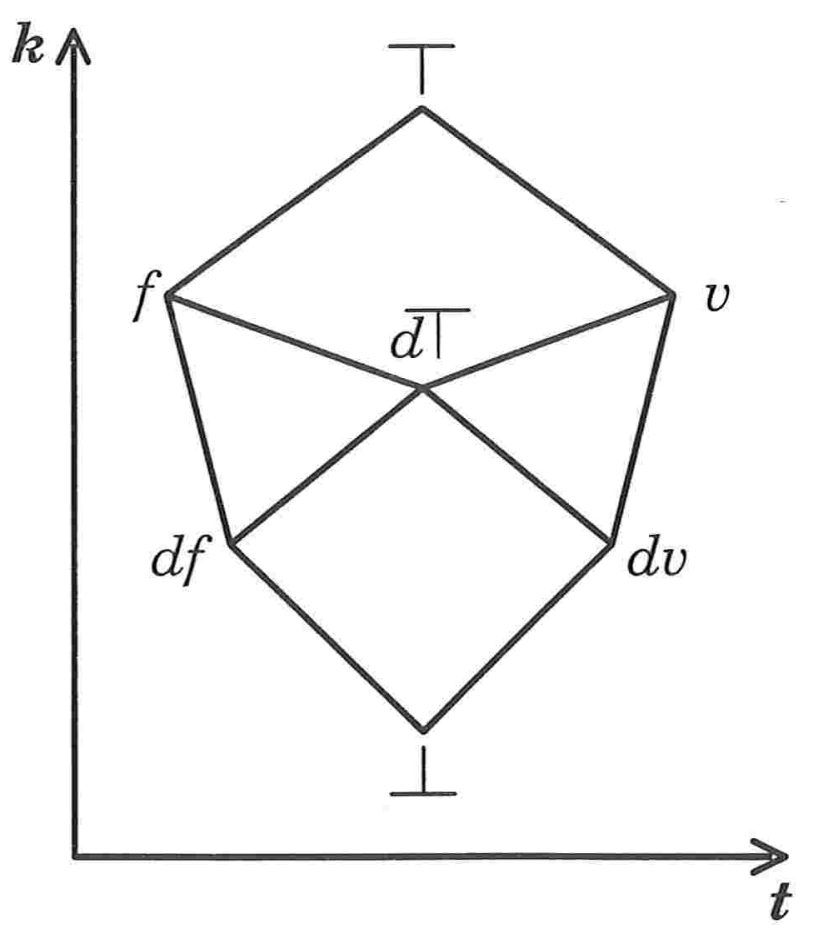

Figura 6.2: O Bi-reticulado SEVEN 
Podemos definir mais um operador unário em um bi-reticulado entrelaçado:

Definição 6.7 Um bi-reticulado entrelaçado S tem um operador de conflação se existe um mapeamento - : $S \rightarrow S$ tal que:

1. Se $x \leq_{k} y$, então $-y \leq_{k}-x$;

2. Se $x \leq_{t} y$, então $-x \leq_{t}-y$;

3. $-x=x$.

Se o operador $\sim$ for associado ao operador de conflação de um bi-reticulado, ele terá então duas propriedades: antitonicidade (pois consideramos a ordem $\leq_{k}$ ) e involução. Portanto, os resultados apresentados nos lemas 6.8 e 6.1 são válidos para $\sim$, prevalecendo assim o resultado relativo à involução, que é mais forte em relação à antitonicidade.

Outras características podem ser associadas aos elementos de um bi-reticulado pelo operador de conflação.

Definição 6.8 Em um bi-reticulado entrelaçado $S$ com conflação, para todo $x$ em $S$,

1. $x$ é exato se $x=-x$;

2. $x$ é consistente se $x \leq_{k}-x$;

Assim, se existir algum elemento exato em $\tau$, podemos derivar o resultado apresentado no lema 6.6.

Quanto à característica de consistência, só podemos derivar algum resultado se todos os elementos do reticulado forem consistentes. Senão, não há como estabelecer um comportamento padrão.

Se todos os elementos de $\tau$ forem consistentes, temos em particular que

$$
x \leq_{k} \sim x \leq_{k} \sim \sim x .
$$

Este é um resultado um pouco mais forte do que o intuicionismo, uma vez que não é necessário aplicar duas vezes para obter um certo comportamento do operador. Intuitivamente, a cada aplicação de $\sim$ a um átomo anotado $A$, a a crença (o conhecimento) associada a $A$ não diminui. Podemos derivar o seguinte resultado, semelhante ao lema 6.2 .

Lema 6.9 Se $\sim:|\tau| \rightarrow|\tau|$ é tal que todos os elementos de $\tau$ são consistentes em relação $a \sim$, então:

$$
\neg^{k} A: \mu \rightarrow \neg^{k^{\prime}} A: \mu, k^{\prime} \leq k .
$$

\footnotetext{
${ }^{3}$ Seria necessário no mínimo um capítulo inteiro para falarmos sobre bi-reticulados e suas aplicações. Faremos aqui uma breve apresentação, envolvendo os conceitos mais importantes. Ver [Fit91] para uma leitura mais detalhada.

${ }^{4} \mathrm{~A}$ ordem $\leq_{k}$ abrevia knowledge $\mathrm{e} \leq_{t}$ abrevia truth.
} 


\subsection{Instâncias da Lógica Anotada}

Após investigar alguns resultados decorrentes da especificação do operador $\sim$, nesta seção investigamos as aplicações decorrentes da especificação do próprio reticulado $\tau$.

Em geral, seguiremos um certo padrão em cada apresentação: definimos brevemente o formalismo original e depois definimos o mesmo formalismo como uma instância das lógicas anotadas; por último, ilustramos esta especificação com exemplos de programas que podem ser desenvolvidos no meta-interpretador apresentado.

\subsubsection{Programação Paraconsistente}

Nada mais natural do que apresentar em primeiro lugar um formalismo que constitui uma das principais motivações do desenrolvimento das lógicas anotadas.

As noções de paraconsistência e de programa paraconsistente foram introduzidas anteriormente neste trabalho ${ }^{5}$, já como um caso particular das lógicas anotadas. Portanto, nesta seção apresentaremos apenas alguns exemplos.

Exemplo 6.1 Considere um sistema relativo ao investimento em terras, representado pelo seguinte PLA sobre o reticulado FOUR:

(1) compra $(\mathrm{X}): \mathrm{v}:-$ ponto_turistico(X):v.

(2) $\operatorname{compra}(X): v:-\operatorname{tem} \_p e t r o l e o(X): v$.

(3) $\operatorname{compra}(X): f$ :- possiveis_problemas(X):v.

(4) possiveis_problemas(X):v :- proximo_usina_nuclear(X):v.

(5) possiveis_problemas(X):v :- terra_disputada(X):v .

(6) tem_petroleo(mossoro): $\mathrm{v}:-$.

(7) terra_disputada (mossoro): $\mathrm{v}:-$.

(8) ponto_turistico(icapui):v :-.

O sistema acima nos diz que vale a pena comprar terras em uma região turística ou petrolífera. Ao contrário, não vale a pena investir em regiões envolvendo conflitos de terras ou próximas a usinas nucleares. O programa nos diz ainda que a região de Mossoró tem petróleo, mas é bastante disputada, enquanto Icapuí é uma região turística que não apresenta problemas.

Este programa contém informações inconsistentes, pois

\footnotetext{
${ }^{5}$ cf. Seçōes 2.4 e 6.1.1.
} 


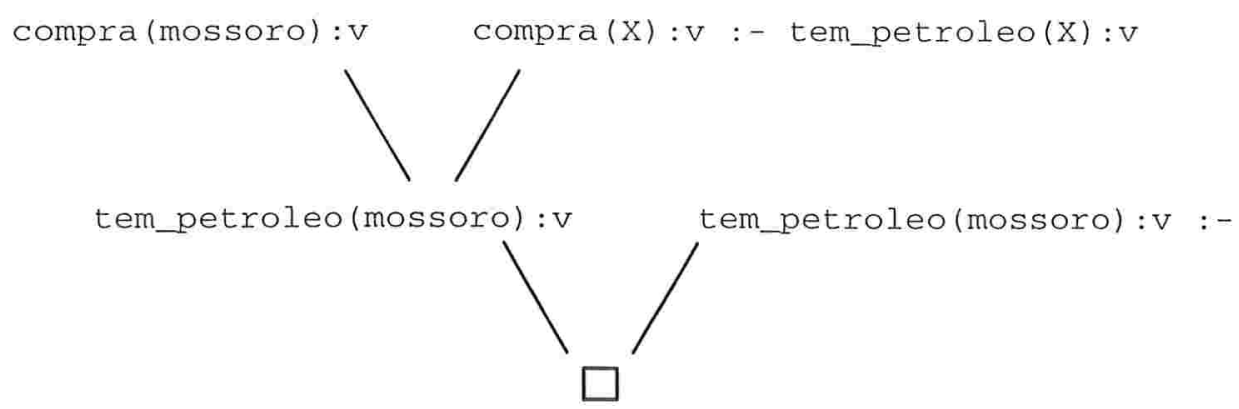

Figura 6.3: Refutação-SLDa de compra(mossoro) :v em relação ao exemplo 6.1

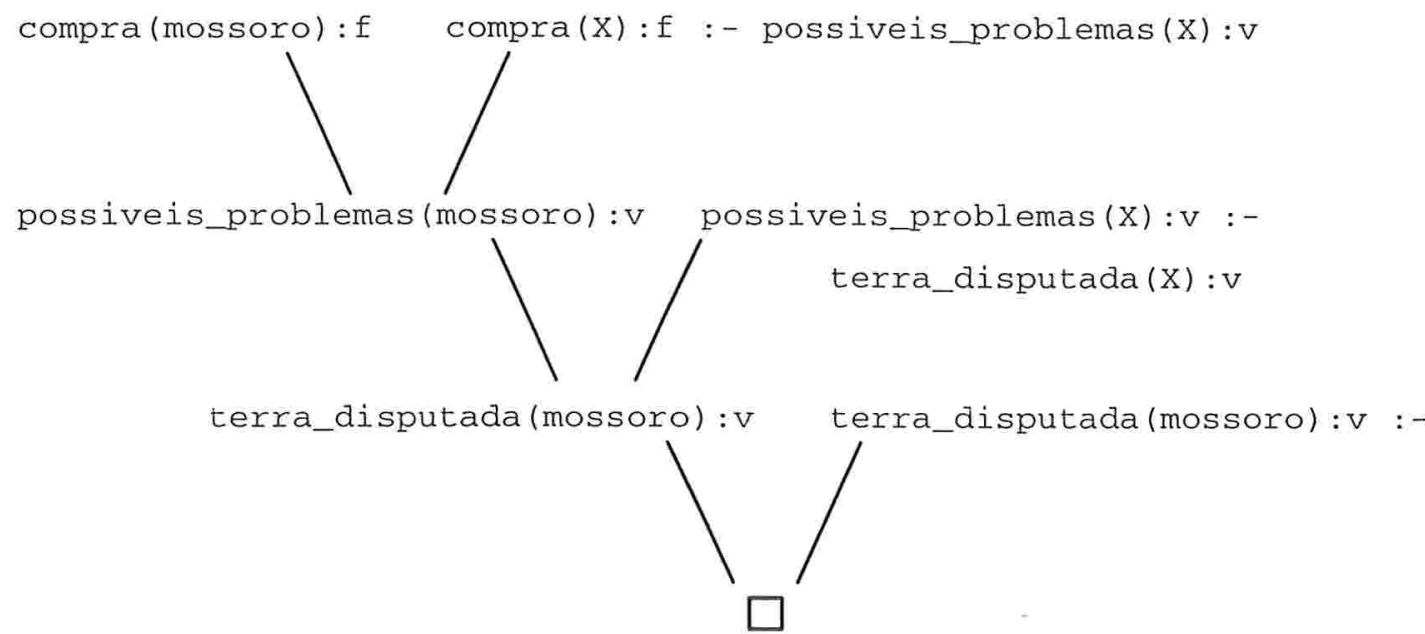

Figura 6.4: Refutação-SLDa de compra(mossoro) :f em relação ao exemplo 6.1

1. Das cláusulas 2 e 6, temos que compra (mossoro):v.

2. Das cláusulas 3, 5 e 7, temos que compra (mossoro) :f.

Sabemos assim que existem prós e contras ao investir em terras na região de Mossoró. Já em Icapuí, a compra de terras é uma boa idéia.

Em [LHSdC91], é apresentado um exemplo baseado em uma variação do reticulado SEVEN, cuja ordem é definida pela figura 6.5.

Os valores-verdade máximo $(\top)$ e mínimo $(\perp)$ indicam, respectivamente, inconsistente e desconhecido. Os valores $f$ e $v$ indicam falso e verdadeiro, enquanto $p v$ e $p f$ podem ser informalmente descritos como é provável que seja verdadeiro e é provável que seja falso, respectivamente. Intuitivamente, o valor-verdade $m \& m$ ("meio a meio") indica que a probabilidade de ser verdadeiro é igual à probabilidade de ser falso.

Baseados na intuição por trás desta ordem, podemos definir um operador de negação 


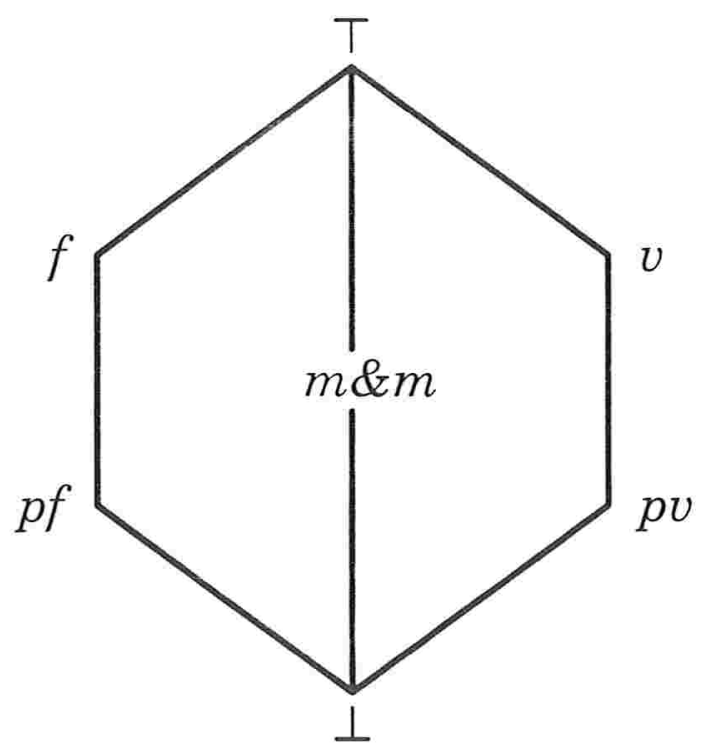

Figura 6.5: Uma Variação do Reticulado SEVEN

$\sim$ da seguinte forma: $\sim(v)=f, \sim(f)=v, \sim(p v)=p f, \sim(p f)=p v$, enquanto os demais valores são associados a eles mesmos.

Exemplo 6.2 Considere uma pequena base de conhecimento em um hospital, cujo objetivo é diagnosticar três doenças $d_{1}, d_{2}$ e $d_{3}$. Para construir o sistema, foram consultados dois especialistas. O primeiro diz que:

1. Se um paciente apresenta o sintoma $s_{1}$ e não apresenta o sintoma $s_{2}$, então é provável que ele esteja com a doença $d_{2}$.

2. É improvável que um paciente apresente simultaneamente as doenças $d_{1}$ e $d_{3}$.

O segundo especialista afirma que:

1. Se um paciente não apresenta o sintoma $s_{2}$ e apresenta o sintoma $s_{3}$, então a probabilidade deste paciente estar com a doença $d_{2}$ é de $50 \%$.

2. Se um paciente apresenta o sintoma $s_{4}$, então é provável que ele esteja com a doença $d_{1}$.

Assim, o sistema pode ser escrito pelo seguinte PLA:

(1) $\mathrm{d} 2(\mathrm{X}): \mathrm{pv}:-\mathrm{s} 1(\mathrm{X}): \mathrm{v} \& \mathrm{~s} 2(\mathrm{X}): f$.

(2) $\mathrm{d} 1(\mathrm{X}): \mathrm{pf}:-\mathrm{d} 3(\mathrm{X}): \mathrm{pv}$. 


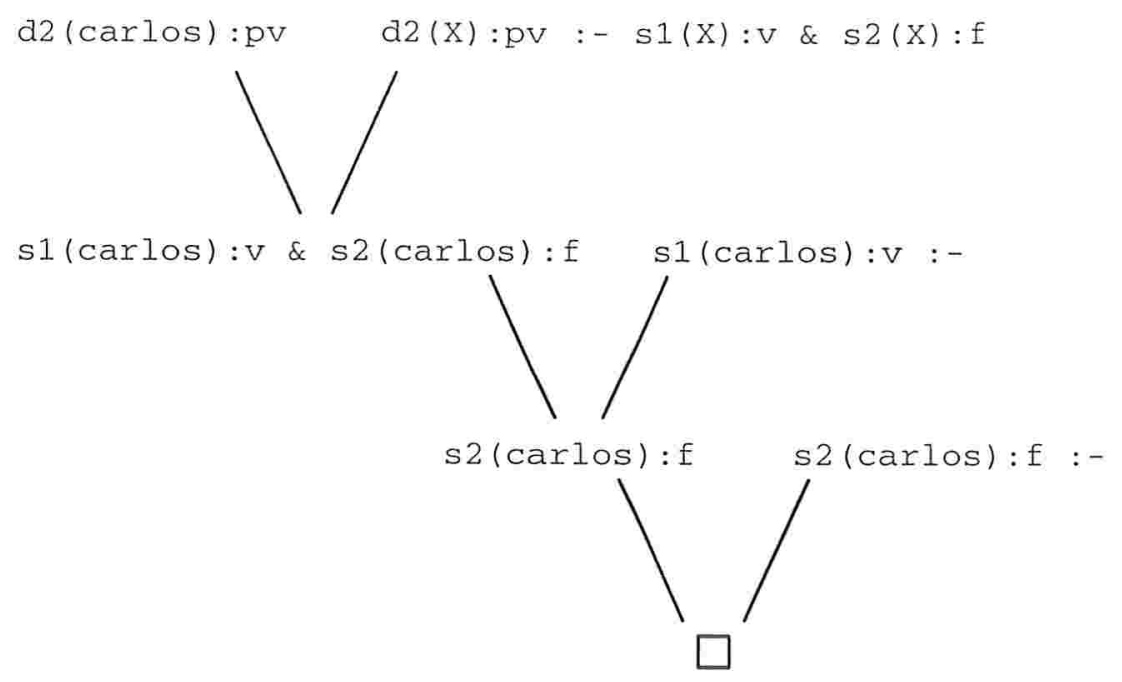

Figura 6.6: Refutação-SLDa de d2(carlos) :pv em relação ao exemplo 6.2

(3) $\mathrm{d} 3(\mathrm{X}): \mathrm{pf}:-\mathrm{d} 1(\mathrm{X}): \mathrm{pv}$.

(4) $d 2(X): m \& m:-s 2(X): f \& s 3(X): v$.

(5) $\mathrm{d} 1(\mathrm{X}): \mathrm{pv}:-\mathrm{s} 4(\mathrm{X}): \mathrm{v}$.

Temos ainda os resultados dos exames de um paciente, Carlos.

(6) $\mathrm{s} 1(\operatorname{carlos}): \mathrm{v}:-$.

(7) $\mathrm{s} 2(\operatorname{carlos}): f$ :- .

(8) $\mathrm{s} 3(\operatorname{carlos}): \mathrm{v}:-$.

(9) $\mathrm{s} 4(\operatorname{carlos}): \mathrm{v}:-$.

Este programa contém informações inconsistentes, pois

1. Das cláusulas 1, 6 e 7, temos que d2(carlos):pv.

2. Das cláusulas 4,7 e 8 , temos que d2(carlos):m\&m.

Este resultado registra que os especialistas consultados não concordam em relação ao diagnóstico de $d_{2}$. Ao contrário, sabemos que é improvável que Carlos esteja com a doença $d_{3}$. 


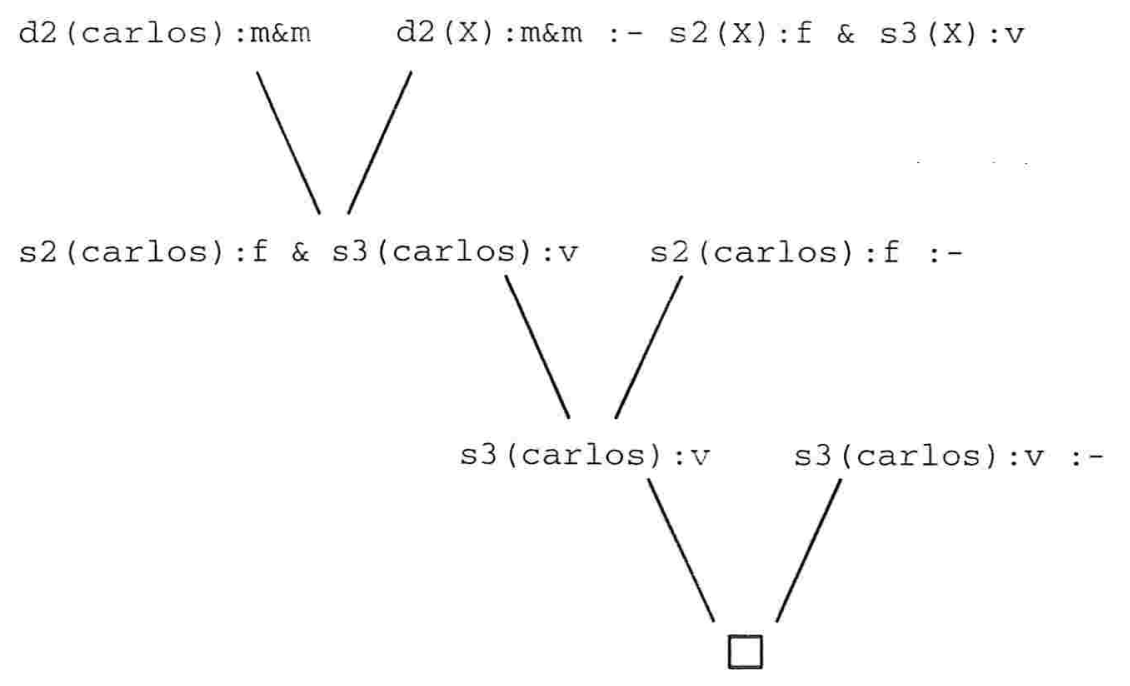

Figura 6.7: Refutação-SLDa de d2(carlos) : m\&m em relação ao exemplo 6.2

Em relação ao tratamento de inconsistências através das lógicas anotadas, gostaríamos de ressaltar alguns pontos. A inconsistência associada a um átomo em um PLA não nos permite, como no caso clássico, deduzir um resultado qualquer. Como nos exemplos acima, temos valores inconsistentes associados aos átomos compra (mossoro) e d2 (carlos), mas não podemos deduzir compra (icapui) : f ou d3 (carlos) :pv. Porém, em relação ao átomo inconsistente, podemos associar qualquer valor-verdade. Assim, deduzimos, por exemplo

$$
\begin{aligned}
& \mathrm{d} 2(\operatorname{carlos}): \mathrm{pf} \\
& \mathrm{d} 2(\operatorname{carlos}): \mathrm{v}
\end{aligned}
$$

onde a anotação pode ser qualquer valor-verdade de reticulado. Por esta característica, as lógicas anotadas (e as lógicas paraconsistentes em geral) são também chamadas de lógicas localmente inconsistentes.

Outro ponto que gostaríamos de enfatizar é de que informações inconsistentes podem estar presente nos vários tipos de formalismos para representação de conhecimento, como por exemplo nas lógicas clássica, "default" 6 , ou ainda para raciocínio sobre evidência. A presença de inconsistência na programação em lógica usual foi tratada nesta seção. Eventuais inconsistências presentes nas aplicações abaixo serão tratadas da mesma forma, uma vez que estes exemplos constituem casos particulares da programação em lógica anotada.

\footnotetext{
${ }^{6}$ cf. Seção 5.2.3.
} 


\subsubsection{Programação em Lógica Usual}

Como vimos na seção anterior, a lógica anotada trata de forma mais adequada inconsistências que possam surgir na programação em lógica usual ${ }^{7}$. Desta forma, é razoável pensar que também é possível especificar programas em lógica usual como PLA's, mesmo quando não há necessidade de tratar inconsistências.

Exemplo 6.3 O PLA abaixo define algumas noções de aritmética, que poderiam claramente ser especificadas por um programa em lógica usual.

numero_natural (0):v :-.

numero_natural $(\mathrm{s}(\mathrm{X})): \mathrm{v}:-$ numero_natural $(\mathrm{X}): \mathrm{v}$.

mais $(O, X, X): v$ :- numero_natural $(X): v$.

$\operatorname{mais}(\mathrm{s}(\mathrm{X}), \mathrm{Y}, \mathrm{s}(\mathrm{Z})): \mathrm{V}:-\operatorname{mais}(\mathrm{X}, \mathrm{Y}, \mathrm{Z}): \mathrm{V}$.

Vamos analisar agora o seguinte exemplo:

Exemplo 6.4 Considere o programa em lógica usual:

estudante_nao_casado $(X)$ :- estudante $(X)$ \& $\backslash+$ casado $(X)$.

estudante(carlos).

O PLA correspondente ao programa acima é naturalmente definido como:

estudante_nao_casado $(X): v$ :- estudante $(X): v$ \& $\operatorname{casado}(X): f$.

estudante (carlos): v .

No primeiro programa, podemos deduzir que estudante_nao_casado(carlos), pois sabemos que Carlos é um estudante e não conseguimos provar que Carlos é casado.

No PLA, ao contrário, não conseguimos deduzir que estudante_nao_casado (carlos). De fato, nao conseguimos provar nem que Carlos é casado, nem que Carlos não é casado; este é um fato desconhecido. Portanto, a negação clássica só é traduzida fielmente para a negação epistêmica da lógica anotada nos casos onde é possível especificar também os fatos negativos associados, não apenas adotando a hipótese de mundo fechado.

\footnotetext{
${ }^{7}$ cf. Seção 4.1 e [Apt90].
} 


\subsubsection{Raciocínio sobre Evidência}

No raciocínio sobre evidência, dois fatores são associados a cada átomo $A$ da linguagem, que podem ser interpretados como evidência a favor de $A$ e evidência contra $A$. Cada um destes fatores está no intervalo $[0,1]$.

Programas em lógica sobre evidência (PLE's) foram introduzidos em [Sub87b]. Intuitivamente, a motivação para a definição desta classe de programas reside na importância de evidências e experiências anteriores para o processo de raciocínio e para a tomada de decisões.

A linguagem apresentada em [Sub87b] é a própria linguagem de primeira ordem anotada restrita a um reticulado $\tau$ específico. Se $A$ é um átomo e $\mu_{1}, \mu_{2} \in[0,1]$, então $A:\left[\mu_{1}, \mu_{2}\right]$ é um átomo anotado. Assim, a anotação representa os fatores de evidência $a$ favor e contra associados a cada átomo. Note que tais fatores independem um do outro.

Uma cláusula sobre evidência é então uma fórmula da forma

$$
A \leftarrow A_{1} \wedge \ldots \wedge A_{n}
$$

onde $A, A_{1}, \ldots, A_{n}$ são átomos anotados. Um PLE é um conjunto finito de cláusulas sobre evidência.

Desta forma, $\tau$ é o reticulado completo $<[0,1] \times[0,1], \leq>$, onde $\leq$ é definida da seguinte forma:

$$
\left[\mu_{1}, \mu_{2}\right] \leq\left[\nu_{1}, \nu_{2}\right] \text { se e somente se } \mu_{1} \leq \nu_{1} \text { e } \mu_{2} \leq \nu_{2}
$$

O operador $\sim:[0,1] \times[0,1] \rightarrow[0,1] \times[0,1]$ que consitui o significado da negação pode ser definido como abaixo:

$$
\sim\left[\mu_{1}, \mu_{2}\right]=\left[\mu_{2}, \mu_{1}\right]
$$

Intuitivamente, os $[0,1]$ e $[1,0]$ correspondem aos valores-verdade clássicos falso e verdadeiro, respectivamente. Os elementos mínimo e máximo de $\tau$ são $[0,0]$ e $[1,1]$.

Como já foi dito antes, as anotações representam o grau de evidência a favor e contra um determinado fato. Intuitivamente, o átomo $A:\left[\mu_{1}, \mu_{2}\right]$ pode ser lido como "as evidências a favor de $A$ são de pelo menos $\mu_{1}$, enquanto as evidências contra $A$ são de pelo menos $\mu_{2}$ ".

O reticulado em questão é completo, porém infinito. Para aplicações práticas (por exemplo, para podermos usar o meta-interpretador), basta considerarmos subconjuntos finitos $S_{1}, S_{2}$ de $[0,1] \times[0,1]$, ambos contendo $\{0,1\}$ e os valores-verdade apropriados, tal que $<S_{1} \times S_{2}, \leq>$ forme um reticulado completo.

Considere o exemplo abaixo, onde $S_{1}=\{0,0.7,0.8,0.9,1\}$ e $S_{2}=\{0,1\}$.

Exemplo 6.5 Seja o seguinte sistema relativo ao investimento em terras. 


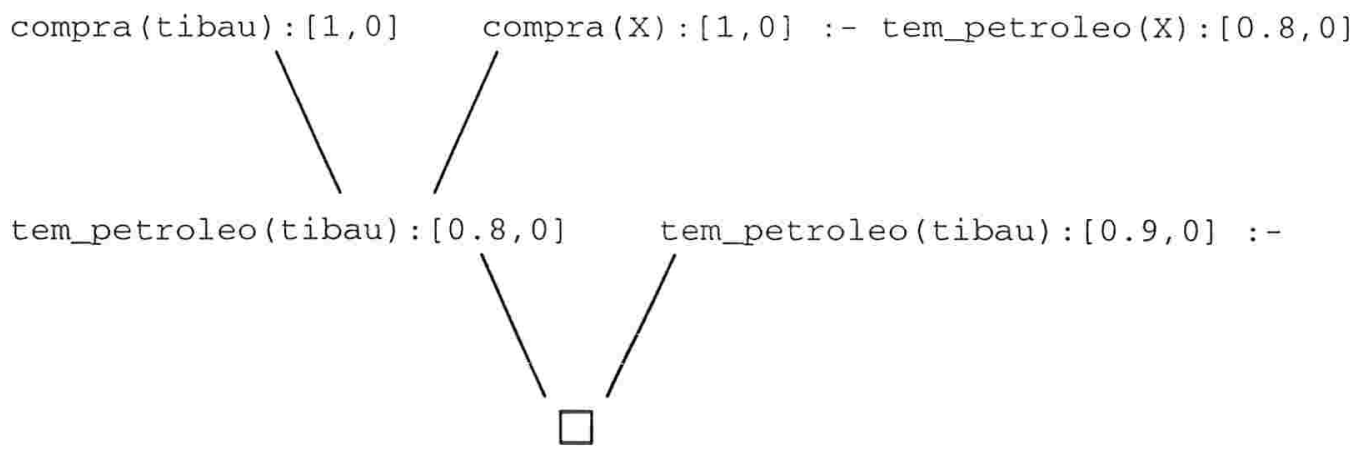

Figura 6.8: Refutação-SLDa de compra(tibau) : $[1,0]$ em relação ao exemplo 6.5

(1) $\operatorname{compra}(\mathrm{X}):[1,0]:-$ ponto_turistico(X):[0.9,0].

(2) $\operatorname{compra}(X):[1,0]$ :- tem_petroleo $(X):[0.8,0]$.

(3) $\operatorname{compra}(\mathrm{X}):[0,1]:-\operatorname{possiveis} \operatorname{problemas}(\mathrm{X}):[0.7,0]$.

(4) possiveis_problemas (X):[0.9,0] :- proximo_usina_nuclear $(\mathrm{X}):[0.7,0]$.

(5) possiveis_problemas $(X):[0.8,0]$ :- terra_disputada $(X):[0.8,0]$.

(6) tem_petroleo(tibau): $[0.9,0]:-$.

(7) proximo_usina_nuclear(angra): $[0.8,1]:-$.

(8) ponto_turistico(angra): $[0.9,0]$ :- .

O exemplo acima retoma o exemplo 6.1. Baseados nas evidências de que a região de Tibau é rica em petróleo, deduzimos das cláusulas 2 e 6 que vale a pena adquirir terras por lá.

Como no primeiro exemplo, aqui também nos deparamos com uma inconsistência relacionada à região de Angra, representada pela anotação [1,1].

Exemplo 6.6 Considere agora uma simples base de conhecimento médica, cujo objetivo é decidir se um dado medicamento med pode ou não ser administrado a um paciente. Tal medicamento só pode ser administrado a um paciente se as evidências contra uma reação a esta droga forem de pelo menos $80 \%$. Porém, se um paciente apresenta um dado sintoma $s_{1}$, as evidências que indicam uma reaçâo negativa são de pelo menos 90\%, contra pelo menos $10 \%$ que registram uma boa aceitação. O sistema pode ser representado pelo seguinte PLE. 
(1) $\operatorname{med}(X):[1,0]:-\operatorname{reacao}(X):[0,0.8]$.

(2) $\operatorname{reacao}(X):[0.9,0.1]:-\mathrm{s} 1(\mathrm{X}):[1,0]$.

Suponha agora que um dado paciente, Carlos, apresente o sintoma $s_{1}$. Assim, temos:

(3) $s 1(\operatorname{carlos}):[1,0]:-$.

Desta forma, baseados nas evidências, chegamos à conclusão de que administrar o tal medicamento a Carlos não seria uma boa idéia, uma vez que não conseguimos deduzir med(carlos): $[1,0]$.

\subsubsection{Raciocínio sobre Incertezas}

Incerteza é sem dúvida um fenômeno múltiplo em formas e origens. Na literatura de sistemas de representação de conhecimento, o termo incerteza é usado para denotar as várias formas de informações imperfeitas: informações incertas, imprecisas, vagas, probabilistas, possibilistas, inconsistentes, parcialmente ou totalmente incompletas [Bit96, Som90]. Existe um modelo formal para tratar cada um dos tipos de informação imperfeita. As lógicas anotadas, por exemplo, são um modelo formal para tratar informações inconsistentes.

Como consequência do surgimento de tantos formalismos para tratar incertezas em suas várias formas, surge também uma questão a respeito da existência de um formalismo "mais geral" para este raciocínio.

Em [CdS96], o autor sugere que a resposta a tal questão seja não, argumentando que existem pelo menos dois tipos de problemas distintos envolvendo incertezas que devem ser tratados também de formas distintas. Em uma discussão semelhante à do capítulo 3, o autor exibe diferenças entre raciocinar com incertezas e sobre incertezas. A primeira forma de raciocínio determina a incerteza das conclusões dadas as premissas, enquanto a segunda determina as conclusões dadas as incertezas das premissas.

Para exibir esta diferença, duas linguagens são apresentadas em [CdS96], baseadas no mesmo formalismo: uma versão simplificada de medidas de necessidade. As medidas estudadas neste modelo são baseadas em uma estrutura $\mathcal{N}$ parcialmente ordenada de valores, que associam um grau de qualidade ou certeza a cada proposição (átomo). Quanto maior este grau, maior a certeza, ou credibilidade da proposição associada. Assim, a necessidade de uma proposição $p$ é o grau com que $p$ pode ser considerado necessariamente ou certamente verdadeira.

A linguagem para raciocinar sobre incertezas é apresentada como sendo a própria linguagem anotada. Esta linguagem permite resolver questões do tipo se a necessidade de $A$ é $n_{1}\left(A: n_{1}\right)$, e a necessidade de $A$ sendo $n_{2}$ implica que a necessidade de $B$ é $n_{3}$ $\left(A: n_{2} \rightarrow B: n_{3}\right)$, então $B$ tem necessidade $n_{4}$ ? 


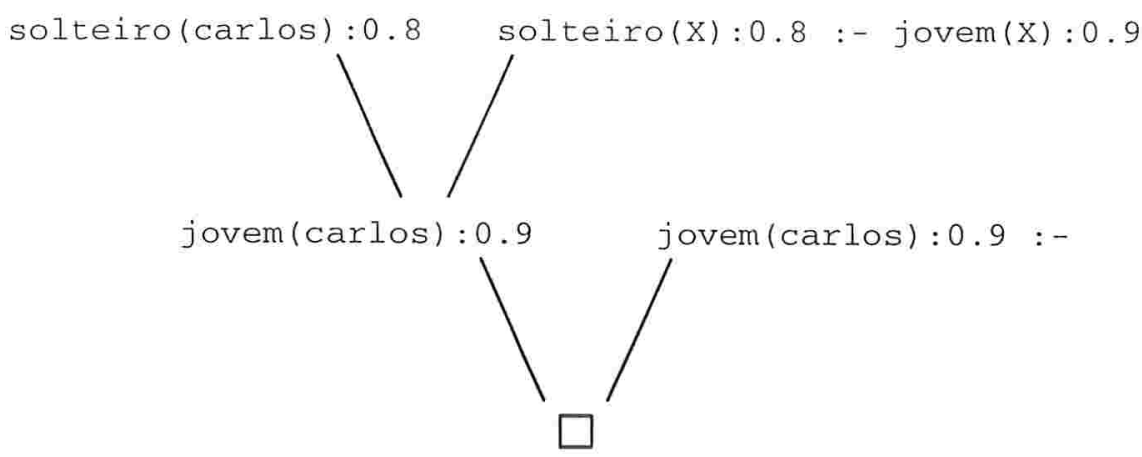

Figura 6.9: Refutação-SLDa de solteiro(carlos) :0.8 em relação ao exemplo 6.7

Exemplo 6.7 Seja $\mathcal{N}$ o reticulado formado por um número finito de elementos do intervalo $[0,1]$ e a ordem $\leq$ naturalmente associada.

Raciocinamos aqui sobre uma pequena base de conhecimento, considerando dados relacionados a um grupo de pessoas, como estado civil, idade e profissão. Podemos dizer, por exemplo, que alguns jovens são estudantes e que jovens são solteiros. Se considerarmos como modelo o formalismo acima, podemos ter o seguinte programa:

(1) estudante $(X): 0.6:-$ jovem $(X): 0.7$.

(2) $\operatorname{solteiro}(X): 0.8:-j o v e m(X): 0.9$.

(3) jovem (carlos):0.9:-.

(4) jovem(marta) :0.7:-.

A cláusula 1 acima pode ser intuitivamente interpretada da seguinte forma: se uma pessoa pode ser considerada jovem com grau de certeza de no mínimo 0.7, então ela é estudante com grau de certeza de no mínimo 0.6. Da mesma forma, Carlos e Marta são pessoas consideradas jovens com graus de certeza 0.9 e 0.7 , respectivamente.

Do PLA acima podemos deduzir, por exemplo, que a necessidade de Carlos ser solteiro é 0.8 , mas não podemos deduzir nada a respeito da necessidade de Marta ser solteira.

\subsubsection{Raciocínio por "Defaults"}

Em [Rei80], foi proposta a lógica "default" (lógica de exceções), uma extensão nãomonotônica da lógica de primeira ordem. A não-monotonicidade é tratada pela introdução de regras "default", ou exceções, que são expressões da forma: 


$$
\frac{A: B_{1} \ldots, B_{n 2}}{C}
$$

A regra acima pode ser lida como se A é um teorema, e é consistente assumir que $B_{1}, \ldots, B_{n}$ são teoremas, então podemos deduzir $C$. Neste caso, $A$ é chamado prérequisito, $B_{1}, \ldots, B_{n}$ justificativas e $C$ consequente.

Intuitivamente, a regra

$$
\frac{\operatorname{ave}(X): \operatorname{voa}(X)}{\operatorname{voa}(X)}
$$

diz que se $X$ é uma ave e é consistente assumir que $X$ pode voar, então podemos deduzir que $X$ pode voar.

Uma teoria "default" é um par $(D, W)$. onde $D$ é um conjunto de regras de "default" e $W$ é um conjunto de fórmulas de primeira ordem. Um conjunto $E$ de fórmulas é uma extensão de uma teoria "default" $(D, W)$ se e somente se $E=\Gamma(E)$ onde, para um conjunto qualquer de fórmulas $S, \Gamma(S)$ é o menor conjunto de fórmulas tal que:

1. $W \subseteq \Gamma(S)$

2. Se $\Gamma(S) \vdash F$, então $F \in \Gamma(S)$

3. Seja $\frac{A: B_{1}, \ldots, B_{n}}{C}$ uma regra "default". Se $A \in \Gamma(S)$ e $\neg B_{i} \notin \Gamma(S), 1 \leq i \leq n$, então $C \in \Gamma(S)$.

O papel de uma regra "default" é completar a teoria de primeira ordem associada, incompleta no sentido de que não temos todas as informações a respeito do mundo em questão. Desta forma, uma extensão de uma teoria "default" especifica formalmente o conjunto de crenças induzido pelo conjunto de regras de "default". O problema é que não existe nenhuma caracterização que defina o número de extensões ou a própria existência de extensões de uma teoria.

Em [Rei80], o autor apresenta uma série de resultados para uma certa classe de teorias "default", as teorias "default" normais. Uma teoria "default" é dita normal se contém apenas regras "default" normais, que são expressões da forma:

$$
\frac{A: B}{B} \text {. }
$$

Neste caso, podemos garantir que uma teoria apresenta pelo menos uma extensão.

Para representar uma regra "default" através de um PLA, é preciso, em primeiro lugar, definir o reticulado de valores-verdade associado. Vamos considerar, então, o reticulado SEVEN definido na seção 5.2, onde discutimos uma das extensões da programação em lógica anotada, inclusive sua aplicação em sistemas de raciocínio não-monotônico.

Uma regra "default" normal da forma

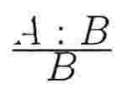




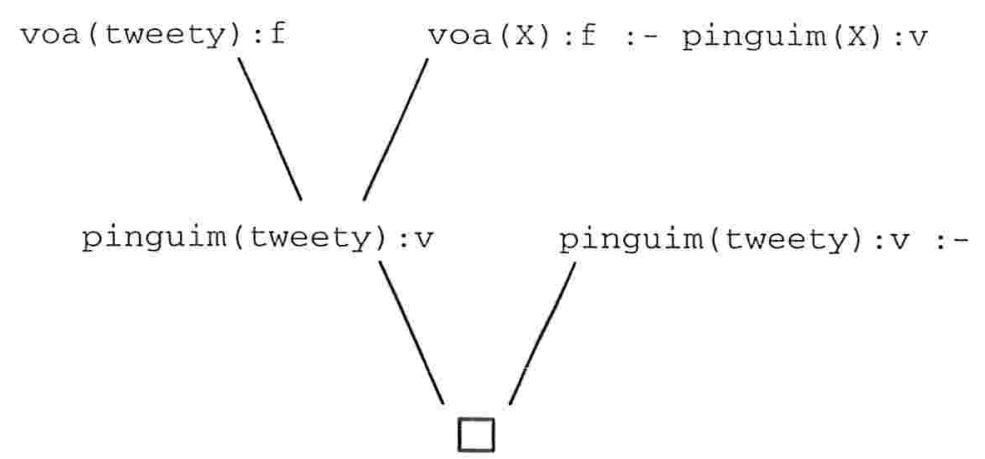

Figura 6.10: Refutação-SLDa de voa (tweety) :f em relação ao exemplo 6.8

é então representada pela cláusula

$$
B: d v \leftarrow A: v,
$$

onde $d v$ representa o valor verdadeiro por "default".

Exemplo 6.8 Vamos considerar o seguinte PLA:

(1) $\operatorname{voa}(X): d v:-\operatorname{ave}(X): v$.

(2) $\operatorname{voa}(X): f:-\operatorname{pinguim}(X): v$.

(3) ave (tweety):v :-.

Neste caso, deduzimos que voa(tweety):dv, ou seja, que como Tweety é uma ave e nenhum conhecimento contradiz o fato de que Tweety pode voar, assumimos por "default" que Tweety voa.

Exemplo 6.9 Considere o PLA do exemplo anterior (6.8), acrescido da seguinte cláusula:

(4) pinguim(tweety):v :-.

Das cláusulas 2 e 4, podemos deduzir agora que Tweety não voa, ou seja, voa (tweety) :f, uma vez que um novo conhecimento adquirido pelo sistema nos diz que Tweety é um pinguim.

O programa especificado acima tem apenas uma extensão. Mas as teorias "default" normais podem ter duas ou mais extensões. No raciocínio por "defaults", duas extensões equivalem a dois modelos para o conjunto de fórmulas considerado. A lógica anotada, porém, sintetiza tais informações em uma única anotação. Se pudermos chegar a dois resultados, $A: v$ e $A: f$, por exemplo, esta especificação nos forneceria o valor-verdade $\top$ associado a $A$. 
Desta forma, nesta formulação podemos apenas constatar a existência de duas ou mais extensões, mas não conseguimos diferenciá-las. Portanto, apenas um fragmento das lógicas "default" pode ser especificado via lógicas anotadas, sem que se perca nenhuma informação.

\subsection{Considerações a Respeito das Aplicações}

Antes de encerrar esta seção, gostaríamos de fazer algumas pequenas considerações a respeito das aplicações apresentadas aqui.

Em primeiro lugar, gostaríamos de ressaltar a importância destes exemplos no que diz respeito ao contexto das lógicas anotadas em IA. Todos estes são formalismos adequados para tratar certos tipos de situações, bastante utilizados na área de representação de conhecimento. A possibilidade de se representar vários destes formalismos como instâncias de PLA's vem constatar que estas lógicas podem ser consideradas como um "formalismo mais geral" capaz de tratar assim várias situações.

Algumas destas aplicações já foram desenvolvidas em trabalhos anteriores. Em outros casos, como o raciocínio por "defaults", já existem relações estabelecidas com extensões da teoria original de programação em lógica anotada. Neste capítulo, porém, nos preocupamos em desenvolver e apresentar aplicações para a teoria original, com o intuito de ilustrar a importância das idéias básicas desta área. Mesmo quando as aplicações tratam um fragmento do formalismo a ser representado, este estudo é fundamental, principalmente para motivar o desenvolvimento de extensões que generalizem cada vez mais a idéia de representação de conhecimento baseada nas lógicas anotadas. Apresentamos assim vários exemplos neste sentido, desenvolvendo áinda um estudo sobre o comportamento do operador de negação fraca em algumas situações específicas.

Outro ponto em relação aos exemplos aqui apresentados é que todos os PLA's associados foram executados no meta-interpretador construído segundo as discussões e definições do capítulo 4. Obedecendo tais especificações, se um PLA for bem-definido ou fechado, ele pode ser diretamente executado pelo meta-interpretador. Caso contrário, é preciso antes efetuar seu fecho. 


\section{Capítulo 7}

\section{Conclusão}

As lógicas anotadas são um formalismo que pode ser usado como fundamento para várias situações de representação de conhecimento em IA. Estudamos casos onde as lógicas anotadas são aplicadas para raciocinar com informações incompletas, inconsistentes ou incertas, por exemplo.

Este foi o principal aspecto do presente trabalho: apresentar estas lógicas como uma ferramenta para pesquisadores em Inteligência Artificial. Desta forma, este trabalho foi caracterizado por um breve estudo dos fundamentos matemáticos das lógicas anotadas, dando ênfase, porém, ao estudo da linguagem de programação em lógica associada.

Outro aspecto a ser considerado é que o estudo feito neste trabalho foi desenvolvido baseado na teoria original de programação em lógica anotada. Como vimos, várias outras extensões foram desenvolvidas desde a sua introdução. Porém, acreditamos que um estudo de suas bases e aplicações sejam fundamentais para o entendimento da idéia e da importância que envolvem tais lógicas.

Constatamos assim que a teoria original da programação em lógica anotada, além de constituir um formalismo adequado para tratar inconsistências, pode expressar várias situações em representação de conhecimento.

Investigamos aqui vários destes aspectos, desenvolvendo alguns resultados que contribuem para a importâncias das lógicas anotadas no contexto da IA. No capítulo 3, apresentamos uma nova abordagem em relação a estas lógicas, caracterizando-as como um formalismo para o raciocínio no nível de argumentos e metalinguagens. No capítulo 6, investigamos e apresentamos uma série de aplicações da teoria original de programação em lógica anotada, desenvolvendo um estudo sobre o comportamento do operador de negação fraca através da especificação deste de acordo com certas propriedades. Desenvolvemos ainda um sistema para raciocínio dedutivo para a lógica anotada na forma de um meta-interpretador PROLOG. Este sistema permite que o conjunto de valoresverdade e o operador de negação fraca sejam especificados pelo próprio usuário. $\mathrm{O}$ principal aspecto deste desenvolvimento foi justamente mostrar que as lógicas anotadas realmente constituem uma ferramenta para It que pode ser bastante aplicada. 
Várias destas constatações, aliadas à constante busca de um formalismo "mais geral" em várias áreas da IA, motivaram um intenso estudo destas lógicas, principalmente no sentido de se estabelecer relações entre a linguagem associada à programação em lógica anotada e outros formalismos já existentes. Como decorrência desta motivação, surgiram várias extensões da teoria original, algumas das quais apresentamos neste trabalho. O resultado, como vimos, são formalismos cada vez mais generalizados, e portanto podem ser aplicados a um número cada vez maior de situações em representação de conhecimento.

Tais resultados, tanto no sentido das aplicações da teoria original estudadas aqui, bem como no âmbito do crescente desenvolvimento de extensões desta teoria, vêm estabelecer e confirmar a importância destas lógicas para pesquisadores em certas áreas da Inteligência Artificial.

\subsection{Trabalhos Futuros}

O presente trabalho tem um caráter prático: apresentar as lógicas anotadas como uma ferramenta importante para a IA. Neste aspecto, um possível desenvolvimento seria no âmbito dos sistemas de raciocínio dedutivo para tais lógicas. Dada a importância de suas aplicações, um estudo mais profundo sobre a sua eficiência computacional seria também de grande importância. Neste sentido, aqui só mostramos que é possível construir um tal sistema.

Esta abordagem pode ser retomada também em outras circustâncias, como no estudo de extensões da teoria apresentada aqui. Em alguns destes casos, algumas considerações e estratégias a este respeito já foram feitas e discutidas [LL95].

Outros aspectos a serem desenvolvidos estão relacionados com as próprias extensões já existentes. Além daquelas citadas no capítulo 5, há outras relacionadas com bancos de dados orientados a objetos [KW93], bases de conhecimento amalgamadas [Sub94] e bases de conhecimento hibridas [LNRS], estas últimas envolvendo bancos de dados dedutivos e várias formas de raciocínio associadas, como por exemplo raciocínio temporal, incerto e não-monotônico. Para cada uma destas extensões, pode-se fazer um estudo de suas instâncias e aplicações, além de considerações sobre sua eficiência. Ou ainda buscar um formalismo generalizado, a fim de aproveitar ao máximo os resultados já existentes em relação a aplicações.

O desenvolvimento de extensões e a busca de uma extensão "mais geral" podem ainda ser guiadas por uma outra linha de trabalho. Ao invés de analisar as aplicações e instâncias de uma determinada extensão, pode-se proceder da forma inversa: desenvolver e definir extensões que abrangem certos tipos de situações.

Assim, estas são algumas linhas de desenvolvimento destas lógicas que se mostraram de grande importância para estudos em raciocínio dedutivo e outras áreas da Inteligência Artificial. 


\section{Referências Bibliográficas}

[Abe92] J. M. Abe. Fundamentos da Lógica Anotada (Foundations of Annotated Logic) - in portuguese. PhD thesis, Universidade de São Paulo, 1992.

[Abe93] J. M. Abe. On Annotated Model Theory. Coleção DOCUMENTOS - Lógica e Teoria da Ciência 11, Instituto de Estudos Avançados, Universidade de São Paulo, Junho 1993.

[Apt90] K. R. Apt. Logic Programming. In J. van Leeuwen, editor, Handbook of Theoretical Computer Science. The MIT Press/Elsevier, 1990.

[Bil94] S. Bilaniuk. A Problem Course in Mathematical Logic. 1994.

[Bit96] G. Bittencourt. Inteligência Artificial: Ferramentas e Teorias. 10ạ Escola de Computação, 1996.

[BS71] J. L. Bell and A. B. Slomson. Models and Ultraproducts: an Introduction. North-Holland Publishing Company, 1971.

[BS88] H. A. Blair and V. S. Subrahmanian. Paraconsistent Foundations for Logic Programming. The Journal of Non-Classical Logic, 5(2), November 1988.

[BS89] H. A. Blair and V. S. Subrahmanian. Paraconsistent Logic Programming. Theoretical Computer Science, 68:135-154, 1989.

[BS90] H. A. Blair and V. S. Subrahmanian. Strong Completeness Results for Paraconsistent Logic Programming. Technical Report SU-CIS-90-12, School of Computer and Information Science, Syracuse University, 1990.

[CdS96] F. S. Corrêa da Silva. On Reasoning With and Reasoning About Uncertainty in AI. In Proceedings of the Logic Colloquium'96 (versão resumida) - submetido para publicação, 1996.

[CGF87] M. A. Casanova, F. A. C. Giorno, and A. L. Furtado. Programaçâo em Lógica e a Linguagem PROLOG. Edgard Blucher, 1987. 
[dC77] N. C. A. da Costa. Introdução aos Fundamentos da Matemática. HUCITEC, 1977.

[dCAS91] N. C. A. da Costa, J. M. Abe, and V. S. Subrahmanian. Remarks on Annotated Logic. Zeitschr. f. Math. Logik und Grundlagen d. Math., 37:561-570, 1991.

[dCPA ${ }^{+95}$ N. C. A. da Costa, J. P. de A. Prado, J. M. Abe, B. C. Ávila, and M. Rillo. Paralog: Um Prolog Paraconsistente Baseado em Lógica Anotada. Coleção DOCUMENTOS - Lógica e Teoria da Ciência 18, Instituto de Estudos Avançados, Universidade de São Paulo, Abril 1995.

[dCSV91] N. C. A. da Costa, V. S. Subrahmanian, and C. Vago. The Paraconsistent Logics P . Zeitschr. f. Math. Logik und Grundlagen d. Math., 37:139-148, 1991.

[Fit91] M. Fitting. Bilattices and the Semantics of Logic Programming. The Journal of Logic Programming, 11:91-116, 1991.

[Ga191] J. Gallier. Constructive Logics. Part II: Linear Logic and Proof Nets. Technical Report 9, Paris Research Laboratory - Digital Equipment Corporation, May 1991.

[GB93] A. Gupta and N. Belnap. The Revision Theory of Truth. The MIT Press, 1993.

[GdQ92] D. M. Gabbay and R. J. G. B. de Queiroz. Extending the Curry-howard Interpretation to Linear, Relevant and Other Resource Logics. The Journal of Symbolic Logic, 57(4):1319-1365, 1992.

[Gir87] J.-Y. Girard. Linear Logic. Theoretical Computer Science, 50:1-102, 1987.

[Hof79] D. Hofstadter. Godel, Escher, Bach: an Eternal Golden Braid. Basic Books, Inc., Publishers, 1979.

[KL92] M. Kifer and E. L. Lozinskii. A Logic for Reasoning with Inconsistency. Journal of Automated Reasoning, 9:179-215, 1992.

[KS92] M. Kifer and V. S. Subrahmanian. Theory of Generalized Annotated Logic Programs and its Applications. Journal of Logic Programming, 12:335-367, 1992.

[KW93] M. Kifer and J. Wu. A Logic for Programming with Complex Objects. Journal of Computer and System Sciences, 47:77-120. 1993. 
[LHSdC91] J. J. Lu, L. J. Henschen, V. S. Subrahmanian, and N. C. A. da Costa. Reasoning in Paraconsistent Logics. In R. Boyer, editor, Automated Reasoning: Essays in Honor of Woody Bledsoe, pages 181-210. Kluwer Academic, 1991.

[LL95] S. M. Leach and J. J. Lu. Query Processing in Annotated Logic Programming: Theory and Implementation. Journal of Intelligent Information Systems, pages 1-28, 1995.

[Llo87] J. W. Lloyd. Foundations of Logic Programming (2ed). Springer Verlag, 1987.

[LMR] J. J. Lu, N. V. Murray, and E. Rosenthal. A Framework for Automated Reasoning in Multiple-Valued Logics. Journal of Automated Reasoning (a aparecer).

[LNRS] J. J. Lu, A. Nerode, J. Remmel, and V. S. Subrahmanian. Towards a Theory of Hybrid Knowledge Bases.

[NS89] R. T. Ng and V. S. Subrahmanian. Probabilistic Logic Programming. Technical report, University of Maryland, 1989.

[Rei80] R. Reiter. A Logic for Default Reasoning. Artificial Intelligence, 13:81-132, 1980 .

[Rob65] J. A. Robinson. A Machine-oriented Logic Based on the Resolution Principle. Journal of the ACM, 12(1):23-41, 1965.

[Sho67] J. R. Shoenfield. Mathematical Logic. Addison-Wesley, 1967.

[Som90] Léa Sombé. Reasoning under Incomplete Information in Artificial Intelligence: a Comparison of Formalisms Using a Single Example. International Journal of Intelligent Systems, 5(4), 1990.

[SU88] V. S. Subrahmanian and Z. D. Umrigar. Quantlog: A System for Approximate Reasoning in Inconsistent Formal Systems. In E. Lusk and R. Overbeek, editors, Proc. $9^{\text {th }}$ International Conference on Automated Deduction, pages 746-747. Springer Lecture Notes in Computer Science (310), 1988.

[Sub87a] V. S. Subrahmanian. On the Semantics of Quantitative Logic Programs. In Proc. $4^{\text {th }}$ IEEE Symposium on Logic Programming, pages 173-182, San Francisco, September 1987.

[Sub87b] V. S. Subrahmanian. Towards a Theory of Evidential Reasoning in Logic Programming. Technical Report SU-CIS-87-3, School of Computer and Information Science, Syracuse University, 1987. 
[Sub88] V. S. Subrahmanian. Query Processing in Quantitative Logic Programming. In E. Lusk and R. Overbeek. editors. Proc. $9^{\text {th }}$ International Conference on Automated Deduction, pages 81-100. Springer Lecture Notes in Computer Science (310), 1988.

[Sub90] V. S. Subrahmanian. Mechanical Proof Procedures for Many-Valued Lattice-Based Logic Programming. The Journal of Non-Classical logic, 7(1/2):73-107, 1990.

[Sub94] V. S. Subrahmanian. Amalgamating Knowledge Bases. ACM Transactions on Database Systems, 19(2):291-331, 1994.

[Tar55] A. Tarski. A Lattice-Theoretical Fixpoint Theorem and its Applicatios. Pacific J. Math., 5:285-309, 1955.

[Tar69] A. Tarski. Truth and Proof. Scientific American, 220(6):63-77, 1969.

[Thi95] K. Thirunarayan. On the Relationship between Annotated Logic Programs and Nonmonotonic Formalisms. J. Expt. Theor. Artif. Intell., 7:391-406, 1995.

[vE86] M. H. van Emden. Quantitative Deduction and its Fixpoint Theory. Journal of Logic Programming, 1:37-53, 1986. 